\title{
Nonlinear Relations Between Achievement and Academic Self-Concepts in \\ Elementary and Secondary School: An Integrative Data Analysis Across 13 Countries
}

\section{Lena Keller}

Department of Educational Sciences, University of Potsdam, Potsdam, Germany, Department of Education and Psychology, Freie Universität Berlin, Berlin, Germany;

Franzis Preckel

Department of Psychology, University of Trier, Trier, Germany;

Martin Brunner

Department of Educational Sciences, University of Potsdam, Potsdam, Germany.

This paper has been accepted for publication at the Journal of Educational Psychology (April 26, 2020).

Please cite this version as:

Keller, L., Preckel, F., \& Brunner, M. (in press). Nonlinear Relations Between Achievement and Academic Self-Concepts in Elementary and Secondary School: An Integrative Data Analysis Across 13 Countries. Journal of Educational Psychology. https://doi.org/10.1037/edu0000533

\section{Author Note}

While working on her dissertation, Lena Keller was a predoctoral fellow at the International Max Planck Research School on the Life Course (LIFE, www.imprs-life.mpg.de). The supplemental online materials and R syntax can be accessed via the Open Science Framework at https://osf.io/9cgzm/. The databases used in this manuscript can be downloaded from https://www.oecd.org/pisa/pisaproducts/ and https://timssandpirls.bc.edu/databases-landing.html. The manuscript has been posted as a preprint on PsyArXiv (doi:10.31234/osf.io/8z563). Jane Zagorski's editing substantially contributed to the readability of the manuscript.

Correspondence concerning this article should be addressed to Lena Keller, Department of Educational Sciences, University of Potsdam, Karl-Liebknecht-Str. 24-25, 14476 Potsdam, email: lena.keller@uni-potsdam.de. 


\begin{abstract}
It is well-documented that academic achievement is associated with students' self-perceptions of their academic abilities, that is, their academic self-concepts. However, low-achieving students may apply self-protective strategies to maintain a favorable academic self-concept when evaluating their academic abilities. Consequently, the relation between achievement and academic selfconcept might not be linear across the entire achievement continuum. Capitalizing on representative data from three large-scale assessments (i.e., TIMSS, PIRLS, PISA; $N=470,804$ ), we conducted an integrative data analysis to address nonlinear trends in the relations between achievement and the corresponding self-concepts in mathematics and the verbal domain across 13 countries and two age groups (i.e., elementary and secondary school students). Polynomial and interrupted regression analyses showed nonlinear relations in secondary school students, demonstrating that the relations between achievement and the corresponding self-concepts were weaker for lower achieving students than for higher achieving students. Nonlinear effects were also present in younger students, but the pattern of results was rather heterogeneous. We discuss implications for theory as well as for the assessment and interpretation of self-concept.
\end{abstract}

Keywords: academic achievement, academic self-concept, mathematics, reading, nonlinear relations 


\section{Educational Impact and Implications Statement}

The present study significantly advances the understanding of how performance on a standardized achievement test in a certain academic domain is related to students' corresponding academic self-concept. In representative student samples, we show that the relations between achievement and self-concepts in mathematics and the verbal domain can be better approximated by nonlinear relations, demonstrating weaker relations for lower achieving students than for higher achieving students in secondary school (and to some extent also in elementary school). Practitioners should be aware that there is no general linear trend between students' achievement and their corresponding academic self-concepts and should take this into consideration when assessing and interpreting students' academic self-concepts in counseling contexts. 


\section{Nonlinear Relations Between Achievement and Academic Self-Concepts in Elementary and Secondary School: An Integrative Data Analysis Across 13 Countries}

Students' academic achievement is a major determinant of their academic self-concepts ${ }^{1}$ (e.g., Harter, 2012; Marsh, 1986; Marsh \& Craven, 2006; Möller, Pohlmann, Köller, \& Marsh, 2009; Shavelson, Hubner, \& Stanton 1976; Trautwein \& Möller, 2016). Typically, researchers implicitly assume linear relations between achievement and self-concepts (e.g., Huang, 2011; Marsh, 1986; Marsh \& Hau, 2004; Möller et al., 2009; Möller, Zimmermann, \& Köller, 2014; Skaalvik \& Rankin, 1992). Linear relations between achievement and self-concepts imply that some constant amount of increase in achievement (e.g., an increase of one standard deviation) is associated with a constant increase in the corresponding self-concept (e.g., an increase of .30 standard deviations) across the entire achievement continuum. However, negative performance feedback can constitute a major threat to the self, which in turn may motivate lower achieving students to engage in self-protective strategies (Alicke \& Sedikides, 2009). These self-protective strategies may weaken the potentially damaging effects of negative feedback on lower achieving students' self-concepts (Leary, 2007). Thus, it is likely that lower achieving students have more strongly inflated self-concepts than higher achieving students do. Consequently, linear models might not fully capture the relation between achievement and the corresponding self-concept for a large part of the student body. Rather, the relations between achievement and self-concepts may be better approximated by a nonlinear function that assumes weaker relations for lower achieving students and stronger positive relations for higher achieving students. Although nonlinear relations between achievement and self-concepts seem highly plausible, such relations have rarely been studied empirically. Therefore, the major aim of the present cross-national integrative

\footnotetext{
${ }^{1}$ Unless otherwise indicated, the term "achievement" will be used to indicate "academic achievement" and the term "self-concept" to indicate "academic self-concept" for the remainder of the article.
} 
data analysis was to substantially expand the body of knowledge on the forms of the functional relations between achievement and self-concepts. As a major strength of this study, we tested the generalizability of our hypothesis across domains (i.e., mathematical and verbal), age groups (i.e., elementary and secondary school students), and countries. In addition, we replicated our results in different data sets. To this end, we drew on representative student samples from several cycles of international large-scale assessments: the Trends in International Mathematics and Science Study (TIMSS), the Progress in International Reading Literacy Study (PIRLS), and the Programme for International Student Assessment (PISA). In doing so, the present results allowed us to draw reliable conclusions concerning theory (e.g., for models of self-concept formation) and the assessment and interpretation of self-concepts.

\section{Integrative Data Analysis: A Tool for Enhancing the Robustness and Generalizability of}

\section{Results}

Scientific research is currently facing critical concerns about the replicability of results in many areas of psychology, education, and other fields (e.g., Ioannidis, 2005; Open Science Collaboration, 2015). Because any single study's results are influenced by that study's design, sample, measurement, and quantification of key constructs, we conducted a coordinated analysis to examine consistency in the findings across multiple data sets (Hofer \& Piccinin, 2009). In a coordinated analysis - a form of integrative data analysis - several data sets that differ in samples and measures but assess similar constructs are first analyzed by applying an identical analysis protocol. Then, effect sizes are summarized across data sets using meta-analytic techniques to answer a specific research question (see also Graham et al., 2017). Similar to other tools that are used to synthesize research (e.g., meta-analysis or systematic literature reviews), coordinated analysis meets the need for a cumulative approach to scientific inquiry (Curran, 2009; Hunter \& Schmidt, 1996; Meehl, 1978). Finally, the particular advantage of a coordinated analysis is that it 
can be used to obtain multiple replications from independent data sets to thereby strengthen the confidence, robustness, and generalizability of findings.

Specifically, for the current investigation, we identified eight cycles from three international large-scale assessments that assessed both student achievement and students' selfconcepts in mathematics and the verbal domain (i.e., TIMSS, PIRLS, and PISA) to examine the generalizability of nonlinear relations between achievement and the corresponding self-concepts across countries and time. In doing so, we took advantage of having access to individual participant data from representative probability samples of students. This allowed us to examine relations between achievement and self-concepts across the entire range of students' achievement and self-concepts because the data were not affected by range restrictions or selection bias. The present study involves the first integrative data analysis to use representative student data in the areas of student achievement and achievement motivation.

\section{From Tools to Theories: Linear and Nonlinear Relations between Achievement and Self- Concepts}

Theories are the starting point of scientific discoveries. Theory informs and guides scientific practices, such as the choice of methods that are applied to investigate a research question. However, theory is also shaped by scientific methods (tools-to-theories heuristic; Gigerenzer, 1991). This is exemplified in an allegory from Eddington (1939; see Cacioppo \& Bernston, 1994) in which a hypothetical scientist attempted to determine the size of fish in the sea by sampling catches from a 2-inch net. After extensive fishing, the scientist did not find any fish smaller than 2 inches and therefore concluded that there were no fish smaller than 2 inches in the sea.

How is this allegory aligned with research on the relation between achievement and selfconcept? Conducting a literature search in the data bases PsycINFO and ERIC for the term 
"academic achievement" in combination with "academic self concept" resulted in a total of 1,229 peer-reviewed academic articles in PsycINFO and 1,005 peer-reviewed academic articles in ERIC published between 2009 and 2019, thus illustrating the large amount of research interest in this topic. Typically, researchers implicitly assume linear relations between achievement and selfconcepts across the entire achievement continuum (e.g., Huang, 2011; Marsh, 1986; Marsh \& Hau, 2004; Möller et al., 2009, 2014; Skaalvik \& Rankin, 1992). In other words, most researchers have applied the "linear net" to study the relations between achievement and self-concepts. For example, a review of all studies $\left(N=66^{2}\right)$ that were included in the two most recent metaanalyses on the relations between achievement and self-concept by Huang (2011) and Möller et al. (2009) revealed that all of these studies analyzed only linear relations between achievement and self-concept. Findings from the vast majority of these studies indicated positive relations between domain-specific achievement tests and corresponding self-concepts. The meta-analysis by Möller et al. (2009) reported a mean path coefficient for the relations between achievement on mathematics tests and mathematics self-concept of $r=.57$, and for the relations between achievement on verbal tests and verbal self-concept of $r=.47$. In the meta-analysis by Huang (2011), the longitudinal correlation between prior achievement (as measured with standardized tests) and subsequent self-concepts ranged from $r=.19$ to .23 .

Only a few published studies have used the "nonlinear net" when examining the relation between achievement and self-concept. These studies can be grouped by the analytic strategy they applied. The first group of studies examined mean-level differences in self-concepts in relation to achievement differences by splitting the achievement continuum into discrete groups (i.e., low-, average-, and high-achieving students) using planned contrasts, ANOVAs, or

\footnotetext{
${ }^{2}$ The coding scheme and the results of the review can be accessed via the Open Science Framework (Soderberg, 2018) at https://osf.io/9cgzm/. Of note, one dissertation included in the meta-analysis by Huang (2011) could not be found and was therefore not included in our review.
} 
multigroup comparisons in structural equation models (Möller \& Pohlmann, 2010; Prast, Van de Weijer-Bergsma, Miočević, Kroesbergen, \& Van Luit, 2018; Schurtz, Pfost, \& Artelt, 2014; Van der Beek, Van der Ven, Kroesbergen, \& Leseman, 2017). The second group of studies investigated the relation between achievement and self-concept by using polynomial regression analyses (Marsh, 2004; Marsh \& Rowe, 1996).

A series of studies by Möller and Pohlmann (2010) and Schurtz et al. (2014) examined the relation between achievement and self-concept in the verbal domain (Möller \& Pohlmann, 2010; Schurtz et al., 2014) and in mathematics (Schurtz et al., 2014) by comparing groups of low-, average-, and high-achieving students. Their results provided initial evidence that the strength of the relation between achievement and self-concept varies with students' level of achievement with stronger relations for higher achieving students and lower relations for lower achieving students in German (native language education; Möller \& Pohlmann, 2010; Schurtz et al., 2014). However, the findings were heterogeneous for English as a foreign language and for mathematics (Schurtz et al., 2014).

It is important to note that estimates of the strength of a relation between two variables are biased when a continuous variable, such as student achievement, is split into discrete groups (MacCallum, Zhang, Preacher, \& Rucker, 2002; Preacher, Rucker, MacCallum, \& Nicewander, 2005). This limitation was overcome in the second group of studies that (a) tackled the achievement continuum as a whole and (b) integrated polynomial components into their analyses of the relation between the two constructs (Marsh, 2004; Marsh \& Rowe, 1996). In a study that drew on a representative U.S. sample of male students in Grade 10, Marsh and Rowe (1996) found a positive quadratic relation $(\beta=0.274)$ between students' ability (as measured with an ability test) and their general academic self-concept. This indicated that increments in achievement were more strongly related to the self-concept of students with higher ability than to 
the self-concept of students with lower ability (Marsh \& Rowe, 1996). In a representative Australian sample of 15-year-old students, Marsh (2004) found a positive quadratic relation $(\beta=$ 0.061 ) between general academic achievement (as measured with an achievement test) and general academic self-concept. This finding again implied that the relation between achievement and self-concept was stronger for higher achieving students and weaker for lower achieving students (Marsh, 2004). In the following section, we will present a possible mechanism that may underlie nonlinear relations between achievement and the corresponding self-concepts.

\section{Self-Protection}

One major reason for why the relations between achievement and self-concepts might vary as a function of individual student achievement is that being asked to evaluate one's own abilities in self-concept questionnaires may trigger self-protective strategies. When students are asked to evaluate their abilities with items such as "I learn quickly in mathematics" or "Reading is easy for me," they infer their abilities from achievement indicators, such as grades, tests, or other achievement-related feedback (Duckworth \& Yeager, 2015; Marsh \& Craven, 2006; Möller et al., 2009, 2014), and from social comparisons with their peers (Festinger, 1954; Huguet et al., 2009; Suls, Martin, \& Wheeler, 2002; Wheeler \& Suls, 2005). Intuitively, one can expect that students with lower achievement in a specific domain should have lower evaluations of their abilities in this domain. However, a negative self-evaluation constitutes a major threat to the self. To protect their self-worth, low-achieving students are likely to engage in self-protective strategies that lead to more positive self-evaluations (Alicke \& Sedikides, 2009). Self-protection originates from the assumption that people want to feel good or want to avoid feeling bad about themselves (Alicke \& Sedikides, 2011). Self-protective strategies are aimed at avoiding, minimizing, and compensating for negative self-views (Hepper, Gramzow, \& Sedikides, 2010). For example, by changing the comparison group (i.e., comparing oneself with groups that have 
worse performances in the relevant dimensions; Tajfel \& Turner, 1979), having poorer recall of self-threatening feedback than non-self-threatening feedback (Green \& Sedikides, 2004), or downplaying the importance of a negative event (Alicke \& Sedikides, 2009), students can weaken the negative effect of their low achievement on their corresponding self-concept.

Empirical research has supported these theoretical propositions: In a study by Hacker, Bol, Horgan, and Rakow (2000), university students repeatedly took exams in a course and rated how well they thought they would perform before and after each test. Better performing students were able to increase the accuracy of their predictions as the semester proceeded, whereas poorly performing students showed no increase in their predictions despite the feedback the students received on their exam results (Hacker et al., 2000). Another study compared university students' self-reported grades from the previous semester with their actual grades and found that students with poorer grades overestimated their grades more than students with better grades did (Gramzow, Elliot, Asher, \& McGregor, 2003).

Furthermore, there is evidence that from the ages of 8 to 10 , children already use selfprotective strategies and that the need to use these strategies increases with students' (cognitive) development and life experience: In middle to late childhood, children develop many cognitive skills that enable them to integrate positive and negative information into their self-views (Harter, 2012). At about this age, most children have gathered experience with comparative grading practices and consequently with absolute failure or comparative performance feedback (Stipek \& Daniels, 1988). However, achievement-related feedback becomes stricter and more varied in adolescence (Eccles, Midgley, \& Adler, 1984). In addition, children's ability to draw social comparisons improves in middle to late childhood (Frey \& Ruble, 1990; Harter, 2012; Ruble \& Frey, 1990). Moreover, research has suggested that students at higher levels of cognitive maturation should show greater variability in their use of self-protective strategies (e.g., Alicke \& 
Sedikides, 2011; Harter, 2012). In contrast to children, adolescents possess the cognitive skills that enable them to engage in attributional biases, such as attributing their successes to internal, stable characteristics (e.g., intelligence) and their failures to external factors (e.g., the difficulty of a test; Harter, 2012). Furthermore, adolescents are able to protect their positive self-views by viewing their positive attributes as central and important and their negative characteristics as unimportant to their selves (Harter, 2012).

\section{The Present Study}

The overarching goal of the present study was to examine whether relations between achievement and corresponding self-concepts are nonlinear and to what extent the nonlinearity is generalizable across different domains, age groups, and countries. On the basis of theoretical considerations regarding strategies that support a positive self-view (e.g., Alicke \& Sedikides, 2009), we expected that the relations between achievement and the corresponding self-concepts would be weaker for lower achieving students and stronger and positive for higher achieving students in the mathematical and verbal domains.

There are a few studies that have empirically supported this prediction to some extent (Marsh, 2004; Marsh \& Rowe, 1996; Möller \& Pohlmann, 2010; Schurtz et al., 2014). However, these studies have embodied several limitations. First, some of the studies used an analytical approach that can result in biased estimates (i.e., splitting the achievement continuum into discrete groups; Möller \& Pohlmann, 2010; Schurtz et al., 2014). We capitalized on two analytical approaches that did not entail this limitation (i.e., quadratic and interrupted regressions). Second, other previous studies examined only general academic achievement and general academic self-concept (Marsh, 2004; Marsh \& Rowe, 1996). However, self-concepts are highly domain-specific (e.g., Gogol, Brunner, Martin, Preckel, \& Goetz, 2017). Therefore, we examined relations between achievement and self-concepts in mathematics and the verbal 
domain. Third, previous research has only investigated the relation between achievement and self-concept in secondary school students (Marsh, 2004; Marsh \& Rowe, 1996). Yet, selfevaluations and the use of self-protective strategies are subject to age-related changes (e.g., Eccles et al.,1984; Guay, Marsh, \& Boivin, 2003; Harter, 2012; Marsh, 1989, 1990a; Wigfield \& Eccles, 2002). Consequently, we examined the functional forms of the relations between achievement and self-concepts in different age groups (i.e., elementary and secondary school students). Fourth, a lesson learned from cross-cultural research is that "universality can never be assumed in advance" (Segall \& Lonner, 1988, p. 1103; see also Henrich, Heine, \& Norenzayan, 2010). It is not clear to what extent the findings from Australia (Marsh \& Rowe, 1996) or the United States (Marsh, 2004) can be transferred to other countries. Thus, in the present study, we set out to examine the relations between achievement and self-concepts across 13 different countries. Fifth, given the current concerns about replicability (e.g., Ioannidis, 2005), we conducted an integrative data analysis (Curran \& Hussong, 2009; Hofer \& Piccinin, 2009) in which we applied the same analysis protocol to representative high-quality individual student data from three major large-scale assessments. This approach offered the advantage that we did not rely on findings based on a single study but rather integrated results across studies (Open Science Collaboration, 2015). To sum up, the results of the present study will significantly expand the body of knowledge on the functional forms of the relations between achievement and self-concepts in (a) different domains (i.e., mathematical and verbal), (b) age groups (i.e., elementary and secondary school students), and (c) countries.

\section{Method}

\section{Samples}

We used individual student data from three international large-scale assessments. The TIMSS, PIRLS, and PISA studies are designed and conducted to compare education systems 
worldwide and to provide policy makers, educators, researchers, and practitioners with reliable information about trends in mathematics, science, and/or reading achievement and learning contexts over time (Mullis, Martin, Kennedy, Trong, \& Sainsbury, 2009; Mullis, Martin, Ruddock, O'Sullivan, \& Preuschoff, 2009; Organisation for Economic Co-Operation and Development [OECD], 2013). In TIMSS, students' skills and knowledge in mathematics and science are assessed every 4th year in Grades 4 and 8 (Mullis, Martin, Ruddock et al., 2009). The PIRLS studies assess students' reading skills in Grade 4 every 5th year (Mullis, Martin, Kennedy, et al., 2009), and PISA assesses students' skills and knowledge in the core domains mathematics, reading, and science at the age of 15 every 3rd year (OECD, 2013). In every TIMSS, PIRLS, and PISA cycle, the school staff, students, and parents were informed about the nature of the test and the test date, and parental permission was secured if requested by the school or education system (Martin \& Mullis, 2012; OECD, 2002).

Besides assessing students' skills and knowledge, several TIMSS, PIRLS, and PISA cycles measured students' domain-specific self-concepts. In stark contrast to other cycles from these large-scale assessments, the data on achievement and self-concepts in both the mathematical and verbal domains were collected from the same students in TIMSS/PIRLS 2011 (fourth-graders) and in PISA 2000 (15-year-olds). In other words, each student provided both mathematical and verbal data. Using the same samples of students when analyzing the domainspecificity of the relation between achievement and the corresponding self-concept measure ensured that the respective relations could only be influenced by the domain (mathematical or verbal) because other potentially confounding, person-related factors (e.g., socioeconomic background, cognitive ability, cohort membership) were controlled for. Given this strength of the data, we selected the countries that participated in the TIMSS/PIRLS 2011 cycle and the PISA 2000 cycle for our analyses (see Table 1). On the basis of this selection criterion, Romania would 
also have been included in the present analyses. However, preliminary analyses indicated severe problems with the PISA 2000 data such that there was a highly implausible relation between mathematics achievement and mathematics self-concept in Romania of $r=.00$. We therefore excluded the data from Romania from the present analyses.

To replicate our results, we additionally included the following assessment cycles in which both achievement and self-concept were measured in either mathematics or the verbal domain. We added cycle 2015 for TIMSS, cycle 2016 for PIRLS, and cycles 2003 and 2012 for PISA (covering the mathematics domain) to our analyses. In PISA 2000, a mathematics achievement score was provided for (a random subsample of) $56 \%$ of the students in the public use file. This resulted in a smaller number of students compared with the other PISA cycles where a mathematics achievement score was provided for all students. Only eight (out of 13) countries participated in the TIMSS assessment for Grade 8 in 2011 and 2015 (see Table 1). Austria did not participate in the TIMSS 2015 Grade 4 assessment. Because PISA assessed students' self-concept in the verbal domain in the year 2000 cycle only, it was not possible to replicate these results. Finally, some information on students' gender was missing. In sum, 328 students were excluded from the analyses because information on their gender was missing (most of these cases came from PISA 2000 from which 239 students were excluded).

TIMSS, PIRLS, and PISA capitalize on a two-stage stratified sampling design to achieve representative probability samples (a detailed description of the sampling procedures can be found in the supplemental online materials [SOM], which can be accessed via the Open Science Framework (Soderberg, 2018) at https://osf.io/9cgzm/). All in all, our analyses were based on representative student samples comprising data from a total of 470,804 students in 23,307 classes or schools in which $50 \%$ of the students were female, and the mean age ranged from 10.30 years (TIMSS/PIRLS 2011, Grade 4) to 15.78 years (PISA 2003; see Table 1). Sample sizes, 
percentages of female students, and numbers of participating schools and classes for each assessment cycle and each country can be found in Tables S1 and S2 in the SOM. Students' mean age in every assessment cycle is shown in Tables S3 to S10 in the SOM.

\section{Measures}

Achievement. Student achievement in mathematics and reading was measured with the standardized tests used in the respective TIMSS, PIRLS, and PISA assessments. In Grade 4, the TIMSS mathematics assessment contained the content domains number, geometric shapes and measure, and data display; in Grade 8, the assessment covered the domains number, algebra, geometry, and data and chance (Mullis, Martin, Ruddock, et al., 2009; Mullis \& Martin, 2013). The PIRLS assessment framework focused on the two overarching purposes for reading in Grade 4: literary experience, and acquiring and using information (Mullis \& Martin, 2015; Mullis, Martin, Kennedy, et al., 2009). In PISA cycles 2003 and 2012, mathematical content knowledge was assessed in four categories: change and relationships, space and shape, quantity, and uncertainty and data (OECD, 2003, 2013). In PISA 2000, the assessment covered just two categories: space and shape, and change and relationships. Reading literacy was assessed in three different categories in PISA: the abilities to access and retrieve information, integrate information and interpret texts, and reflect upon and evaluate texts (OECD, 2000).

The achievement assessments in TIMSS, PIRLS, and PISA were designed to pursue different goals: Whereas the TIMSS and PIRLS assessments are classroom- and curriculumbased, PISA focuses on literacy concepts, that is, students' abilities to apply their skills and knowledge in mathematics and reading to everyday life problems. Thus, at least for mathematics, for which secondary school students are tested in both PISA and TIMSS (Grade 8), PISA is considered a more challenging assessment (e.g., Else-Quest, Hyde, \& Linn, 2010). 
In all TIMSS, PIRLS, and PISA assessments, the achievement scores for mathematics and reading were scaled to have an international mean of 500 points and a standard deviation of 100 points (Martin, Mullis, \& Hooper, 2016, 2017; OECD, 2014). All achievement scales underwent extensive field testing before being implemented in the respective assessments (Martin et al., 2016, 2017; OECD, 2014). Means and standard deviations for the achievement measures from all countries and assessments are reported in Tables S3 to S10 in the SOM. Table 2 shows the median reliability of mathematics and reading achievement and self-concept scales in each assessment. The reliabilities were satisfactory in all assessment cycles in all participating countries. The reliabilities of the achievement and self-concept scales in each country can be found in Tables S11 to S14 in the SOM.

To estimate students' achievement scores, TIMSS, PIRLS, and PISA used plausible values. Plausible values are representations of the range of abilities a student may reasonably have. Hence, TIMSS, PIRLS, and PISA estimated probability distributions for each student's true achievement score. Applying plausible values offers the methodological advantage of unbiased estimates of population parameters (e.g., means and standard deviations). Overall, TIMSS, PIRLS, and PISA provided five plausible values for each achievement scale.

Academic self-concept. To assess students' self-concepts in mathematics (TIMSS, PISA) and reading (PIRLS) or the verbal domain (PISA), students used 4-point rating scales to provide answers in all assessments with higher scores indicating a higher self-concept in the respective domain. The mathematics and verbal self-concept items used in the TIMSS, PIRLS, and PISA assessments rely on established items whose wordings were identical or similar to wellestablished and researched questionnaires such as the Self-Description Questionnaire (SDQ; e.g., Marsh, 1990b; Byrne, 1996, 2002; Marsh, Trautwein, Lüdtke, Köller, \& Baumert, 2006): e.g., “I learn quickly in [domain]" (used in the SDQ II), "I get good marks in [domain]," "I learn 
[domain] quickly" (used in PISA 2000, 2003, 2012), or "I usually do well in [domain]" (used in PIRLS 2011, 2016; TIMSS 2011, 2015). All self-concept scales underwent extensive field testing before being implemented in the respective assessments (Martin et al., 2016, 2017; OECD, 2014). To create scale scores, the ratings for the single self-concept items were averaged. The reliabilities for all the TIMSS, PIRLS, and PISA self-concept scales were consistently satisfactory in all cycles and across all participating countries (see Tables S11 to S14). Means, standard deviations (Tables S3 to S10), item wording, and response scales (Tables S15 to S18) can be found in the SOM.

\section{Data Analysis}

As to be expected in any (large-scale) study, there were some missing data. Specifically, $4 \%$ to $8 \%$ of the self-concept data were missing in each sample, with one exception of $37 \%$ missing from PISA 2012 because students' responses were missing by design in this cycle (OECD, 2014). The country-specific percentage of missing information in each assessment and cycle can be found in Tables S3 to S10 in the SOM. Missing data in students' self-concepts were handled by applying nested multiple imputation (e.g., Weirich, Haag, Hecht, Böhme, Siegle, \& Lüdtke, 2014) using the R package "miceadds" (version 2.14-26; Robitzsch, Grund, \& Henke, 2018). For each plausible value representing students' achievement, we imputed the missing selfconcept data five times, yielding 25 nested imputations for every data set. We imputed the missing data in students' self-concepts separately for female and male students because research has shown that female students typically report higher self-concepts in the verbal domain but lower self-concepts in mathematics in comparison with their male counterparts (e.g., Jacobs, Lanza, Osgood, Eccles, \& Wigfield, 2002; Marsh \& Yeung, 1998; Skaalvik, \& Skaalvik, 2004). All analyses on the relation between achievement and self-concept in this study were computed 
25 times, and then the results were integrated using standard procedures to obtain an average estimate as well as corresponding standard errors (Martin et al., 2016, 2017; OECD, 2014).

We conducted an integrative data analysis (see Curran \& Hussong, 2009; Hofer \& Piccinin, 2009) where we applied the same analysis protocol to investigate the functional forms of the relations between achievement and self-concept in mathematics and the verbal domain. Specifically, we proceeded in two ways. First, we ran domain-specific regression models for every country in every assessment and every cycle with achievement in mathematics or reading as the predictor variable and mathematics or reading/verbal self-concept as the outcome variable. The linear model specified a linear relation between achievement and self-concept; the quadratic model specified a nonlinear relation and included a linear term and a quadratic term. To analyze the regression models, we used the statistical software $\mathrm{R}$ (version 3.5.1; R Core Team, 2018) and the R package "BIFIEsurvey" (version 2.18-6; BIFIE, 2018). Before computing the regression models, we standardized $(M=0.00, S D=1.00)$ students' achievement and self-concept scores around each country mean in every TIMSS, PIRLS, and PISA cycle, respectively. In doing so, we (a) facilitated the comparison of regression parameters between achievement and self-concept scales across assessments and (b) removed nonessential multicollinearity, that is, the multicollinearity between a variable and the higher order function of the same variable (here: achievement) that exists merely because of the scaling (nonzero mean) of the variable (Cohen, Cohen, West, \& Aiken, 2003). To evaluate the significance of the linear and quadratic regression coefficients, we computed $95 \%$ confidence intervals (CIs). If the $95 \%$ CI did not contain 0 , the changes in achievement were interpreted as significantly related to changes in the corresponding self-concept (Cohen et al., 2003). The regression coefficients for single countries and cycles can be found in Tables S19 to S23 in the SOM. 
Second, we ran interrupted regressions using the two-lines test (Simonsohn, 2018) with the R packages “mgcv” (version 1.8-24; Wood, 2017) and "survey” (version 3.34; Lumley, 2004) for every assessment and cycle. We used the interrupted regressions to explore other possible nonlinear trends apart from quadratic effects between students' domain-specific achievement and the corresponding self-concept. In the two-lines test, an interrupted regression for low and high achievement scores is estimated by dividing the achievement continuum into two segments (Figure 1a). The breakpoint between segments is determined by the so-called Robin Hood algorithm, which maximizes the precision with which the regression parameters $\beta_{1}$ and $\beta_{2}$ are estimated. $\beta_{1}$ and $\beta_{2}$ describe the linear relation between achievement and self-concept within each segment, respectively. To this end, the algorithm allocates the observations between the two segments such that the standard errors of the regression parameters $\beta_{1}$ and $\beta_{2}$ are minimized without changing the values of $\beta_{1}$ and $\beta_{2}$ too much (Simonsohn, 2018). If $\beta_{1}$ and $\beta_{2}$ are equal, this would argue for a linear relation between achievement and the corresponding self-concept. Consequently, if $\beta_{1}$ and $\beta_{2}$ are not equal (e.g., $\beta_{1}$ is notably smaller than $\beta_{2}$ ), this would argue for a nonlinear relation between the two constructs. The breakpoint is particularly important for the latter case. Because the distribution of students' achievement can be well-approximated by a (standard) normal distribution within each country (Figure 1a), we can estimate the proportion of students for which a single linear regression coefficient does not fully capture the relation between achievement and the corresponding self-concept. To provide a conservative estimate, we computed the proportion such that it represented the students whose achievement scores were located in the segment with fewer observations below or above the breakpoint, respectively. To this end, we computed the proportion of students under a standard normal distribution who had achievement scores below the breakpoint if the breakpoint was less than or equal to 0 . For example, a breakpoint of $z=-1.04$ (as depicted in Figure 1a) suggests that for about $15 \%$ of the 
students, the relation between achievement and self-concept was not accurately represented by a single linear regression coefficient. If the breakpoint was greater than 0 , we computed the proportion of students under a standard normal distribution who had achievement scores above the breakpoint.

For both analytic strategies, we used meta-analytic techniques to integrate the results across 13 countries and several cycles for each domain and student group (i.e., Grade 4, Grade 8, 15-year-olds), respectively. In accordance with the analysis strategy proposed by Cheung and Jak (2016) for big data, we proceeded in two steps. First, we analyzed the individual student data according to the detailed TIMSS, PIRLS, and PISA guidelines for statistical analyses on how to apply population weights, compute standard errors, and compute regression coefficients with plausible values as achievement indicators (Martin \& Mullis, 2012; OECD, 2014). Second, to obtain a single estimator within each student group (Grade 4, Grade 8, 15-year-olds), we computed weighted mean regression coefficients across countries (see Tables S19 to S23 and S29 to $\mathrm{S} 33$ in the SOM). To this end, we used three-level random-effects models with maximum likelihood estimation to account for the dependencies between regression coefficients when the regression coefficients were obtained for several cycles within countries (i.e., in TIMSS, PIRLS, PISA mathematics). Because verbal self-concepts were only measured in one PISA cycle (PISA 2000), there was no dependency in regression coefficients within countries. Thus, we conducted a two-level random-effects model with maximum likelihood estimation in this case. We applied random-effects models to allow the true effect to vary between (and within) countries (Borenstein, Hedges, Higgins, \& Rothstein, 2009; Cheung, 2015). For the three-level randomeffects models, estimates of the variability in the regression coefficients defined Level 1. Level 2 captured variability in regression coefficients between assessment cycles within countries, and Level 3 captured variability in regression coefficients between countries. For the two-level 
random-effects model, Level 1 captured the estimates of the variability in the regression coefficients, and Level 2 captured the variability in regression coefficients between countries. We used the R package "metaSEM" (version 1.2.2; Cheung, 2015) to analyze the two- and threelevel random-effects models.

We computed three statistics to assess the heterogeneity of the effect sizes: $I^{2}, \tau$, and $Q$ (Borenstein et al., 2009). Higgins and Thompson's (2002) measure of heterogeneity $I^{2}$ represents the proportion of observed heterogeneity that is real and not due to random noise. $I^{2}$ has a range of $0 \%$ to $100 \%$, such that $30 \%$ to $60 \%$ may represent moderate heterogeneity, $50 \%$ to $90 \%$ may represent substantial heterogeneity, and $75 \%$ to $100 \%$ may represent considerable heterogeneity (Higgins \& Green, 2011; Higgins \& Thompson, 2002). In our study, $I^{2}$ Level2 captured the heterogeneity between cycles within countries, $I^{2}$ Level3 captured the heterogeneity between countries, and $I^{2}$ total captured the total heterogeneity (i.e., the sum of $I^{2}$ Level2 and $I^{2}$ Level3). We also report the standard deviation of the regression coefficients $\tau$ (see Borenstein et al., 2009) to estimate heterogeneity in regression coefficients between cycles within countries $\left(\tau_{\text {Level } 2}\right)$ and between countries $\left(\tau_{\text {Level3 }}\right)$ plus the total heterogeneity $\left(\tau_{\text {total }} ; \tau_{\text {total }}=\sqrt{\left.\tau_{\text {Level2 }}^{2}+\tau_{\text {Level3 }}^{2}\right)}\right.$. Finally, the $Q$ test statistic (introduced by Cochran, 1954) is computed by summing the squared deviations of each individual effect size estimate from the corresponding overall (average) effect estimate where individual effect sizes are weighted by their sampling variance (Huedo-Medina, Sánchez-Meca, Marín-Martínez, \& Botella, 2006). A statistically significant $Q$ value indicates effect size heterogeneity (Borenstein et al., 2009).

All figures were produced using the R package "ggplot2” (version 3.1.0; Wickham, 2009). The R code for reproducing the results and figures from the present study can be accessed via the Open Science Framework (Soderberg, 2018) at https://osf.io/9cgzm/. 


\section{Results}

\section{Linear and Quadratic Regressions}

Mathematics. Figure 2 displays the standardized linear and quadratic relations between mathematics achievement and mathematics self-concept. The results obtained for the linear model indicated that math achievement and self-concept were positively related for students in Grades 4 and 8 and for students at age 15: The higher students' achievement, the higher their corresponding self-concept. ${ }^{3}$

The results obtained for the quadratic model showed significant quadratic relations between achievement and self-concept in mathematics across countries. As shown in Figure 2, we observed positive quadratic relations in the group of 15-year-old students (mean $\beta=0.12$, 95\% CI $[0.10,0.14])$ and Grade 8 students (mean $\beta=0.12,95 \%$ CI $[0.08,0.15])$, implying that the increase in students' mathematics self-concept was weaker for lower achieving students than for higher achieving students. Importantly, these quadratic relations were found across cycles and countries with very few exceptions ( 1 in 39 cases $n s$ for PISA and 2 in $16 n s$ for TIMSS; Figures 2 and 3). The linear and quadratic terms demonstrated significant heterogeneity (Tables 3).

In younger students, the mean quadratic relation between mathematics achievement and mathematics self-concept was positive (mean $\beta=0.04,95 \%$ CI $[0.03,0.06]$ ). Similar to the group of older students, this indicated that the increase in students' mathematics self-concept in Grade 4 was lower for lower achieving students than it was for higher achieving students. However, across countries, positive quadratic relations were found less consistently for younger students than for older students; in 13 out of 25 cases, the quadratic relations were significant (see Table

\footnotetext{
${ }^{3}$ In line with previous research (e.g., Marsh, 1986), in almost all countries, male students reported a higher selfconcept in mathematics than female students did, whereas female students reported a higher self-concept in the verbal domain than male students did. The addition of students' gender as a predictor of their domain-specific selfconcept did not change the functional forms of the relations between achievement and the corresponding selfconcepts. Results of the linear and quadratic regression models when controlling for students' gender are presented in Tables S24 to S28 in the SOM.
} 
S19 in the SOM). Heterogeneity analyses indicated significant heterogeneity in the linear and quadratic relations for students in Grade 4 (Table 3).

Verbal domain. Figure 4 shows the standardized linear and quadratic relations between reading achievement and reading self-concept for students in Grade 4 and between reading achievement and verbal self-concept in 15-year-olds. The direction of the quadratic relations differed between younger and older students. Whereas the average quadratic relation between reading achievement and verbal self-concept was significantly positive in the group of 15-yearolds (mean $\beta=0.05,95 \%$ CI [0.03, 0.07], Figure 4), it was significantly negative in Grade 4 (mean $\beta=-0.02,95 \%$ CI $[-0.03,-0.01]$ ). For 15-year-old students, reading achievement was more strongly related to verbal self-concept for higher achieving students than for lower achieving students. The negative quadratic relation found in younger students implied that reading achievement and self-concept were to some extent more strongly related for lower achieving students than for higher achieving students.

Across countries, in the group of 15-year-olds, 6 out of 13 quadratic relations were significant. For fourth-graders, 5 out of 26 quadratic relations were significant (Figures 4 and 5 , and Tables S22 and S23 in the SOM). For both fourth-graders and 15-year-olds, we observed significant heterogeneity in the linear and quadratic relations (Table 4).

\section{Interrupted Regressions and Two-Lines Tests}

Mathematics. The results from the interrupted regression models for 15-year-olds revealed that mathematics achievement was not significantly related to mathematics self-concept for lower achieving students, but the relation was significantly positive for higher achieving students (mean $\beta_{1}=0.03,95 \%$ CI [-0.01, 0.07]; mean $\beta_{2}=0.47,95 \%$ CI [0.41, 0.53]; Figure 1b). This finding held for the vast majority of countries across three assessment cycles (Figure 1b). We observed significant heterogeneity in both regression coefficients (i.e., $\beta_{1}$ and $\beta_{2}$; Table 5). 
The mean percentage of students for whom a common linear model did not accurately describe the relation between achievement and self-concept in mathematics was $16 \%$.

For students in Grade 8, the relation between achievement and self-concept in mathematics was stronger for higher achieving students than for lower achieving students (mean $\beta_{1}=0.25,95 \%$ CI $[0.08,0.42]$; mean $\beta_{2}=0.58,95 \%$ CI [0.50, 0.66]; Figure $\left.1 \mathrm{~b}\right)$. We observed significant heterogeneity in both regression coefficients (i.e., $\beta_{1}$ and $\beta_{2}$; Table 5). In about half of the countries, $\beta_{1}$ (as obtained for lower achieving students) and $\beta_{2}$ (as obtained for higher achieving students) were both positive; in the other half of the countries, $\beta_{1}$ was close to zero, but $\beta_{2}$ was positive. The mean percentage of students for whom a single linear regression coefficient did not fully capture the relation between achievement and self-concept in mathematics was $12 \%$.

For Grade 4, the achievement-related increase in mathematics self-concept was on average almost identical in magnitude for higher and lower achieving students (mean $\beta_{1}=0.32$, 95\% CI [0.26, 0.39]; mean $\beta_{2}=0.34,95 \%$ CI [0.29, 0.38]; Figure $\left.1 \mathrm{~b}\right)$. This implied that the achievement-related increase in self-concept did not vary across the achievement distribution for students in Grade 4. Both regression coefficients exhibited significant heterogeneity that was entirely located between assessment cycles within countries (Table 5). There were three countries (i.e., Australia, Portugal, and Sweden in TIMSS 2011) in which the relation between mathematics achievement and mathematics self-concept was close to zero for lower achieving students but positive for higher achieving students. For an average of $17 \%$ of the students, a common linear model did not accurately describe the relation between achievement and self-concept in mathematics.

Verbal domain. The achievement-related increase in verbal self-concept in 15 -year-olds was somewhat stronger for higher than for lower achieving students (mean $\beta_{1}=0.20,95 \% \mathrm{CI}$ $[0.14,0.26]$; mean $\beta_{2}=0.32,95 \%$ CI $[0.25,0.39]$; Figure $\left.1 b\right)$. For some countries, the relation 
between reading achievement and verbal self-concept was close to zero for lower achieving students but positive for higher achieving students, whereas in other countries, the relation was positive for both lower and higher achieving students (Figure 1b). Heterogeneity measures showed that the magnitudes of the regression coefficients varied significantly (Table 6). The mean percentage of students for whom a single linear regression coefficient did not fully capture the relation between reading achievement and verbal self-concept was $22 \%$.

The relation between achievement and self-concept in reading was stronger for lower achieving students than for higher achieving students in Grade 4 (mean $\beta_{1}=0.45,95 \%$ CI $[0.42$, $0.48]$; mean $\beta_{2}=0.27,95 \%$ CI $[0.22,0.31]$; Figure $\left.1 \mathrm{~b}\right)$. Heterogeneity measures showed that the magnitudes of $\beta_{1}$ varied significantly, whereas the magnitudes of $\beta_{2}$ did not (Table 6 ). For an average of $13 \%$ of the students, a common linear model did not describe the relation between achievement and self-concept in reading very well. The results for single countries and cycles can be found in Tables S29 to S33 in the SOM.

\section{Discussion}

The major aim of the present integrative data analysis was to investigate whether the relations between achievement and self-concept are nonlinear and to what extent the nonlinearity can be generalized across (a) different domains (i.e., mathematics and verbal), (b) different age groups (i.e., elementary and secondary school students), and (c) 13 different countries. Most previous research applied a "linear net" to capture relations between achievement and selfconcept measures. Yet, this approach fails to capture potential nonlinear relations between the two constructs and thus might not accurately describe the relations between achievement and self-concepts for a considerable proportion of the student body. In the present integrative data analysis, we capitalized on representative individual student data from eight assessment cycles of three major educational large-scale studies (i.e., TIMMS, PIRLS, PISA) and applied polynomial 
and interrupted regression analyses as "nonlinear nets." Our findings provided strong evidence of nonlinear relations between achievement and self-concepts for students in secondary schools in mathematical and verbal domains. Nonlinear effects were also present in younger students, but the result patterns were rather heterogeneous across countries and applied methods.

\section{Implications for Theories of Self-Concept Formation}

For secondary school students, the relations between achievement and the corresponding self-concepts in mathematics and the verbal domain were weaker for lower achieving students than for higher achieving students. This conclusion was supported by the quadratic and interrupted regression analyses. For 15-year-olds in mathematics, the relation between mathematics achievement and mathematics self-concept was even close to zero for lower achieving students but positive for higher achieving students. Importantly, we replicated the positive quadratic relation between achievement and self-concept in mathematics in secondary school students over three (PISA) and two (TIMSS) assessment cycles, underpinning the robustness of our findings (achievement and self-concept in the verbal domain were only assessed once in PISA 2000, and therefore, it was not possible to replicate the effect). Similar nonlinear findings have been reported for the association between global achievement and global academic self-concept for students in Grade 10 and 15-year-olds (Marsh, 2004; Marsh \& Rowe, 1996).

One plausible explanation for the finding that lower achieving students' self-concepts in mathematics and the verbal domain were only weakly related to their corresponding achievement is that lower achieving students are more likely to apply self-protective strategies to prevent the damaging effects of negative performance feedback on their self-views as has been shown, for example, in studies by Gramzow et al. (2003) and Hacker et al. (2000). Besides self-protective motives, students' self-enhancing motives might also contribute to the nonlinearity between 
achievement and the corresponding self-concepts to some extent. For instance, self-enhancing motives might motivate better performing students to increase the positivity of their self-concepts in response to positive performance feedback. However, there is evidence that lower achieving students are more inclined to apply self-serving strategies compared with higher achieving students (e.g., Baumeister, Bratslavsky, Finkenauer, \& Vohs, 2001; Gramzow et al., 2003; Hacker et al., 2000). This underscores the plausibility of self-protection as one driving mechanism that leads to nonlinear relations between achievement and self-concepts.

Nonlinear effects were also present in younger students, but the result patterns were rather heterogeneous. On average, we found a positive quadratic relation between achievement and selfconcept in mathematics. However, in more than half of the countries, the quadratic regression coefficient was not significant. Further, the interrupted regression analyses indicated that the relations between achievement and self-concept in mathematics were positive and almost identical in magnitude for lower and higher achieving students.

In the verbal domain, we found a negative quadratic relation, indicating that reading achievement and reading self-concept were less strongly related for higher achieving students in elementary school than for lower achieving students. The results from the interrupted regressions confirmed these findings. On the one hand, these findings could support the assumption that there are age differences in nonlinear relations. On the other hand, the nonlinear effects in the verbal domain could differ for younger and older students because younger students were asked to rate their reading self-concept in PIRLS, whereas older students rated their national language class self-concept in PISA. Typically, students do not receive specific grades for their reading performance, but instead they receive a global assessment of their performance in diverse areas of their national language class (e.g., writing, reading, grammar). Because grades are usually the most salient source of performance feedback for students, younger students have probably gained 
less comparative feedback experience that they can take into account when evaluating their reading performance. Consequently, we cannot distinguish whether the differences between younger and older students occurred for developmental reasons or due to differences in the assessed constructs (reading vs. verbal self-concept). More research and data in which verbal self-concepts are measured consistently across age groups are needed to answer this question.

In sum, the present results support two major conclusions. First, the results of the present study indicated that a linear regression model could not fully capture the relations between achievement and the corresponding self-concepts in mathematics and the verbal domain for a substantial proportion of the student body in secondary school. Considering the country-specific breakpoints from the interrupted regression analyses, the "substantial proportion" ranged from, on average, $12 \%$ (TIMSS, Grade 8 ) to $22 \%$ (PISA, verbal domain) of the students (see Tables S29 to S33). Consequently, it would be advisable to refine current models of self-concept formation that assume that the relations between achievement and self-concepts are solely linear. For example, the internal/external frame of reference model (Marsh, 1986) states that students' self-concepts are formed by two processes: (a) an external (social) comparison process in which students compare their own achievement in a domain with their classmates' achievement in the same domain and (b) an internal comparison process in which students compare their own achievement in different domains. For example, to better capture the relation between achievement and self-concept in this model, a quadratic term could be included in the regression of self-concept on achievement in the same domain when modeling the external comparison process.

Second, the findings of the present cross-sectional study were mixed regarding age differences in nonlinear relations between achievement and self-concepts in mathematics and the verbal domain. Given the great heterogeneity in results as observed for elementary school 
students, we strongly recommend that nonlinear models also be specified for this student group. By using the "nonlinear net," researchers will avoid missing any nonlinear relations between achievement and self-concept. Doing so will also improve current theories on self-concept formation because this approach will eventually help to identify the boundary conditions and moderating factors that lead to linear relations for elementary school students in some countries and nonlinear relations in others.

\section{Implications for the Assessment of Self-Concepts}

In addition to research contexts, self-concepts are also assessed in guidance and counseling contexts. Our findings showed that lower achieving secondary school students tended to overestimate their academic abilities in mathematics and the verbal domain relative to higher achieving students in these domains. The tendency to overestimate one's own abilities can introduce a systematic bias when lower achieving students seek guidance or counseling, and school counselors, school psychologists, or teachers make recommendations for their further educational or occupational pathways on the basis of students' scores on self-concept measures.

In the following, we suggest three methodological approaches that can be applied in practice to derive more nuanced interpretations of students' scores on self-concept scales. One approach could be to compare a student's self-reported self-concept with this student's actual performance (e.g., the student's grades or his or her achievement of performance benchmarks on tests). Another way could be to estimate students' tendency to engage in self-protection. This could be done, for example, by measuring how strongly the self-view of a (low-achieving) student diverges from others' (e.g., classmates') assessments of this student's academic abilities in a particular domain (e.g., Krueger \& Wright, 2011). A self-protective tendency would be apparent when students evaluated their own abilities more positively than others did. Finally, students' self-protective tendency could also be measured by using self-report scales that directly 
assess students' application of self-protective strategies as suggested, for instance, by Hepper et al. (2010). These self-protection parameters could then be included when interpreting students' observed scores on self-concept scales.

\section{Limitations and Outlook}

Although this integrative data analysis significantly expands the body of knowledge on nonlinear relations between achievement and self-concepts in different domains, age groups, and countries, we see three limitations that should be addressed in future research.

Causal mechanisms. We drew on self-protection as the theoretical basis (e.g., Alicke \& Sedikides, 2009) for expecting nonlinear relations between achievement and the corresponding self-concepts. However, given the limitations of our study design, we could not conclude that self-protective strategies caused the nonlinear relations found in this study. Other research designs would be needed to do so. If self-protective strategies caused the nonlinear relation between achievement and self-concept, we would expect that experimentally enhancing students' motives to apply these strategies would lead to a stronger degree of nonlinearity between achievement and self-concept. For example, performance feedback is known to activate the motive to apply self-protective strategies (Alike \& Sedikides, 2009). Hence, using experimental manipulations, students could be randomly assigned to groups that either receive feedback or do not receive feedback on their actual performance on a standardized achievement test before they evaluate their self-concepts. We would expect the degree of nonlinearity between achievement and self-concepts (as expressed in the quadratic or interrupted regression models) to increase for students in the feedback group because the experimental manipulation has direct consequences for how students evaluate their achievement (e.g., performance feedback [vs. no performance feedback] should intensify the threat to the self for lower achieving students). Another nonexperimental study design that could be applied to approximate the causal mechanism is to 
examine how (individual) differences in the application of self-protective strategies as measured with questionnaires (see Hepper et al., 2010) may moderate the functional form between achievement and self-concept.

Further influences on the functional form. By investigating students' self-concepts with data from TIMSS, PIRLS, and PISA, we were bound to the 4-point rating scales that were applied in these large-scale assessments. If a broader rating scale (e.g., a 6- or 7-point rating scale) had been used to measure the self-concepts, it may have been possible to find additional inflection points (e.g., at the high end of the achievement continuum). One possible reason for this is that the number of response categories seems to influence individuals' response behavior (Weijters, Cabooter, \& Schillewaert, 2010). For example, Weijters et al. (2010) found that the tendency to choose extreme anchor points on rating scales was reduced when more response categories were added to a rating scale. Future research should investigate the extent to which response format influences the functional form of relations between achievement and corresponding self-concepts. In addition, future studies should take into account possible response styles. For example, a study by Buckley (2009) provided initial evidence that adjusting for students' response biases (acquiescence, disacquiescence, extreme response styles, noncontingent responding) tended to result in stronger nonlinear relations between science achievement and science attitude scales in PISA 2006. Moreover, the anchoring vignette approach is a promising way to control for response style effects (Bolt, Lu, \& Kim, 2014; He, Buchholz, \& Klieme, 2017) and was first applied in PISA 2012 (Kyllonen \& Bertling, 2014; OECD, 2014). However, the anchoring vignette approach for self-concept scales still needs to be refined (e.g., He et al., 2017).

Heterogeneity in effects. Heterogeneity analyses revealed considerable heterogeneity in the linear and quadratic relations as well as in almost all interrupted regression coefficients in all 
domains and especially in older students. In particular, even the magnitudes of the linear relations were subject to variation. This may have (at least) two probable reasons. One explanation could be that relations between achievement and self-concept are stronger for some countries (and/or successive student cohorts within countries) than for others because the curriculum in mathematics or the verbal domain better matches the conceptual frameworks defined and measured in PISA, TIMSS, or PIRLS. Another explanation could be that the culture of feedback in the classroom varies across countries (and/or successive student cohorts within countries). For example, countries might differ in the extent to which they emphasize social comparisons versus individualized performance feedback (Lüdtke \& Köller, 2002; Lüdtke, Köller, Marsh, \& Trautwein, 2005) or in how common it is to apply differentiated instruction (i.e., individually altering students' expectations and goals, varying the complexity of tasks; Roy, Guay, \& Valois, 2015). In countries in which teachers provide individualized performance feedback and differentiated instruction, students' achievement and their corresponding self-concepts should be less strongly related than in countries in which teachers foster social comparisons and no differentiated instruction. Until now, little has been known about these cross-cultural variations (or variations within countries that differently affect successive student cohorts), and thus, this topic is an area for future research.

\section{Conclusion}

The present study makes three main contributions. First, given the size and representativeness of the applied data and our rigorous integrative data analysis, our results provide strong support for the generalizability of nonlinear relations between achievement and corresponding self-concepts in mathematics and the verbal domain across 13 countries at the secondary school level. Second, in light of the current focus on the replication and reproducibility of research results (e.g., Ioannidis, 2005), we used several PISA, TIMSS, and PIRLS cycles to 
replicate our findings. This is of particular importance at this point in time, given the lack of findings that have been replicated in many areas of psychology, educational science, and other fields. Third, the present study advances the current theory in self-concept research. Nonlinear effects between achievement and domain-specific self-concepts have mostly been neglected in previous research (but see Marsh, 2004; Marsh \& Rowe, 1996). From a theoretical point of view, the results of the present investigation suggest that models on self-concept formation may be refined by integrating nonlinear effects (e.g., quadratic effects) to better approximate empirical relations between achievement and corresponding self-concepts for all students. 


\section{References}

Alicke, M. D., \& Sedikides, C. (2009). Self-enhancement and self-protection: What they are and what they do. European Review of Social Psychology, 20(1), 1-48. doi:10.1080/10463280802613866

Alicke, M. D., \& Sedikides, C. (2011). Handbook of self-enhancement and self-protection. New York, NY: The Guilford Press.

Baumeister, R. F., Bratslavsky, E., Finkenauer, C., \& Vohs, K. D. (2001). Bad is stronger than good. Review of General Psychology, 5(4), 323-370. doi:10.1037/1089-2680.5.4.323

BIFIE (2018). BIFIEsurvey: Tools for survey statistics in educational assessment. R package version 3.0-14. https://CRAN.R-project.org/package=BIFIEsurvey

Bolt, D. M., Lu, Y., \& Kim, J. S. (2014). Measurement and control of response styles using anchoring vignettes: A model-based approach. Psychological Methods, 19(4), 528-541. doi: $10.1037 / \operatorname{met} 0000016$

Borenstein, M., Hedges, L. V., Higgins, J. P., \& Rothstein, H. R. (2009). Introduction to metaanalysis. Chichester, UK: John Wiley \& Sons.

Buckley, J. (2009). Cross-national response styles in international educational assessments: Evidence from PISA 2006. Retrieved from https://edsurveys.rti.org/PISA/documents/Buckley_PISAresponsestyle.pdf

Byrne, B. M. (1996). Measuring self-concept across the life span: Issues and instrumentation. Washington, DC: American Psychological Association.

Byrne, B. M. (2002). Validating the measurement and structure of self-concept: Snapshots of past, present, and future research. American Psychologist, 57, 897-909. doi:10.1037/0003-066X.57.11.897 
Cacioppo, J. T., \& Berntson, G. G. (1994). Relationship between attitudes and evaluative space: A critical review, with emphasis on the separability of positive and negative substrates. Psychological Bulletin, 115(3), 401-423. doi:10.1037/0033-2909.115.3.401

Cheung, M. W.-L. (2015). metaSEM: An R package for meta-analysis using structural equation modeling. Frontiers in Psychology, 5(1521). doi: 10.3389/fpsyg.2014.01521

Cheung, M. W.-L. \& Jak, S. (2016). Analyzing big data in psychology: A split/analyze/metaanalyze approach. Frontiers in Psychology, 7(738). doi:10.3389/fpsyg.2016.00738

Cochran, W. G. (1954). The combination of estimates from different experiments. Biometrics, 10(1), 101-129. doi:10.2307/3001666

Cohen, J., Cohen, P., West, S. G., \& Aiken, L. S. (2003). Applied multiple regression/correlation analysis for the behavioral sciences (3rd ed.). Mahwah, NJ: Erlbaum.

Curran, P. J. (2009). The seemingly quixotic pursuit of a cumulative psychological science: Introduction to the special issue. Psychological Methods, 14(2), 77-80. doi:10.1037/a0015972

Curran, P. J., \& Hussong, A. M. (2009). Integrative data analysis: The simultaneous analysis of multiple data sets. Psychological Methods, 14(2), 81-100. doi:10.1037/a0015914

Duckworth, A. L., \& Yeager, D. S. (2015). Measurement matters: Assessing personal qualities other than cognitive ability for educational purposes. Educational Researcher, 44(4), 237-251. doi:10.3102/0013189X15584327

Eccles, J. S., Midgley, C., \& Adler, T. F. (1984). Grade-related changes in the school environment: Effects on achievement motivation. In J. G. Nicholls (Ed.), The development of achievement motivation (pp. 283-331). Greenwich, CT: JAI Press. 
Else-Quest, N. M., Hyde, J. S., \& Linn, M. C. (2010). Cross-national patterns of gender differences in mathematics: A meta-analysis. Psychological Bulletin, 136(1), 103-127. doi:10.1037/a0018053

Eddington, A. (1939). The philosophy of physical science. New York, NY: Macmillan.

Festinger, L. (1954). A theory of social comparison processes. Human Relations, 7(2), 117-140. doi:10.1177/001872675400700202

Frey, K. S., \& Ruble, D. N. (1990). Strategies for comparative evaluation: Maintaining a sense of competence across the life span. In R. J. Sternberg \& J. Kolligian Jr. (Eds.), Competence considered (pp. 167-189). New Haven, CT: Yale University Press.

Gigerenzer, G. (1991). From tools to theories: A heuristic of discovery in cognitive psychology. Psychological Review, 98(2), 254-267. doi:10.1080/14792779143000033

Gogol, K., Brunner, M., Martin, R., Preckel, F., \& Goetz, T. (2017). Affect and motivation within and between school subjects: Development and validation of an integrative structural model of academic self-concept, interest, and anxiety. Contemporary Educational Psychology, 49, 46-65. doi:10.1016/j.cedpsych.2016.11.003

Graham, E. K., Rutsohn, J. P., Turiano, N. A., Bendayan, R., Batterham, P. J., Gerstorf, D., ... \& Bastarache, E. D. (2017). Personality predicts mortality risk: An integrative data analysis of 15 international longitudinal studies. Journal of Research in Personality, 70, 174-186. doi:10.1016/j.jrp.2017.07.005

Gramzow, R. H., Elliot, A. J., Asher, E., \& McGregor, H. A. (2003). Self-evaluation bias and academic performance: Some ways and some reasons why. Journal of Research in Personality, 37, 41-61. doi:10.1016/S0092-6566(02)00535-4 
Green, J. D., \& Sedikides, C. (2004). Retrieval selectivity in the processing of self-referent information: Testing the boundaries of self-protection. Self and Identity, 3(1), 69-80. doi: $10.1080 / 13576500342000059$

Guay, F., Marsh, H. W., \& Boivin, M. (2003). Academic self-concept and academic achievement: Developmental perspectives on their causal ordering. Journal of Educational Psychology, 95, 124-136. doi:10.1037/0022-0663.95.1.124

Hacker, D. J., Bol, L., Horgan, D. D., \& Rakow, E. A. (2000). Test prediction and performance in a classroom context. Journal of Educational Psychology, 92(1), 160-170. doi:10.1037//0022-0663.92.1.160

Harter, S. (2012). The construction of the self: Developmental and sociocultural foundations. New York, NY: Guilford Press.

He, J., Buchholz, J., \& Klieme, E. (2017). Effects of anchoring vignettes on comparability and predictive validity of student self-reports in 64 cultures. Journal of Cross-Cultural Psychology, 48(3), 319-334. doi: 10.1177/0022022116687395

Henrich, J., Heine, S. J., \& Norenzayan, A. (2010). The weirdest people in the world? The Behavioral and Brain Sciences, 33(2-3), 61-135. doi:10.1017/S0140525X0999152X

Hepper, E. G., Gramzow, R. H., \& Sedikides, C. (2010). Individual differences in selfenhancement and self-protection strategies: An integrative analysis. Journal of Personality, 78(2), 781-814. doi:10.1111/j.1467-6494.2010.00633.x

Higgins, J. P. T., \& Green, S. (Eds.) (2011). Cochrane handbook for systematic reviews of interventions (Version 5.1.0, updated March 2011). The Cochrane Collaboration. Available from www.handbook.cochrane.org.

Higgins, J. P. T., \& Thompson, S. G. (2002). Quantifying heterogeneity in a meta-analysis. Statistics in Medicine, 21, 1539-1558. doi:10.1002/sim.1186 
Hofer, S. M., \& Piccinin, A. M. (2009). Integrative data analysis through coordination of measurement and analysis protocol across independent longitudinal studies. Psychological Methods, 14(2), 150-164. doi:10.1037/a0015566

Huang, C. (2011). Self-concept and academic achievement: A meta-analysis of longitudinal relations. Journal of School Psychology, 49, 505-528. doi:10.1016/j.jsp.2011.07.001

Huedo-Medina, T. B., Sánchez-Meca, J., Marín-Martínez, F., \& Botella, J. (2006). Assessing heterogeneity in meta-analysis: Q statistic or $\mathrm{I}^{2}$ index? Psychological Methods, 11(2), 193-206. doi: 10.1037/1082-989X.11.2.193

Huguet, P., Dumas, F., Marsh, H., Wheeler, L., Seaton, M., Nezlek, J., Suls, J., \& Regner, I. (2009). Clarifying the role of social comparison in the Big-Fish-Little-Pond Effect (BFLPE): An integrative study. Journal of Personality and Social Psychology, 97(1). 156-170. doi:10.1037/a0015558

Hunter, J. E., \& Schmidt, F. L. (1996). Cumulative research knowledge and social policy formulation: The critical role of meta-analysis. Psychology, Public Policy, and Law, 2(2), 324-347. doi:10.1037/1076-8971.2.2.324

Ioannidis, J. P. (2005). Why most published research findings are false. PLoS medicine, 2(8), e124. doi:10.1371/journal.pmed.0020124

Jacobs, J. E., Lanza, S., Osgood, D. W., Eccles, J. S., \& Wigfield, A. (2002). Changes in children's self-competence and values: Gender and domain differences across grades one through twelve. Child Development, 73(2), 509-527. doi: 10.1111/1467-8624.00421

Krueger, J. I., \& Wright, J. C. (2011). Measurement of self-enhancement (and self-protection). In M. D. Alicke \& C. Sedikides, Handbook of self-enhancement and self-protection (pp. 472-494). New York, NY: The Guilford Press. 
Kyllonen, P. C., \& Bertling, J. J. (2014). Innovative questionnaire assessment methods to increase cross-country comparability. In L. Rutkowski, M. von Davier, \& D. Rutkowski (Eds.), Handbook of international large-scale assessment: Background, technical issues, and methods of data analysis (pp. 277-286). Boca Raton, FL: CRC Press.

Leary, M. R. (2007). Motivational and emotional aspects of the self. Annual Review of Psychology, 58, 317-344. doi:10.1146/annurev.psych.58.110405.085658

Lüdtke, O., \& Köller, O. (2002). Individuelle Bezugsnormorientierung und soziale Vergleiche im Mathematikunterricht Einfluss unterschiedlicher Referenzrahmen auf das fachspezifische Selbstkonzept der Begabung [Individual reference norm and social comparisons in mathematics classes: The impact of different frames of reference on the domain-specific self-concept of ability]. Zeitschrift für Entwicklungspsychologie und Pädagogische Psychologie, 34 (3), 156-166. doi:10.1026//0049-8637.34.3.156

Lüdtke, O., Köller, O., Marsh, H. W., \& Trautwein, U. (2005). Teacher frame of reference and the big-fish-little-pond effect. Contemporary Educational Psychology, 30, 263-285. doi:10.1016/j.cedpsych.2004.10.002

Lumley, T. (2004). Analysis of complex survey samples. Journal of Statistical Software 9(1), 119. doi:10.18637/jss.v009.i08

MacCallum, R. C., Zhang, S., Preacher, K. J., \& Rucker, D. D. (2002). On the practice of dichotomization of quantitative variables. Psychological Methods, 7(1), 19-40. doi:10.1037//1082-989X.7.1.19

Marsh, H. W. (1986). Verbal and math self-concepts: An internal/external frame of reference model. American Educational Research Journal, 23, 129-149. doi:10.2307/1163048 
Marsh, H. W. (1989). Age and sex effects in multiple dimensions of self-concept: Preadolescence to early adulthood. Journal of Educational Psychology, 81, 417-430. doi:10.1037/00220663.81 .3 .417

Marsh, H. W. (1990a). Causal ordering of academic self-concept and academic achievement: A multiwave, longitudinal panel analysis. Journal of Educational Psychology, 82, 646-656. doi:10.1037/0022-0663.82.4.646

Marsh, H. W. (1990b). Self-Description Questionnaire, II. San Antonio, TX: Psychological Corporation.

Marsh, H. W. (2004). Negative effects of school-average achievement on academic self-concept: A comparison of the big-fish-little-pond effect across Australian states and territories. Australian Journal of Education, 48, 5-26. doi:10.1177/000494410404800102

Marsh, H. W., \& Craven. R. G. (2006). Reciprocal effects of self-concept and performance from a multidimensional perspective: Beyond seductive pleasure and unidimensional perspectives. Perspectives on Psychological Science, 1, 133-163. doi:10.1111/j.17456916.2006.00010.x

Marsh, H. W., \& Hau, K. T. (2004). Explaining paradoxical relations between academic selfconcepts and achievements: Cross-cultural generalizability of the internal/external frame of reference predictions across 26 countries. Journal of Educational Psychology, 96(1), 56-67. doi:10.1037/0022-0663.96.1.56

Marsh, H. W., \& Rowe, K. J. (1996). The negative effects of school-average ability on academic self-concept: An application of multilevel modelling. Australian Journal of Education, 40, 65-87. doi:10.1177/000494419604000105

Marsh, H. W., Trautwein, U., Lüdtke, O., Köller, O., \& Baumert, J. (2006). Integration of multidimensional self-concept and core personality constructs: Construct validation and 
relations to well-being and achievement. Journal of Personality, 74, 403-456. doi:10.1111/j.1467-6494.2005.00380.x

Marsh, H. W., \& Yeung, A. S. (1998). Longitudinal structural equation models of academic selfconcept and achievement: Gender differences in the development of math and English constructs. American Educational Research Journal, 35(4), 705-738.

doi:10.3102/00028312035004705

Martin, M.O., \& Mullis, I.V.S. (2012). Methods and procedures in TIMSS and PIRLS 2011. Chestnut Hill, MA: TIMSS \& PIRLS International Study Center, Boston College.

Martin, M.O., Mullis, I.V.S., \& Hooper, M. (2016). Methods and procedures in TIMSS 2015. Chestnut Hill, MA: TIMSS \& PIRLS International Study Center, Boston College.

Martin, M.O., Mullis, I.V.S., \& Hooper, M. (2017). Methods and procedures in PIRLS 2016. Chestnut Hill, MA: TIMSS \& PIRLS International Study Center, Boston College.

Meehl, P. E. (1978). Theoretical risks and tabular asterisks: Sir Karl, Sir Ronald, and the slow progress of soft psychology. Journal of Consulting and Clinical Psychology, 46(4), 806834. doi:10.1037/0022-006X.46.4.806

Möller, J., \& Pohlmann, B. (2010). Achievement differences and self-concept differences: Stronger associations for above or below average students? British Journal of Educational Psychology, 80, 435-450. doi:10.1348/000709909X485234

Möller, J., Pohlmann, B., Köller, O. \& Marsh, H. W. (2009). A meta-analytic path analysis of the internal/external frame of reference model of academic achievement and academic selfconcept. Review of Educational Research, 79, 1129-1167. doi:10.3102/0034654309337522 
Möller, J., Zimmermann, F., \& Köller, O. (2014). The reciprocal internal/external frame of reference model using grades and test scores. British Journal of Educational Psychology, 84(4), 591-611. doi:10.1111/bjep.12047

Mullis, I. V. S., \& Martin, M. O. (2013). TIMSS 2015 assessment framework (2nd ed.). Chestnut Hill, MA: TIMSS \& PIRLS International Study Center, Boston College.

Mullis, I. V. S., \& Martin, M. O. (2015). PIRLS 2016 assessment framework (2nd ed.). Chestnut Hill, MA: TIMSS \& PIRLS International Study Center, Boston College.

Mullis, I. V. S., Martin, M. O., Kennedy, A. M., Trong, K. L, \& Sainsbury, M. (2009). PIRLS 2011 assessment framework. Chestnut Hill, MA: TIMSS \& PIRLS International Study Center, Boston College.

Mullis, I. V. S., Martin, M. O., Ruddock, G. J., O'Sullivan, C. Y., \& Preuschoff, C. (2009). TIMSS 2011 assessment frameworks. Chestnut Hill, MA: TIMSS \& PIRLS International Study Center, Boston College.

OECD (2000). Measuring student knowledge and skills: The PISA 2000 assessment of reading, mathematical and scientific literacy. Paris: OECD Publishing.

OECD (2002). PISA 2000 technical report. Paris: OECD Publishing.

OECD (2003). The PISA 2003 assessment framework: Mathematics, reading, science and problem solving knowledge and skills. Paris: OECD Publishing.

OECD (2013). PISA 2012 assessment and analytical framework: Mathematics, reading, science, problem solving and financial literacy. Paris: OECD Publishing. OECD (2014). PISA 2012 technical report. Paris: OECD Publishing. Open Science Collaboration (2015). Estimating the reproducibility of psychological science. Science, 349(6251), aac4716. doi: 10.1126/science.aac4716 
Prast, E. J., Van de Weijer-Bergsma, E., Miočević, M., Kroesbergen, E. H., \& Van Luit, J. E. (2018). Relations between mathematics achievement and motivation in students of diverse achievement levels. Contemporary Educational Psychology, 55, 84-96. doi:10.1016/j.cedpsych.2018.08.002

Preacher, K. J., Rucker, D. D., MacCallum, R. C., \& Nicewander, W. A. (2005). Use of the extreme groups approach: A critical reexamination and new recommendations. Psychological Methods, 10(2), 178-192. doi:10.1037/1082-989X.10.2.178

R Core Team (2018). R: A language and environment for statistical computing. R Foundation for Statistical Computing, Vienna, Austria. URL: https://www.R-project.org/.

Robitzsch, A., Grund, S., \& Henke, T. (2018). miceadds: Some additional multiple imputation functions, especially for mice. R package version 3.0-16. https://CRAN.Rproject.org $/$ package $=$ miceadds

Roy, A., Guay, F., \& Valois, P. (2015). The big-fish-little-pond effect on academic self-concept: The moderating role of differentiated instruction and individual achievement. Learning and Individual Differences, 42, 110-116. doi:10.1016/j.lindif.2015.07.009

Ruble, D. N., \& Frey, K. S. (1991). Changing patterns of comparative behavior as skills are acquired: A functional model of self-evaluation. In J. Suls \& T. A. Wills (Eds.), Social comparison: Contemporary theory and research (pp. 70-112). Hillsdale, NJ: Erlbaum.

Schurtz, I. M., Pfost, M., \& Artelt, C. (2014). Variieren die Selbstkonzeptdifferenzen in Abhängigkeit vom Leistungsniveau? Differenzielle Zusammenhänge in Deutsch, Englisch und Mathematik [Do self-concept differences vary in dependence of the achievement level? Differential relations in language arts, English, and mathematics]. Zeitschrift für Pädagogische Psychologie, 28(1-2), 31-42. doi:10.1024/1010-0652/a000122 
Segall, M. H., \& Lonner, W. J. (1998). Cross-cultural psychology as a scholarly discipline. On the flowering of culture in behavioral research. American Psychologist, 53, 1101-1110. doi:10.1037/0003-066X.53.10.1101

Shavelson, R. J., Hubner, J. J., \& Stanton, G. C. (1976). Self-concept: Validation of construct interpretations. Review of Educational Research, 46(3), 407-441. doi:10.3102/00346543046003407

Simonsohn, U. (2018). Two Lines: A valid alternative to the invalid testing of $\mathrm{u}$-shaped relationships with quadratic regressions. Advances in Methods and Practices in Psychological Science, 1(4), 538-555. doi:10.1177/2515245918805755

Skaalvik, E. M., \& Rankin, R. J. (1992). Math and verbal achievement and self-concepts: Testing the internal/external frame of reference model. The Journal of Early Adolescence, 12(3), 267-279. doi:10.1177/0272431692012003003

Skaalvik, S., \& Skaalvik, E. M. (2004). Gender differences in math and verbal self-concept, performance expectations, and motivation. Sex Roles, 50(3-4), 241-252. doi: 10.1023/B:SERS.0000015555.40976.e6

Soderberg, C. K. (2018). Using OSF to share data: A step-by-step guide. Advances in Methods and Practices in Psychological Science, 1, 115-120. doi:10.1177/2515245918757689

Stipek, D. J., \& Daniels, D. H. (1988). Declining perceptions of competence: A consequence of changes in the child or in the educational environment? Journal of Educational Psychology, 80(3), 352-356. doi:10.1037/0022-0663.80.3.352

Suls, J., Martin, R., \& Wheeler, L. (2002). Social comparison: Why, with whom, and with what effect? Current Directions in Psychological Science, 11(5), 159-163. doi:10.1111/14678721.00191 
Tajfel, H., \& Turner, J. C. (1979). An integrative theory of intergroup conflict. In W. G. Austin \& S. Worchel (Eds.), The social psychology of intergroup relations (pp. 33-47). Salt Lake City, UT: Brooks/Cole Publishing Co.

Trautwein, U., \& Möller, J. (2016). Self-concept: Determinants and consequences of academic self-concept in school contexts. In A. A. Lipnevich, F. Preckel, \& R. D. Roberts (Eds.), Psychosocial skills and school systems in the 21st century: Theory, research, and practice (pp. 187-214). Cham, Switzerland: Springer. doi:10.1007/978-3-319-28606-8_8

Van der Beek, J. P., Van der Ven, S. H., Kroesbergen, E. H., \& Leseman, P. P. (2017). Selfconcept mediates the relation between achievement and emotions in mathematics. British Journal of Educational Psychology, 87(3), 478-495. doi:10.1111/bjep.12160

Weijters, B., Cabooter, E., \& Schillewaert, N. (2010). The effect of rating scale format on response styles: The number of response categories and response category labels. International Journal of Research in Marketing, 27(3), 236-247. doi:10.1016/j.ijresmar.2010.02.004

Weirich, S., Haag, N., Hecht, M., Böhme, K., Siegle, T., \& Lüdtke, O. (2014). Nested multiple imputation in large-scale assessments. Large-scale Assessments in Education, 2(9). doi:10.1186/s40536-014-0009-0

Wheeler, L., \& Suls, J. (2005). Social comparison and self-evaluations of competence. In A. J. Elliot \& C. S. Dweck, Handbook of competence and motivation (pp. 566-578). New York, NY: Guilford Press.

Wickham, H. (2009). Elegant graphics for data analysis (ggplot2). New York, NY: Springer. Wigfield, A., \& Eccles, J. S. (2002). The development of competence beliefs, expectancies for success, and achievement values from childhood through adolescence. In A. Wigfield \& J. 
S. Eccles (Eds.), Development of achievement motivation (pp. 91-120). San Diego, CA: Academic Press.

Wood, S. N. (2017). Generalized additive models: An introduction with R (2nd ed.). New York, NY: Chapman and Hall/CRC. doi:10.1201/9781315370279 
Table 1

Number of Examined Countries, Sample Sizes, Percentage of Female Students (\%F), Number of Participating Classes or Schools, and Students' Mean Age for Individual Assessments and in Total

\begin{tabular}{lccccc}
\hline \multicolumn{1}{c}{ Assessment } & $N_{\text {countries }}$ & $N$ & $\% \mathrm{~F}$ & $N_{\text {classes/schools }}$ & Age $_{\text {mean }}$ \\
\hline \multicolumn{7}{c}{ Elementary school students } \\
\hline TIMSS/PIRLS 2011 (Grade 4) & $13^{\mathrm{a}}$ & 56,868 & 49 & 3,159 & 10.30 \\
TIMSS 2015 (Grade 4) & $12^{\mathrm{b}}$ & 55,642 & 49 & 3,104 & 10.38 \\
PIRLS 2016 (Grade 4) & $13^{\mathrm{a}}$ & 59,586 & 49 & 3,305 & 10.36 \\
\hline \multicolumn{7}{c}{ Secondary school students } \\
\hline TIMSS 2011 (Grade 8) & $8^{\mathrm{c}}$ & 39,317 & 49 & 1,990 & 14.35 \\
TIMSS 2015 (Grade 8) & $8^{\mathrm{d}}$ & 42,120 & 50 & 2,108 & 14.42 \\
PISA 2000 (15-year-olds) & $13^{\mathrm{a}}$ & 35,024 & 51 & 2,412 & 15.71 \\
PISA 2003 (15-year-olds) & $13^{\mathrm{a}}$ & 77,910 & 50 & 2,868 & 15.78 \\
PISA 2012 (15-year-olds) & $13^{\mathrm{a}}$ & 104,337 & 49 & 4,361 & 15.76 \\
\hline Total & $13^{\mathrm{a}}$ & 470,804 & 50 & 23,307 & \\
\hline
\end{tabular}

Note. In TIMSS and PIRLS, one or more intact classes of students were randomly sampled within randomly selected schools, whereas in PISA, students were randomly sampled within randomly selected schools.

${ }^{a}$ Australia, Austria, Czech Republic, Finland, Germany, Hong Kong, Hungary, Ireland, Italy, Norway, Portugal, Russian Federation, Sweden.

${ }^{\mathrm{b}}$ Austria did not participate.

${ }^{\mathrm{c}}$ Australia, Czech Republic, Finland, Germany, Hong Kong, Hungary, Ireland, Italy, Norway, Portugal, Russian Federation, Sweden.

d Australia, Hong Kong, Hungary, Ireland, Italy, Norway, Russian Federation, Sweden. 
Table 2

Median Reliabilities (and Range) for Mathematics and Reading Achievement and Self-Concept Scales across the Examined Countries

\begin{tabular}{|c|c|c|c|c|}
\hline \multirow[b]{2}{*}{ Assessment } & \multicolumn{2}{|c|}{ Achievement $^{\mathrm{a}}$} & \multicolumn{2}{|c|}{ Self-concept ${ }^{b}$} \\
\hline & Mathematics & Reading & Mathematics & Verbal/reading \\
\hline \multicolumn{5}{|c|}{ Elementary school students } \\
\hline TIMSS/PIRLS 2011(Grade 4) & $.82(.79-.87)$ & $.87(.81-.89)$ & $.87(.85-.90)$ & $.72(.64-.77)$ \\
\hline TIMSS 2015 (Grade 4) & $.83(.81-.88)$ & - & $.87(.84-.89)$ & - \\
\hline PIRLS 2016 (Grade 4) & - & $.88(.85-.91)$ & - & $.80(.72-.82)$ \\
\hline \multicolumn{5}{|c|}{ Secondary school students } \\
\hline TIMSS 2011 (Grade 8) & $.89(.83-.91)$ & - & $.91(.90-.93)$ & - \\
\hline TIMSS 2015 (Grade 8) & $.89(.83-.91)$ & - & $.91(.89-.92)$ & - \\
\hline PISA 2000 (15-year-olds) & .81 & .89 & $.87(.84-.93)$ & $.76(.66-.82)$ \\
\hline PISA 2003 (15-year-olds) & $.91(.88-.93)$ & - & $.89(.81-.92)$ & - \\
\hline PISA 2012 (15-year-olds) & $.93(.91-.94)$ & - & $.89(.82-.92)$ & - \\
\hline
\end{tabular}

Note. In PISA 2000, only averaged reliabilities were reported for the international PISA scales.

${ }^{a}$ Reliability estimates were based on item response theory.

${ }^{\mathrm{b}}$ Reliability was measured as Cronbach's alpha. 


\section{Table 3}

Meta-Analytic Results for Mathematics: Average Regression Coefficients and Corresponding Heterogeneity Measures (with 95\% Confidence Intervals) from the Linear and Quadratic Regression Models for TIMSS and PISA

\begin{tabular}{|c|c|c|c|c|c|c|c|}
\hline & \multirow{2}{*}{\multicolumn{2}{|c|}{$\begin{array}{c}\text { Linear model } \\
\text { Linear term }\end{array}$}} & \multicolumn{5}{|c|}{ Quadratic model } \\
\hline & & & \multicolumn{2}{|c|}{ Linear term } & \multicolumn{3}{|c|}{ Quadratic term } \\
\hline & Estimate & $95 \% \mathrm{CI}$ & Estimate & $95 \% \mathrm{CI}$ & Estimate & & $95 \% \mathrm{CI}$ \\
\hline \multicolumn{8}{|c|}{ Elementary school students } \\
\hline \multicolumn{8}{|c|}{ TIMSS 2011 \& 2015 (Grade 4) } \\
\hline$\beta_{\text {mean }}$ & 0.38 & {$[0.35,0.42]$} & 0.39 & {$[0.36,0.42]$} & 0.04 & & {$[0.03,0.06]$} \\
\hline$Q$ & 567.092 & $* * *$ & 635.405 & $* * *$ & 79.804 & $* * *$ & \\
\hline$I_{\text {total }}^{2}$ & 95.45 & †ो & 95.80 & $\dagger \dagger$ & 68.37 & $\dagger$ & \\
\hline$I_{\text {Level2 }}^{2}$ & 95.45 & †ो & 95.80 & $\dagger \dagger$ & 62.10 & $\dagger$ & \\
\hline$I_{\text {Level3 }}^{2}$ & 0 & & 0 & & 6.27 & & \\
\hline$\tau_{\text {total }}$ & 0.08 & & 0.08 & & 0.03 & & \\
\hline$\tau_{\text {Level2 }}$ & 0.08 & & 0.08 & & 0.03 & & \\
\hline$\tau_{\text {Level3 }}$ & 0 & & 0 & & 0.01 & & \\
\hline$\underline{k}$ & 25 & & 25 & & 25 & & \\
\hline \multicolumn{8}{|c|}{ Secondary school students } \\
\hline \multicolumn{8}{|c|}{ TIMSS $2011 \& 2015$ (Grade 8) } \\
\hline$\overline{\beta_{\text {mean }}}$ & 0.53 & {$[0.48,0.58]$} & 0.56 & {$[0.52,0.61]$} & 0.12 & & {$[0.08,0.15]$} \\
\hline$Q$ & 374.899 & $* * *$ & 275.647 & $* * *$ & 97.126 & $* * *$ & \\
\hline$I_{\text {total }}^{2}$ & 96.24 & $\dagger \dagger$ & 94.69 & $\dagger \dagger$ & 86.04 & $\dagger \dagger$ & \\
\hline$I_{\text {Level2 }}^{2}$ & 0 & & 0 & & 20.99 & & \\
\hline$I_{\text {Level3 }}^{2}$ & 96.24 & $\dagger \dagger$ & 94.69 & $\dagger \dagger$ & 65.05 & $\dagger$ & \\
\hline$\tau_{\text {total }}$ & 0.08 & & 0.06 & & 0.05 & & \\
\hline$\tau_{\text {Level2 }}$ & 0 & & 0 & & 0.03 & & \\
\hline$\tau_{\text {Level3 }}$ & 0.08 & & 0.06 & & 0.05 & & \\
\hline$\underline{k}$ & 16 & & 16 & & 16 & & \\
\hline
\end{tabular}


Table 3 (Continued)

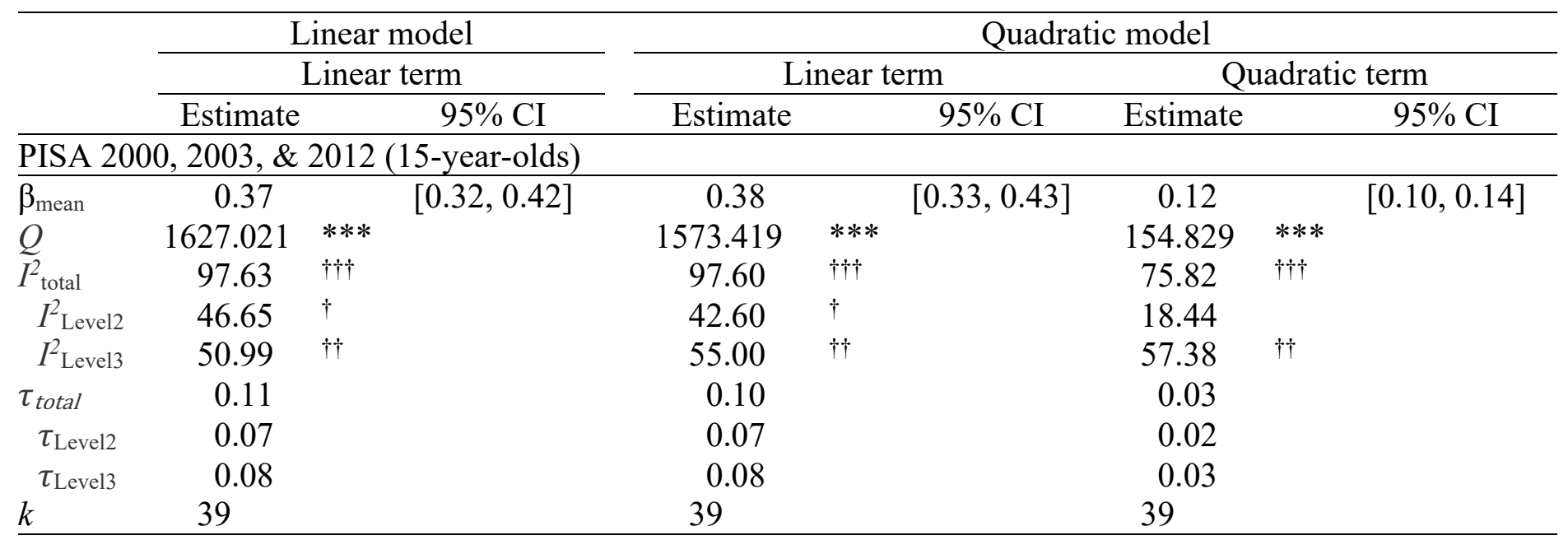

Note. $\beta_{\text {mean }}=$ Average regression coefficient, $Q=$ Cochran's measure of homogeneity $($ Cochran, 1954$), I_{\text {total }}^{2}=$ Higgins and Thompson's (2002) measure of (total) heterogeneity, $I_{\text {Level2 }}^{2}=$ Percentage of the variability in regression coefficients that is due to heterogeneity within countries rather than sampling error; $I^{2}$ Level3 $=$ Percentage of the variability in regression coefficients that is due to heterogeneity between countries rather than sampling error, $\tau_{\text {total }}=$ Total standard deviation of regression coefficients, $\tau_{\text {Level } 2}=$ Within-country standard deviation of regression coefficients, $\tau_{\text {Level } 3}=$ Between-country standard deviation of regression coefficients, $k=$ number of countries.

${ }^{\dagger}$ Moderate heterogeneity $\left(I^{2}>30 \%\right),{ }^{\dagger \dagger}$ Substantial heterogeneity $\left(I^{2}>50 \%\right), \stackrel{\dagger \dagger}{\dagger \dagger}$ Considerable heterogeneity $\left(I^{2}\right.$ $>75 \%$ ).

$* * * p<.001$. 
Table 4

Meta-Analytic Results for the Verbal Domain: Average Regression Coefficients and Corresponding Heterogeneity Measures (with 95\% Confidence Intervals) from the Linear and Quadratic Regression Models for PIRLS and PISA

\begin{tabular}{|c|c|c|c|c|c|c|c|}
\hline & \multirow{2}{*}{\multicolumn{2}{|c|}{$\begin{array}{c}\text { Linear model } \\
\text { Linear term }\end{array}$}} & \multicolumn{5}{|c|}{ Quadratic model } \\
\hline & & & \multicolumn{2}{|c|}{ Linear term } & \multicolumn{3}{|c|}{ Quadratic term } \\
\hline & Estimate & $95 \% \mathrm{CI}$ & Estimate & $95 \% \mathrm{CI}$ & Estimate & & $95 \% \mathrm{CI}$ \\
\hline \multicolumn{8}{|c|}{ Elementary school students } \\
\hline \multicolumn{8}{|c|}{ PIRLS 2011 \& 2016 (Grade 4) } \\
\hline$\beta_{\text {mean }}$ & 0.44 & {$[0.41,0.46]$} & 0.43 & {$[0.41,0.46]$} & -0.02 & & {$[-0.03,-0.01]$} \\
\hline$Q$ & 248.447 & $* * *$ & 244.134 & $* * *$ & 57.989 & $* * *$ & \\
\hline$I_{\text {total }}^{2}$ & 88.41 & $\dagger \dagger$ & 88.62 & $\dagger \dagger$ & 54.48 & $\dagger$ & \\
\hline$I^{2}$ Level2 & 14.29 & & 12.34 & & 46.42 & $\dagger$ & \\
\hline$I^{2}$ Level3 & 74.12 & $\dagger$ & 76.28 & $\dagger$ & 8.06 & & \\
\hline$\tau_{\text {total }}$ & 0.05 & & 0.05 & & 0.02 & & \\
\hline$\tau_{\text {Level2 }}$ & 0.02 & & 0.02 & & 0.02 & & \\
\hline$\tau_{\text {Level3 }}$ & 0.04 & & 0.04 & & 0.01 & & \\
\hline$\underline{k}$ & 26 & & 26 & & 26 & & \\
\hline \multicolumn{8}{|c|}{ Secondary school students } \\
\hline \multicolumn{8}{|c|}{ PISA 2000 (15-year-olds) } \\
\hline$\overline{\beta_{\text {mean }}}$ & 0.27 & {$[0.23,0.31]$} & 0.28 & {$[0.24,0.32]$} & 0.05 & & {$[0.03,0.07]$} \\
\hline$Q$ & 154.299 & $* * *$ & 169.885 & $* * *$ & 28.171 & $* *$ & \\
\hline$I_{\text {total }}^{2}$ & 91.99 & $\dagger$ & 92.67 & $\dagger$ & 53.65 & $\dagger$ & \\
\hline$\tau_{\text {total }}$ & 0.07 & & 0.08 & & 0.03 & & \\
\hline$k$ & 13 & & 13 & & 13 & & \\
\hline
\end{tabular}

Note. $\beta_{\text {mean }}=$ Average regression coefficient, $Q=$ Cochran's measure of homogeneity (Cochran, 1954), $I_{\text {total }}^{2}=$ Higgins and Thompson's (2002) measure of (total) heterogeneity, $I^{2}$ Level2 = Percentage of the variability in regression coefficients that is due to heterogeneity within countries rather than sampling error; $I^{2}$ Level3 $=$ Percentage of the variability in regression coefficients that is due to heterogeneity between countries rather than sampling error, $\tau_{\text {total }}=$ Total standard deviation of regression coefficients, $\tau_{\text {Level } 2}=$ Within-country standard deviation of regression coefficients, $\tau_{\text {Level } 3}=$ Between-country standard deviation of regression coefficients, $k=$ number of countries. 
${ }^{\dagger}$ Moderate heterogeneity $\left(I^{2}>30 \%\right),{ }^{\dagger \dagger}$ Substantial heterogeneity $\left(I^{2}>50 \%\right),{ }^{\dagger \dagger}$ Considerable
heterogeneity $\left(I^{2}>75 \%\right)$.

$* * p<.01 . * * * p<.001$. 
Table 5

Meta-Analytic Results for Mathematics: Average Regression Coefficients and Corresponding Heterogeneity Measures (with 95\% Confidence Intervals) from the Interrupted Regressions for TIMSS and PISA

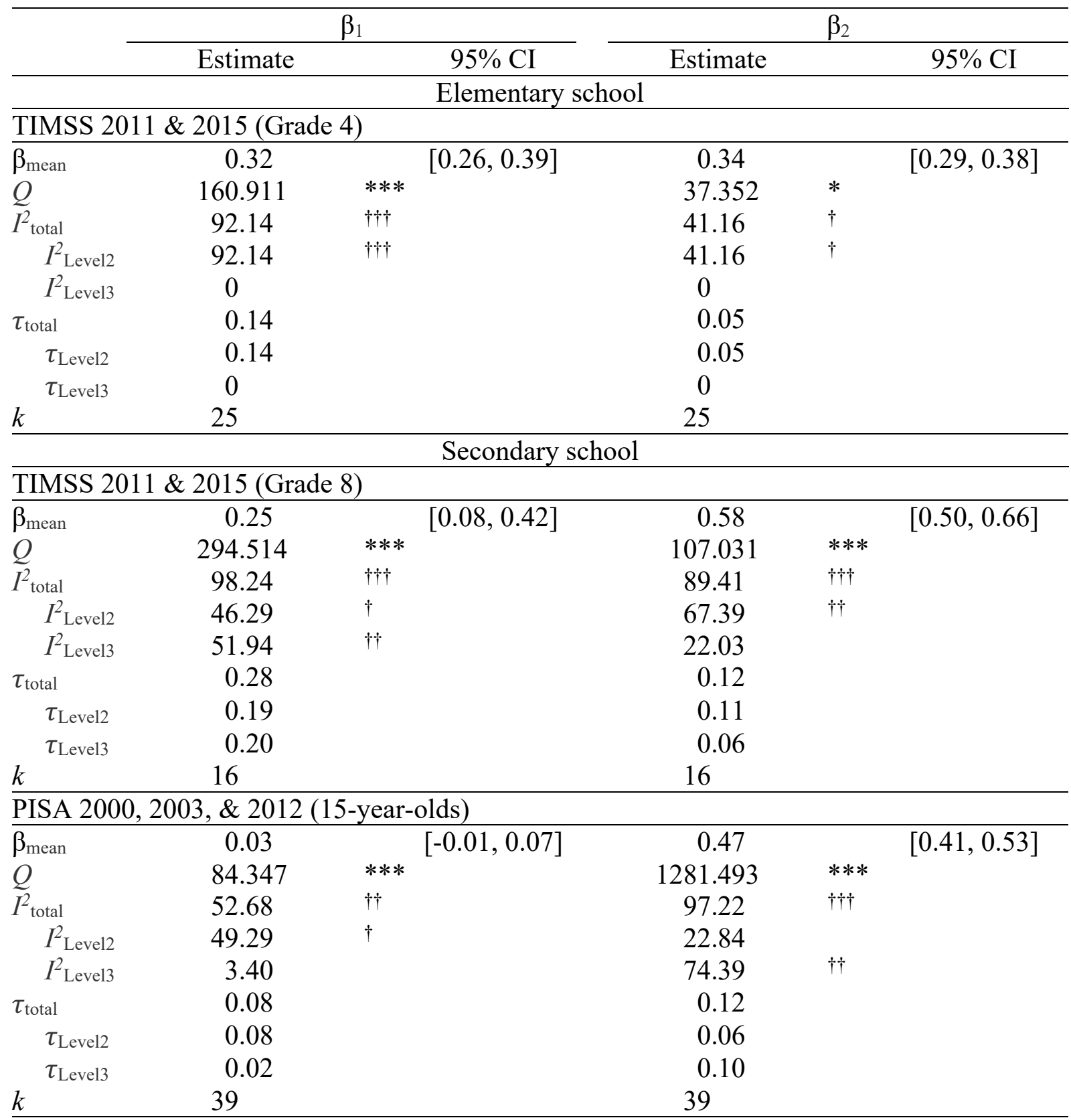

Note. $\beta_{\text {mean }}=$ Average regression coefficient, $Q=$ Cochran's measure of homogeneity (Cochran, 1954), $I_{\text {total }}^{2}=$ Higgins and Thompson's (2002) measure of (total) heterogeneity, $I^{2}$ Level2 $=$ Percentage of the variability in regression coefficients that is due to heterogeneity within countries rather than sampling error; $I^{2}$ Level $3=$ Percentage of the variability in regression coefficients that is due to heterogeneity between countries rather than sampling error, $\tau_{\text {total }}=$ Total standard deviation of regression coefficients, $\tau_{\text {Level } 2}=$ Within-country standard deviation of regression coefficients, $\tau_{\text {Level3 }}=$ Between-country standard deviation of regression coefficients, $k=$ number of countries. 
${ }^{\dagger}$ Moderate heterogeneity $\left(I^{2}>30 \%\right),{ }^{\dagger}$ Substantial heterogeneity $\left(I^{2}>50 \%\right),{ }^{\dagger \dagger}$ Considerable heterogeneity $\left(I^{2}>75 \%\right)$.

$* p<.05$. *** $p<.001$. 
Table 6

Meta-Analytic Results for the Verbal Domain: Average Regression Coefficients and Corresponding Heterogeneity Measures (with 95\% Confidence Intervals) from the Interrupted Regressions for PIRLS and PISA

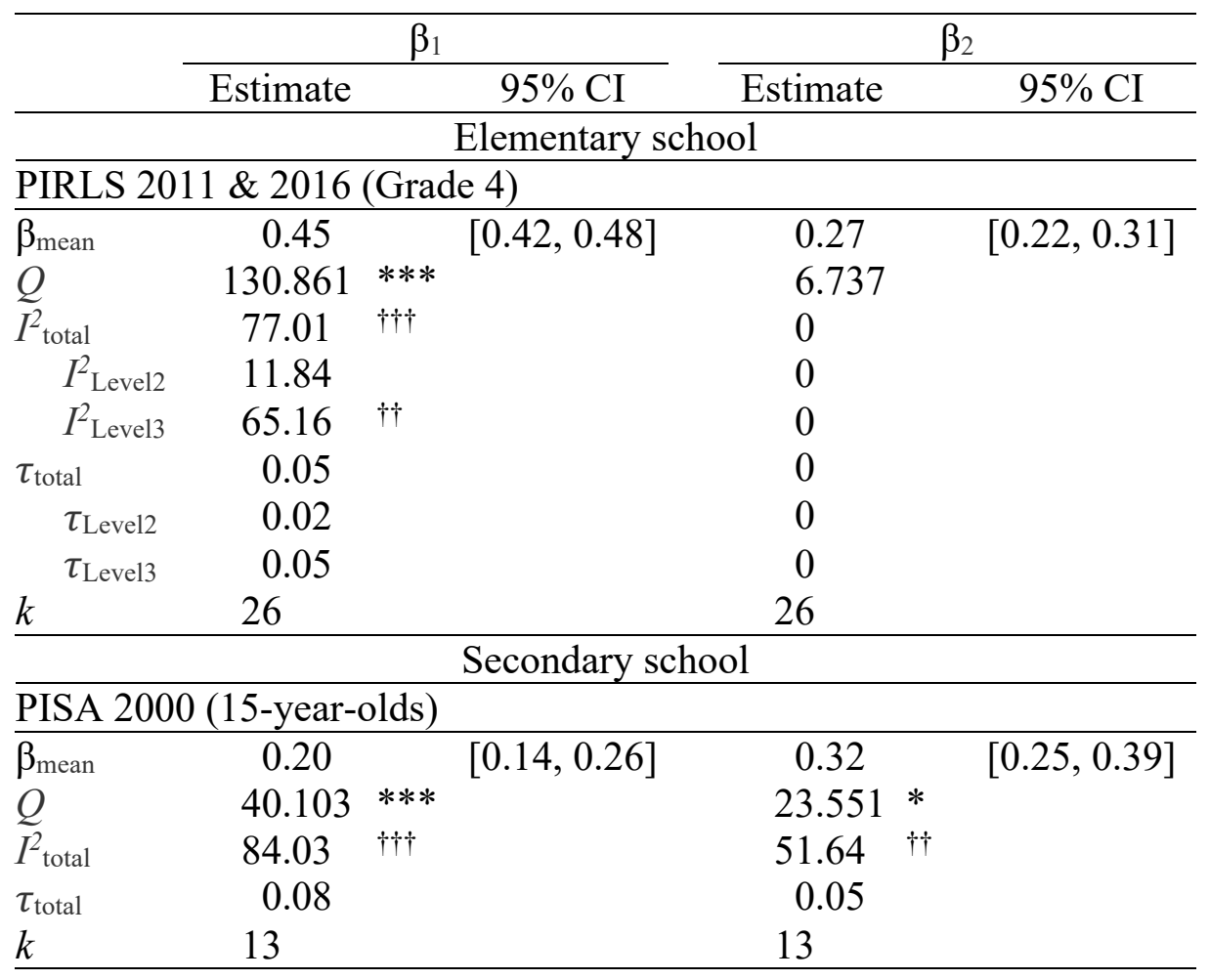

Note. $\beta_{\text {mean }}=$ Average regression coefficient, $Q=$ Cochran's measure of homogeneity (Cochran, 1954), $I^{2}$ total $=$ Higgins and Thompson's (2002) measure of (total) heterogeneity, $I^{2}$ Level $2=$ Percentage of the variability in regression coefficients that is due to heterogeneity within countries rather than sampling error; $I^{2}$ Level3 $=$ Percentage of the variability in regression coefficients that is due to heterogeneity between countries rather than sampling error, $\tau_{\text {total }}=$ Total standard deviation of regression coefficients, $\tau_{\text {Level } 2}=$ Within-country standard deviation of regression coefficients, $\tau_{\text {Level3 }}=$ Between-country standard deviation of regression coefficients, $k=$ number of countries.

$\dagger$ Substantial heterogeneity $\left(I^{2}>50 \%\right), \stackrel{\dagger \dagger}{ }$ Considerable heterogeneity $\left(I^{2}>75 \%\right)$.

$* p<.05 . * * * p<.001$. 

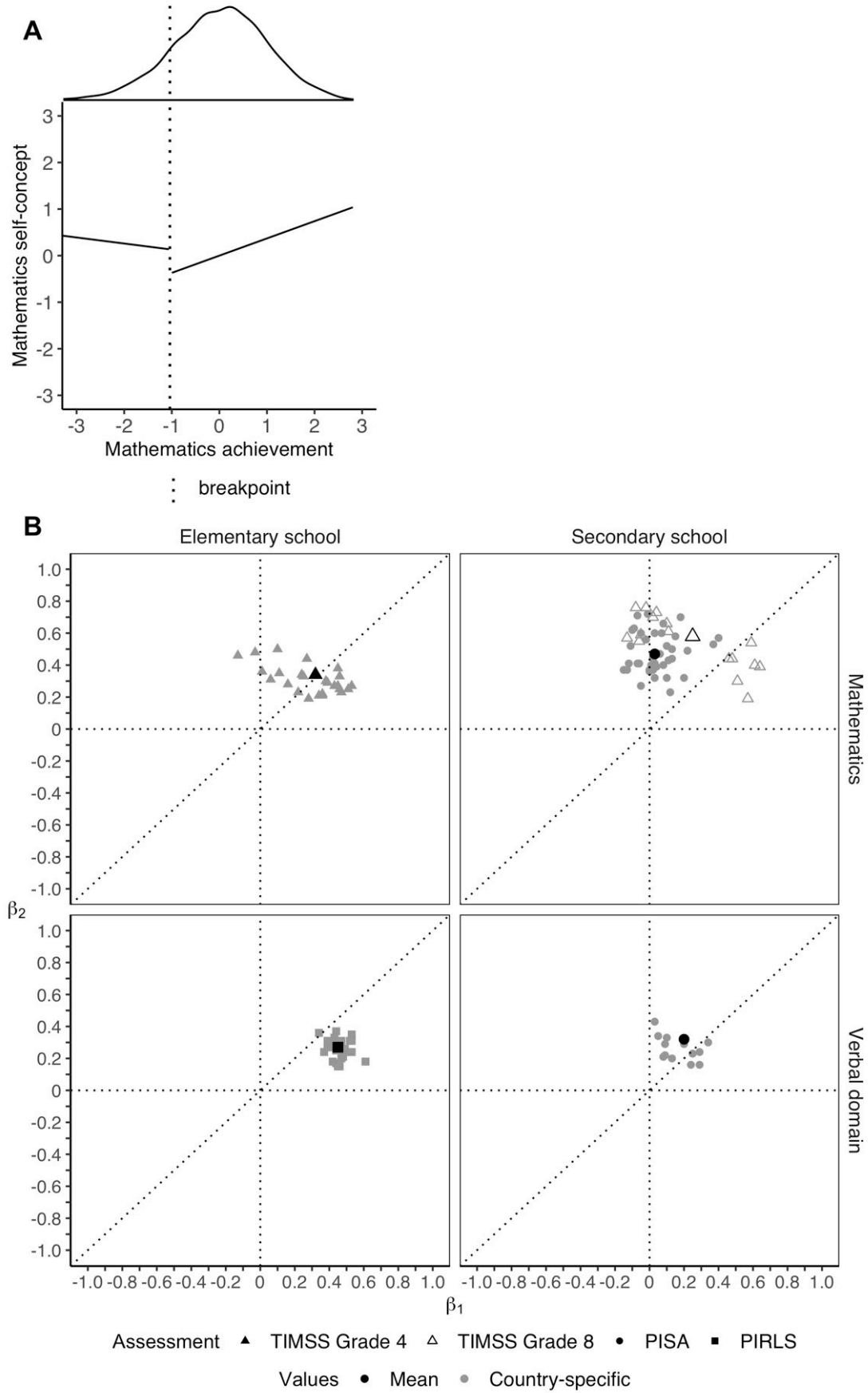

Figure 1. Domain-specific pattern of slopes as obtained from the interrupted regressions: (A) Example graph for a single country (Australia in PISA 2000). The density plot shows the math achievement distribution for the first plausible value. (B) Summary of results depicted separately for mathematics (TIMSS and PISA) and the verbal domain (PIRLS and PISA) and for elementary school students (TIMSS and PIRLS) and secondary school students (TIMSS and PISA). $\beta_{1}$ represents the regression coefficient to the left of the breakpoint (i.e., relatively lower achieving students), $\beta_{2}$ the regression coefficient to the right of the breakpoint (i.e., relatively higher achieving students). Symbols above the diagonal indicate that the relation between achievement and self-concept was weaker for lower achieving students than for higher achieving students in a certain country or assessment. Mean values are depicted in black, country-specific values in grey. 

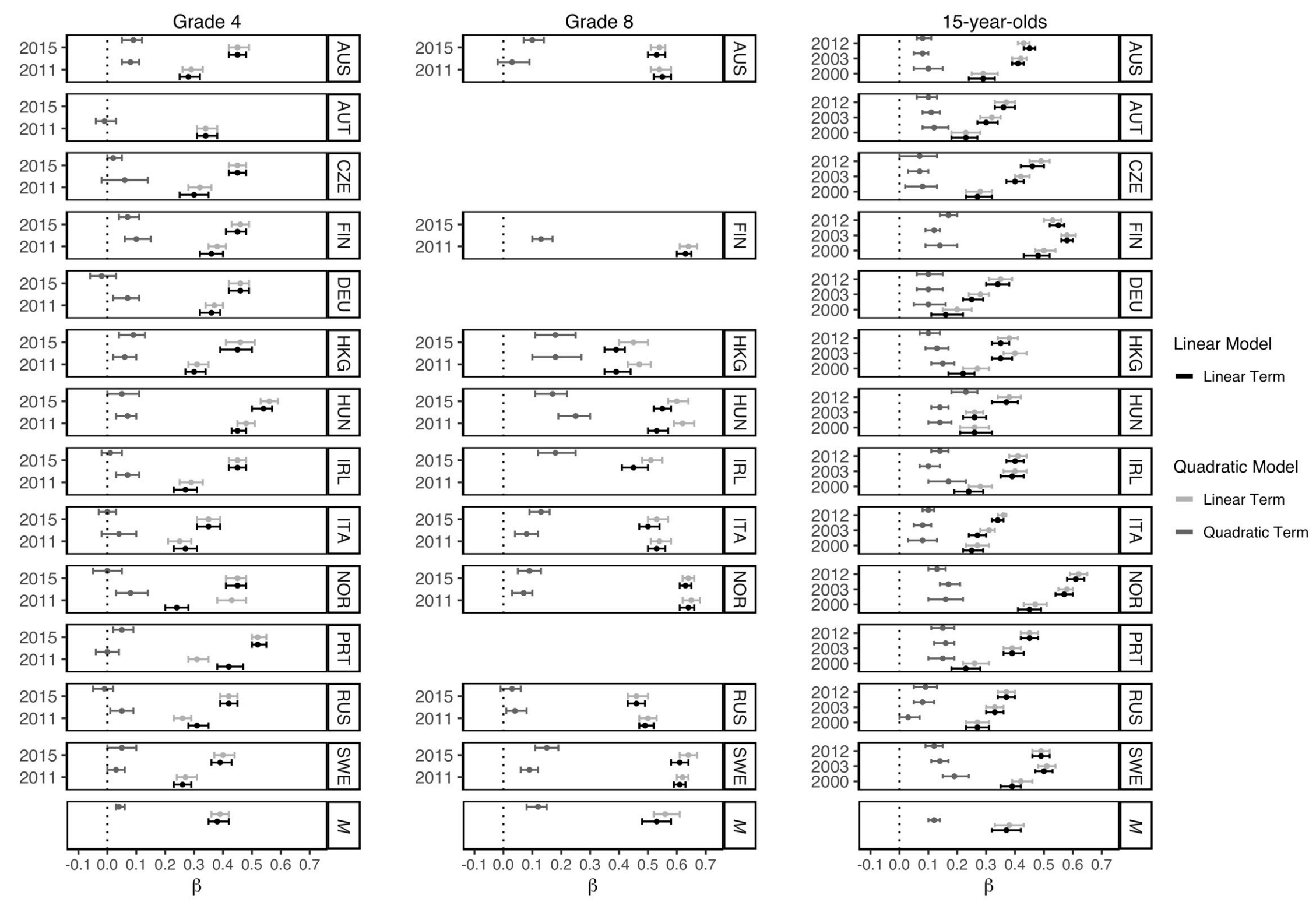

Figure 2. Country-specific relations between mathematics achievement and mathematics self-concept for different age groups (left: TIMSS 2011/2015 Grade 4, middle: TIMSS 2011/2015 Grade 8, right: PISA 2000/2003/2012). AUS = Australia, AUT= Austria, CZE = Czech Republic, FIN = Finland, DEU = Germany, HKG = Hong Kong, HUN = Hungary, IRL = Ireland, ITA = Italy, NOR = Norway, $\mathrm{PRT}=$ Portugal, RUS $=$ Russian Federation, $\mathrm{SWE}=$ Sweden, $M=$ weighted mean. 
Elementary school: Mathematics

TIMSS 2011

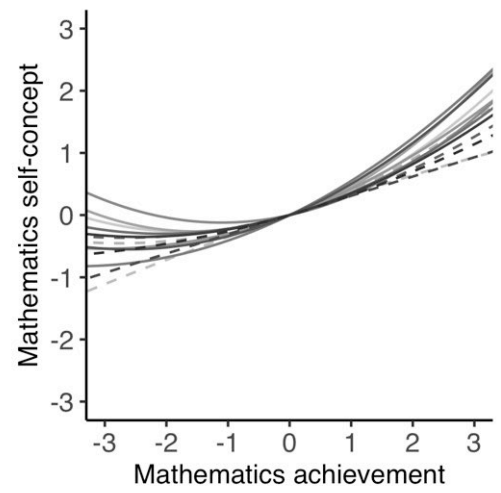

TIMSS 2015

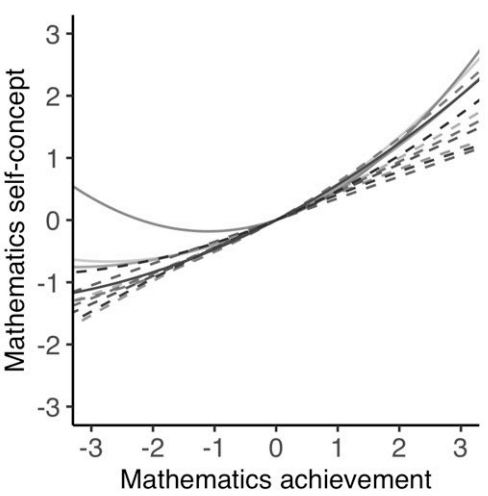

Secondary school: Mathematics

TIMSS 2011

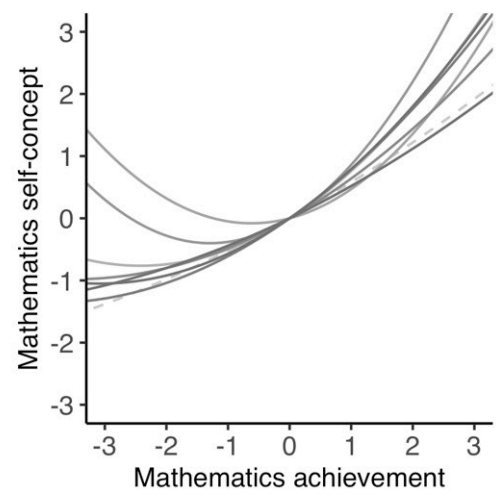

TIMSS 2015

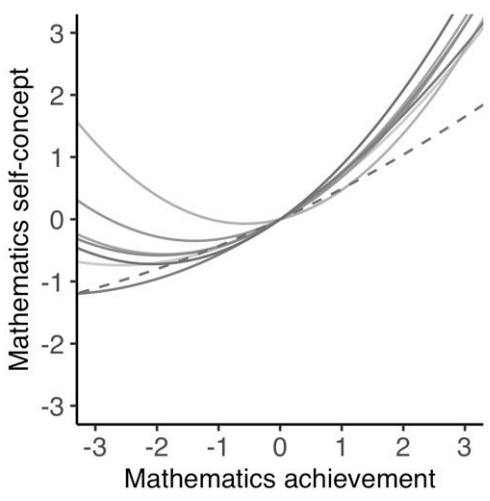

PISA 2000

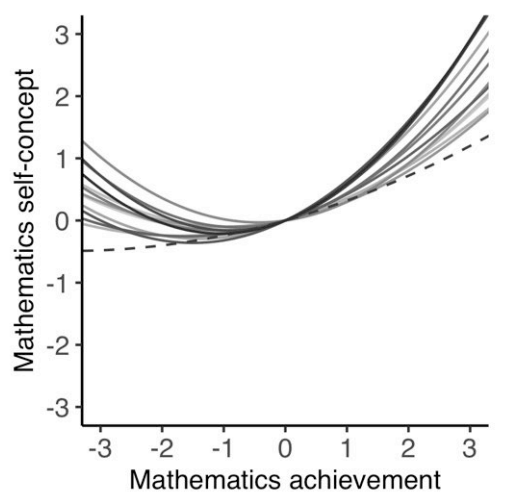

PISA 2003

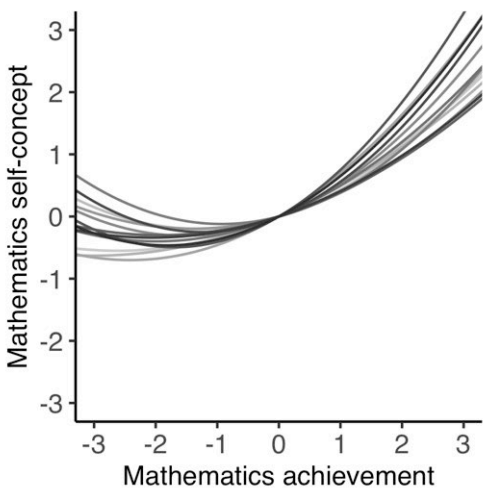

PISA 2012

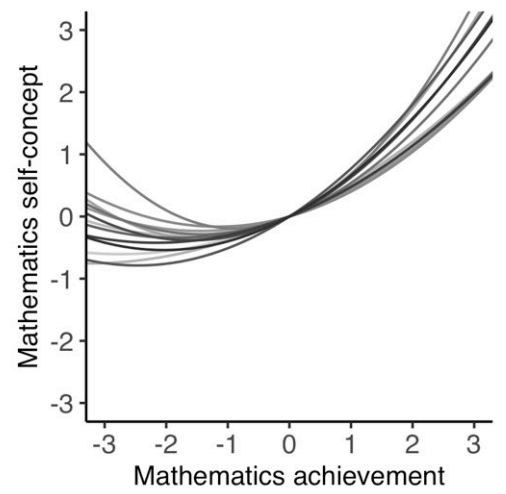

Figure 3. Country-specific quadratic regression lines for the mathematics domain (TIMSS and PISA assessments). Significant quadratic effects are depicted as solid lines, nonsignificant quadratic effects as dashed lines. 
Grade 4

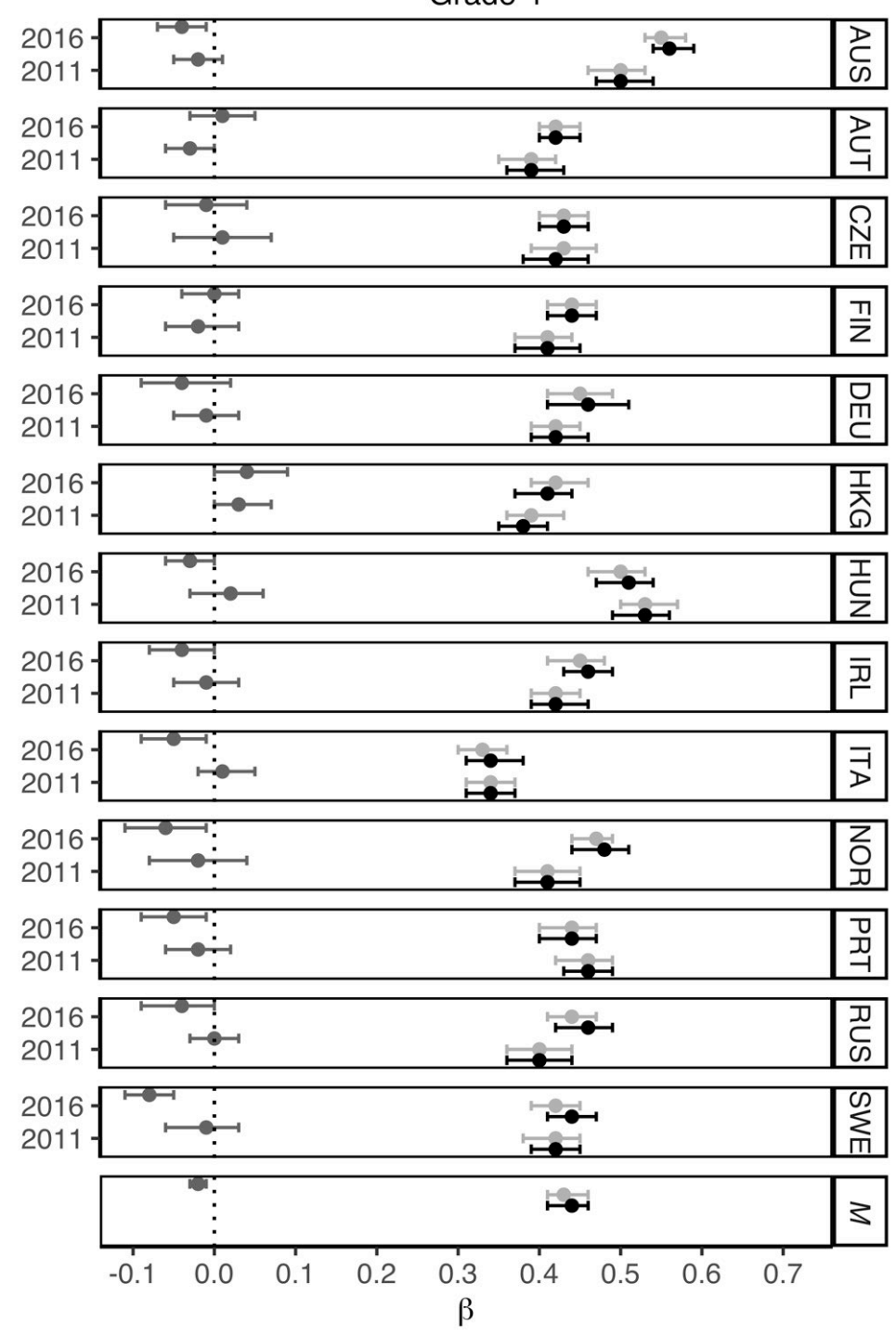

15-year-olds

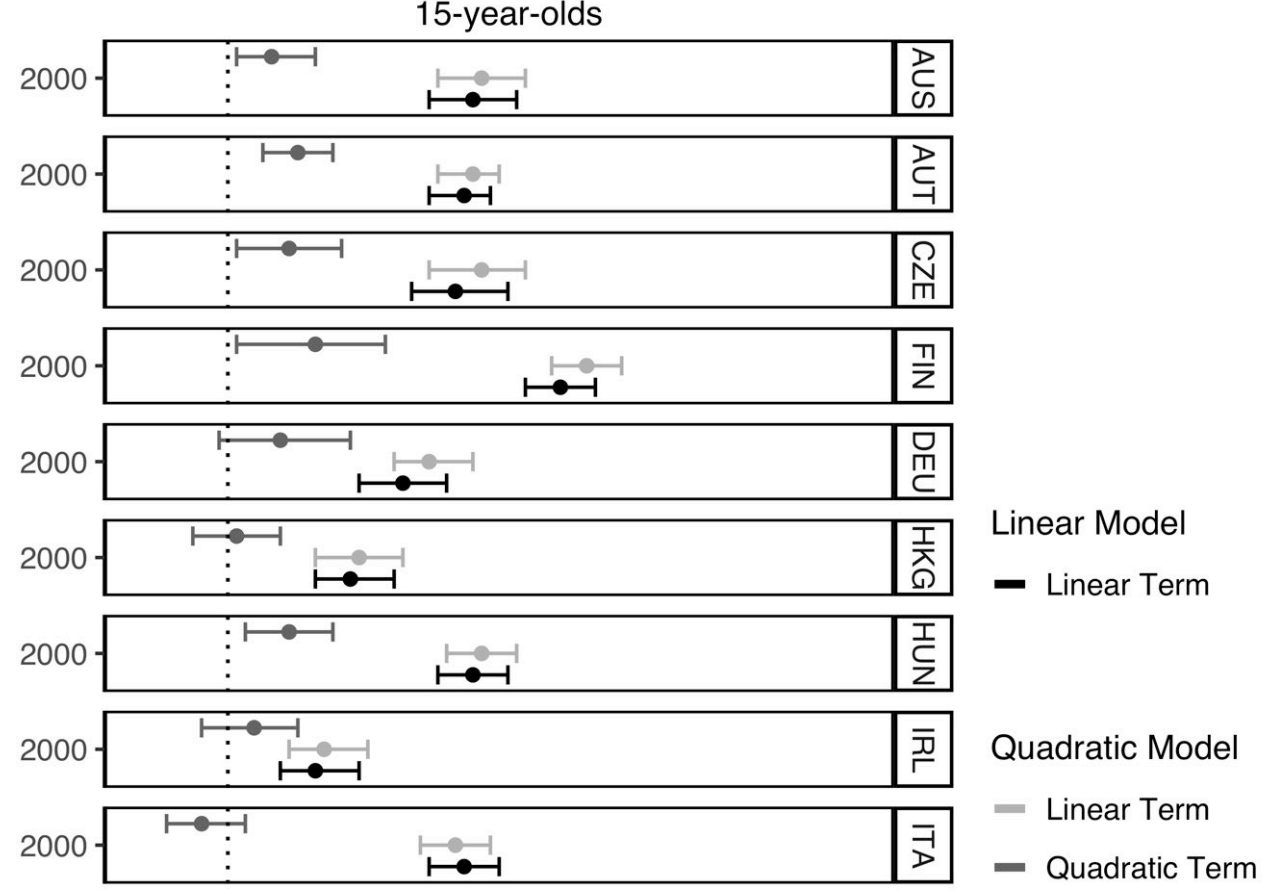

Figure 4. Country-specific relations between reading achievement and reading self-concept (left: PIRLS 2011/2016) or verbal selfconcept (right: PISA 2000). AUS $=$ Australia, AUT $=$ Austria, $\mathrm{CZE}=$ Czech Republic, FIN $=$ Finland, DEU $=\mathrm{Germany}, \mathrm{HKG}=$ Hong Kong, HUN = Hungary, IRL = Ireland, ITA = Italy, NOR = Norway, PRT = Portugal, RUS = Russian Federation, $\mathrm{SWE}=$ Sweden, $M=$ weighted mean. 

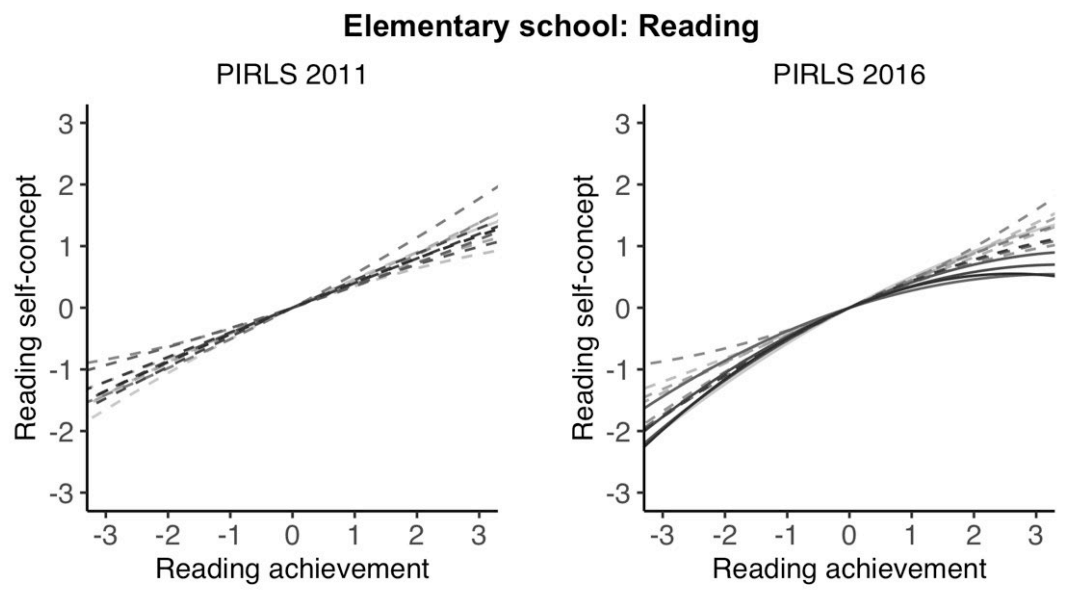

Secondary school: Verbal domain

PISA 2000

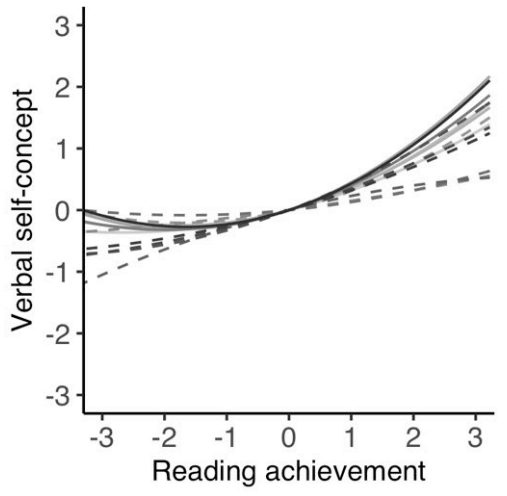

Figure 5. Country-specific quadratic regression lines for the verbal domain (PIRLS and PISA assessments). Significant quadratic effects are depicted as solid lines, nonsignificant quadratic effects as dashed lines. 
Supplemental Online Materials

\section{Nonlinear Relations Between Achievement and Academic Self-Concepts in Elementary and Secondary School: An Integrative Data Analysis Across 13 Countries}

Lena Keller, Franzis Preckel, \& Martin Brunner

\section{Method}

\section{Samples}

Sampling procedures. The TIMSS, PIRLS, and PISA studies differ in their target populations and sampling procedures. The sampling of the data in TIMSS and PIRLS was based on the grade selection of whole classrooms, whereas PISA used an age-based selection of students in schools. TIMSS and PIRLS are designed to represent the population of students after 4 or 8 years of regular schooling, with a mean age at the time of testing of at least 9.5 or 13.5 years, respectively. PISA is designed to represent the population of 15-year-old students, defined as all students from the age of 15 years and 3 months to 16 years and 2 months at the beginning of the assessment period (Mullis \& Martin, 2013, 2015; OECD, 2013).

In all three assessments, high quality standards for collecting representative probability samples were met. For TIMSS and PIRLS, precision requirements were typically met with a school sample of 150 schools and a student sample of 4,000 students per country (Martin \& Mullis, 2012). For PISA, precision requirements were typically met with a school sample of at least 150 schools and a student sample of at least 4,500 students (OECD, 2014). In TIMSS, PIRLS, and PISA, a two-stage sampling design was applied in most countries. In all three assessments, in the first stage, individual schools that had students enrolled in the target population were systematically sampled from a stratified list of all schools with sampling probabilities that were proportional to the number of target students enrolled. Strata were specific 
for each country and included, for example, geographic regions or school type. In the second stage, one or more classes were then randomly sampled within a selected school in TIMSS and PIRLS. In PISA, about 35 students at age 15 were randomly selected within schools and if a school had fewer than 35 students at age 15, all students in this age group were selected. In every TIMSS, PIRLS, and PISA cycle, the school staff, students, and parents were informed about the nature of the test and the test date, and parental permission was secured if requested by the school or education system (Martin \& Mullis, 2012; OECD, 2002). 
Table S1

Sample Size, Percentage of Female Students, and Number of Participating Classes for Each Country and in Total for TIMSS and PIRLS (Based on the Imputed Data Sets)

\begin{tabular}{|c|c|c|c|c|c|c|c|c|c|c|c|c|c|c|c|}
\hline \multirow[b]{3}{*}{ Country } & \multicolumn{6}{|c|}{ TIMSS 2011} & \multicolumn{6}{|c|}{ TIMSS 2015} & \multirow{2}{*}{\multicolumn{3}{|c|}{$\begin{array}{c}\text { PIRLS } 2016 \\
\text { Grade } 4\end{array}$}} \\
\hline & \multicolumn{3}{|c|}{ Grade 4* } & \multicolumn{3}{|c|}{ Grade 8} & \multicolumn{3}{|c|}{ Grade 4} & \multicolumn{3}{|c|}{ Grade 8} & & & \\
\hline & $N$ & $\% \mathrm{~F}$ & $N_{\mathrm{c}}$ & $N$ & $\% \mathrm{~F}$ & $N_{\mathrm{c}}$ & $N$ & $\% \mathrm{~F}$ & $N_{\mathrm{c}}$ & $N$ & $\% \mathrm{~F}$ & $N_{\mathrm{c}}$ & $N$ & $\% \mathrm{~F}$ & $N_{\mathrm{c}}$ \\
\hline Australia & 5,943 & 50 & 438 & 7,556 & 50 & 490 & 6,057 & 49 & 498 & 10,331 & 50 & 645 & 6,341 & 50 & 505 \\
\hline Austria & 4,587 & 49 & 276 & - & - & - & - & - & - & - & - & - & 4,360 & 48 & 257 \\
\hline Czech Republic & 4,433 & 50 & 235 & - & - & - & 5,202 & 50 & 265 & - & - & - & 5,537 & 48 & 269 \\
\hline Finland & 4,541 & 49 & 267 & 4,266 & 49 & 258 & 5,015 & 49 & 300 & - & - & - & 4,896 & 49 & 295 \\
\hline Germany & 3,928 & 50 & 205 & - & - & - & 3,942 & 48 & 213 & - & - & - & 3,959 & 49 & 221 \\
\hline Hong Kong & 3,802 & 47 & 133 & 4,015 & 50 & 121 & 3,600 & 45 & 145 & 4,155 & 48 & 145 & 3,349 & 49 & 145 \\
\hline Hungary & 5,149 & 50 & 249 & 5,178 & 50 & 251 & 5,036 & 50 & 241 & 4,893 & 51 & 241 & 4,623 & 50 & 209 \\
\hline Ireland & 4,383 & 49 & 220 & - & - & - & 4,344 & 47 & 214 & 4,704 & 52 & 204 & 4,607 & 49 & 219 \\
\hline Italy & 4,125 & 51 & 239 & 3,979 & 48 & 205 & 4,371 & 49 & 257 & 4,481 & 50 & 230 & 3,940 & 49 & 217 \\
\hline Norway & 3,054 & 51 & 197 & 3,862 & 49 & 170 & 4,329 & 50 & 222 & 4,697 & 50 & 216 & 4,230 & 50 & 215 \\
\hline Portugal & 3,991 & 49 & 240 & - & - & - & 4,693 & 49 & 321 & - & - & - & 4,642 & 49 & 318 \\
\hline Russian Federation & 4,450 & 49 & 209 & 4,893 & 49 & 229 & 4,921 & 50 & 217 & 4,780 & 48 & 221 & 4,577 & 50 & 208 \\
\hline Sweden & 4,482 & 48 & 251 & 5,568 & 48 & 266 & 4,132 & 50 & 211 & 4,079 & 48 & 206 & 4,525 & 50 & 227 \\
\hline Total & 56,868 & 49 & 3,159 & 39,317 & 49 & 1,990 & 55,642 & 49 & 3,104 & 42,120 & 50 & 2,108 & 59,586 & 49 & 3,305 \\
\hline
\end{tabular}

Note. $\%$ F $=$ percentage of female students; $N_{c}=$ number of participating classes.

*Descriptive statistics from TIMSS 2011 also apply to PIRLS 2011. 
Table S2

Sample Size, Percentage of Female Students, and Number of Participating Schools for Each Country and in Total for PISA (Based on the Imputed Data Sets)

\begin{tabular}{|c|c|c|c|c|c|c|c|c|c|}
\hline \multirow[b]{2}{*}{ Country } & \multicolumn{3}{|c|}{ PISA 2000} & \multicolumn{3}{|c|}{ PISA 2003} & \multicolumn{3}{|c|}{ PISA 2012} \\
\hline & $N$ & $\% \mathrm{~F}$ & $N_{\mathrm{s}}$ & $N$ & $\% \mathrm{~F}$ & $N_{\mathrm{s}}$ & $N$ & $\% \mathrm{~F}$ & $N_{\mathrm{s}}$ \\
\hline Australia & 2,836 & 47 & 231 & 12,551 & 50 & 321 & 14,481 & 49 & 775 \\
\hline Austria & 2,607 & 50 & 212 & 4,597 & 50 & 193 & 4,755 & 50 & 191 \\
\hline Czech Republic & 3,056 & 53 & 229 & 6,320 & 49 & 260 & 5,327 & 50 & 297 \\
\hline Finland & 2,703 & 52 & 155 & 5,796 & 51 & 197 & 8,829 & 49 & 311 \\
\hline Germany & 2,793 & 52 & 219 & 4,614 & 50 & 216 & 5,001 & 49 & 230 \\
\hline Hong Kong & 2,438 & 50 & 140 & 4,478 & 50 & 145 & 4,670 & 46 & 148 \\
\hline Hungary & 2,780 & 48 & 194 & 4,765 & 47 & 253 & 4,810 & 53 & 204 \\
\hline Ireland & 2,111 & 52 & 139 & 3,880 & 49 & 145 & 5,016 & 51 & 183 \\
\hline Italy & 2,747 & 52 & 170 & 11,639 & 52 & 406 & 31,073 & 49 & 1,194 \\
\hline Norway & 2,269 & 51 & 175 & 4,064 & 50 & 182 & 4,686 & 49 & 197 \\
\hline Portugal & 2,524 & 53 & 149 & 4,608 & 52 & 153 & 5,722 & 50 & 195 \\
\hline Russian Federation & 3,713 & 50 & 245 & 5,974 & 52 & 212 & 5,231 & 50 & 227 \\
\hline Sweden & 2,447 & 50 & 154 & 4,624 & 49 & 185 & 4,736 & 50 & 209 \\
\hline Total & 35,024 & 51 & 2,412 & 77,910 & 50 & 2,868 & 104,337 & 49 & 4,361 \\
\hline
\end{tabular}

Note. $\%$ F $=$ percentage of female students; $N_{s}=$ number of participating schools. 
Table S3

(Pooled) Descriptive Statistics for TIMSS/PIRLS 2011 Based on the Imputed Data Sets

\begin{tabular}{|c|c|c|c|c|c|c|c|c|c|c|c|c|c|}
\hline \multirow[b]{2}{*}{ Country } & \multirow[b]{2}{*}{$N$} & \multicolumn{2}{|c|}{$\begin{array}{l}\text { Mathematics } \\
\text { achievement }\end{array}$} & \multicolumn{2}{|c|}{$\begin{array}{c}\text { Reading } \\
\text { achievement }\end{array}$} & \multicolumn{3}{|c|}{$\begin{array}{c}\text { Mathematics } \\
\text { self-concept }\end{array}$} & \multicolumn{3}{|c|}{$\begin{array}{c}\text { Reading } \\
\text { self-concept }\end{array}$} & \multicolumn{2}{|c|}{ Age } \\
\hline & & $M$ & $S D$ & $M$ & $S D$ & $M$ & $S D$ & $\%_{\text {missing }}$ & $M$ & $S D$ & $\%$ missing & $M$ & $S D$ \\
\hline Australia & 5943 & 514.20 & 89.67 & 510.31 & 89.89 & 3.11 & 0.74 & 6 & 3.24 & 0.56 & 7 & 9.99 & 0.44 \\
\hline Austria & 4587 & 505.19 & 65.81 & 512.23 & 71.12 & 3.20 & 0.71 & 6 & 3.36 & 0.55 & 6 & 10.25 & 0.45 \\
\hline Czech Republic & 4433 & 508.28 & 73.11 & 530.42 & 68.15 & 3.03 & 0.70 & 5 & 3.20 & 0.57 & 4 & 10.37 & 0.43 \\
\hline Finland & 4541 & 543.47 & 70.09 & 555.88 & 71.05 & 3.06 & 0.73 & 4 & 3.39 & 0.47 & 5 & 10.79 & 0.34 \\
\hline Germany & 3928 & 524.82 & 64.73 & 526.22 & 73.61 & 3.14 & 0.74 & 20 & 3.33 & 0.55 & 17 & 10.37 & 0.52 \\
\hline Hong Kong & 3802 & 605.43 & 62.63 & 559.31 & 67.23 & 2.85 & 0.76 & 3 & 2.98 & 0.56 & 3 & 10.12 & 0.50 \\
\hline Hungary & 5149 & 512.36 & 92.28 & 524.05 & 87.31 & 3.15 & 0.76 & 5 & 3.22 & 0.62 & 4 & 10.67 & 0.49 \\
\hline Ireland & 4383 & 525.82 & 80.42 & 538.11 & 82.67 & 3.19 & 0.71 & 6 & 3.31 & 0.53 & 5 & 10.34 & 0.41 \\
\hline Italy & 4125 & 503.84 & 75.06 & 526.57 & 73.94 & 3.10 & 0.64 & 6 & 3.16 & 0.51 & 7 & 9.73 & 0.36 \\
\hline Norway & 3054 & 490.96 & 71.41 & 487.59 & 68.20 & 3.29 & 0.62 & 7 & 3.31 & 0.50 & 7 & 9.72 & 0.29 \\
\hline Portugal & 3991 & 529.74 & 71.36 & 525.63 & 73.86 & 2.96 & 0.66 & 5 & 3.22 & 0.51 & 4 & 10.02 & 0.49 \\
\hline Russian Federation & 4450 & 539.59 & 76.40 & 556.23 & 72.83 & 3.01 & 0.75 & 4 & 3.13 & 0.53 & 3 & 10.75 & 0.43 \\
\hline Sweden & 4482 & 501.95 & 68.20 & 527.07 & 71.40 & 3.24 & 0.61 & 8 & 3.38 & 0.49 & 6 & 10.74 & 0.33 \\
\hline (Weighted) mean & 4374 & 523.52 & 73.83 & 529.18 & 74.60 & 3.10 & 0.70 & 7 & 3.25 & 0.53 & 6 & 10.30 & 0.42 \\
\hline
\end{tabular}


Table S4

(Pooled) Descriptive Statistics for TIMSS 2015 (Grade 4) Based on the Imputed Data Sets

\begin{tabular}{|c|c|c|c|c|c|c|c|c|c|}
\hline \multirow[b]{2}{*}{ Country } & \multirow[b]{2}{*}{$N$} & \multicolumn{2}{|c|}{$\begin{array}{l}\text { Mathematics } \\
\text { achievement }\end{array}$} & \multicolumn{3}{|c|}{$\begin{array}{l}\text { Mathematics } \\
\text { self-concept }\end{array}$} & \multicolumn{2}{|c|}{ Age } & \multirow[b]{2}{*}{$\%_{\text {missing }}$} \\
\hline & & $M$ & $S D$ & $M$ & $S D$ & $\%_{\text {missing }}$ & $M$ & $S D$ & \\
\hline Australia & 6,057 & 517.23 & 83.47 & 2.96 & 0.72 & 9 & 10.04 & 0.39 & 0 \\
\hline Czech Republic & 5,202 & 528.14 & 69.86 & 2.92 & 0.69 & 5 & 10.40 & 0.42 & 0 \\
\hline Finland & 5,015 & 535.29 & 66.65 & 3.04 & 0.65 & 8 & 10.75 & 0.32 & 0 \\
\hline Germany & 3,942 & 521.60 & 65.38 & 3.07 & 0.73 & 24 & 10.36 & 0.51 & 0 \\
\hline Hong Kong & 3,600 & 614.52 & 65.64 & 2.78 & 0.71 & 4 & 10.07 & 0.44 & 1 \\
\hline Hungary & 5,036 & 529.19 & 87.97 & 3.09 & 0.72 & 5 & 10.65 & 0.50 & 0 \\
\hline Ireland & 4,344 & 547.34 & 73.13 & 3.14 & 0.66 & 8 & 10.45 & 0.39 & 0 \\
\hline Italy & 4,371 & 506.91 & 71.54 & 3.14 & 0.67 & 9 & 9.72 & 0.35 & 0 \\
\hline Norway & 4,329 & 549.08 & 70.58 & 3.28 & 0.61 & 9 & 10.72 & 0.29 & 0 \\
\hline Portugal & 4,693 & 541.20 & 72.45 & 2.88 & 0.73 & 7 & 9.86 & 0.51 & 0 \\
\hline Russian Federation & 4,921 & 563.92 & 72.72 & 2.96 & 0.72 & 4 & 10.78 & 0.38 & 0 \\
\hline Sweden & 4,132 & 518.69 & 69.10 & 3.19 & 0.61 & 9 & 10.77 & 0.32 & 0 \\
\hline (Weighted) mean & 4,637 & 539.41 & 72.27 & 3.04 & 0.68 & 8 & 10.38 & 0.40 & 0 \\
\hline
\end{tabular}


Table S5

(Pooled) Descriptive Statistics for TIMSS 2011 (Grade 8) Based on the Imputed Data Sets

\begin{tabular}{|c|c|c|c|c|c|c|c|c|}
\hline \multirow[b]{2}{*}{ Country } & \multirow[b]{2}{*}{$N$} & \multicolumn{2}{|c|}{$\begin{array}{l}\text { Mathematics } \\
\text { achievement }\end{array}$} & \multicolumn{3}{|c|}{$\begin{array}{l}\text { Mathematics } \\
\text { self-concept }\end{array}$} & \multicolumn{2}{|c|}{ Age } \\
\hline & & $M$ & $S D$ & $M$ & $S D$ & $\%_{\text {missing }}$ & $M$ & $S D$ \\
\hline Australia & 7,556 & 504.80 & 85.42 & 2.74 & 0.72 & 7 & 13.99 & 0.47 \\
\hline Finland & 4,266 & 514.03 & 64.85 & 2.59 & 0.76 & 5 & 14.78 & 0.35 \\
\hline Hong Kong & 4,015 & 585.57 & 84.47 & 2.41 & 0.70 & 3 & 14.22 & 0.70 \\
\hline Hungary & 5,178 & 504.81 & 89.59 & 2.57 & 0.79 & 4 & 14.71 & 0.62 \\
\hline Italy & 3,979 & 498.38 & 73.17 & 2.64 & 0.71 & 4 & 13.85 & 0.52 \\
\hline Norway & 3,862 & 474.64 & 64.73 & 2.81 & 0.75 & 8 & 13.74 & 0.38 \\
\hline Russian Federation & 4,893 & 538.98 & 81.13 & 2.64 & 0.70 & 3 & 14.74 & 0.48 \\
\hline Sweden & 5,568 & 484.34 & 67.55 & 2.76 & 0.68 & 11 & 14.77 & 0.40 \\
\hline (Weighted) mean & 4,915 & 513.12 & 76.04 & 2.64 & 0.72 & 6 & 14.35 & 0.49 \\
\hline
\end{tabular}


Table S6

(Pooled) Descriptive Statistics for TIMSS 2015 (Grade 8) Based on the Imputed Data Sets

\begin{tabular}{|c|c|c|c|c|c|c|c|c|}
\hline \multirow[b]{2}{*}{ Country } & \multirow[b]{2}{*}{$N$} & \multicolumn{2}{|c|}{$\begin{array}{l}\text { Mathematics } \\
\text { achievement }\end{array}$} & \multicolumn{3}{|c|}{$\begin{array}{l}\text { Mathematics } \\
\text { self-concept }\end{array}$} & \multicolumn{2}{|c|}{ Age } \\
\hline & & $M$ & $S D$ & $M$ & $S D$ & $\%_{\text {missing }}$ & $M$ & $S D$ \\
\hline Australia & 10,331 & 504.97 & 82.35 & 2.64 & 0.73 & 8 & 13.98 & 0.46 \\
\hline Hong Kong & 4,155 & 594.25 & 78.41 & 2.45 & 0.74 & 3 & 14.24 & 0.66 \\
\hline Hungary & 4,893 & 514.41 & 93.39 & 2.70 & 0.77 & 4 & 14.70 & 0.53 \\
\hline Ireland & 4,704 & 523.49 & 73.95 & 2.65 & 0.75 & 5 & 14.43 & 0.43 \\
\hline Italy & 4,481 & 494.39 & 74.54 & 2.65 & 0.82 & 4 & 13.81 & 0.50 \\
\hline Norway & 4,697 & 511.54 & 70.05 & 2.78 & 0.81 & 16 & 14.73 & 0.32 \\
\hline Russian Federation & 4,780 & 538.00 & 81.71 & 2.59 & 0.70 & 3 & 14.75 & 0.44 \\
\hline Sweden & 4,079 & 500.92 & 71.84 & 2.68 & 0.77 & 11 & 14.75 & 0.36 \\
\hline (Weighted) mean & 5,265 & 522.60 & 78.21 & 2.64 & 0.76 & 7 & 14.42 & 0.46 \\
\hline
\end{tabular}


Table S7

(Pooled) Descriptive Statistics for PIRLS 2016 Based on the Imputed Data Sets

\begin{tabular}{|c|c|c|c|c|c|c|c|c|}
\hline \multirow[b]{2}{*}{ Country } & \multirow[b]{2}{*}{$N$} & \multicolumn{2}{|c|}{$\begin{array}{c}\text { Reading } \\
\text { achievement }\end{array}$} & \multicolumn{3}{|c|}{$\begin{array}{c}\text { Reading } \\
\text { self-concept }\end{array}$} & \multicolumn{2}{|c|}{ Age } \\
\hline & & $M$ & $S D$ & $M$ & $S D$ & $\%$ missing & $M$ & $S D$ \\
\hline Australia & 6,341 & 544.36 & 83.60 & 3.26 & 0.64 & 4 & 10.05 & 0.41 \\
\hline Austria & 4,360 & 540.80 & 65.43 & 3.35 & 0.63 & 10 & 10.29 & 0.48 \\
\hline Czech Republic & 5,537 & 543.35 & 68.04 & 3.21 & 0.61 & 4 & 10.31 & 0.44 \\
\hline Finland & 4,896 & 566.01 & 67.11 & 3.41 & 0.56 & 4 & 10.79 & 0.34 \\
\hline Germany & 3,959 & 537.33 & 77.98 & 3.31 & 0.65 & 17 & 10.34 & 0.51 \\
\hline Hong Kong & 3,349 & 568.58 & 63.71 & 3.06 & 0.67 & 3 & 9.93 & 0.47 \\
\hline Hungary & 4,623 & 554.16 & 74.62 & 3.22 & 0.66 & 2 & 10.63 & 0.47 \\
\hline Ireland & 4,607 & 566.60 & 73.77 & 3.33 & 0.63 & 4 & 10.47 & 0.39 \\
\hline Italy & 3,940 & 548.01 & 65.01 & 3.24 & 0.61 & 3 & 9.74 & 0.35 \\
\hline Norway & 4,230 & 559.01 & 65.43 & 3.31 & 0.63 & 6 & 10.80 & 0.30 \\
\hline Portugal & 4,642 & 527.80 & 65.15 & 3.10 & 0.62 & 3 & 9.80 & 0.49 \\
\hline Russian Federation & 4,577 & 580.77 & 66.31 & 3.18 & 0.62 & 2 & 10.81 & 0.43 \\
\hline Sweden & 4,525 & 555.16 & 67.06 & 3.47 & 0.54 & 8 & 10.74 & 0.30 \\
\hline (Weighted) mean & 4,584 & 553.25 & 69.33 & 3.27 & 0.62 & 5 & 10.36 & 0.41 \\
\hline
\end{tabular}


Table S8

(Pooled) Descriptive Statistics for PISA 2000 Based on the Imputed Data Sets

\begin{tabular}{|c|c|c|c|c|c|c|c|c|c|c|c|c|c|c|}
\hline Country & \multicolumn{3}{|c|}{$\begin{array}{l}\text { Mathematics } \\
\text { achievement }\end{array}$} & \multicolumn{2}{|c|}{$\begin{array}{c}\text { Reading } \\
\text { achievement }\end{array}$} & \multicolumn{3}{|c|}{$\begin{array}{c}\text { Mathematics } \\
\text { self-concept }\end{array}$} & \multicolumn{3}{|c|}{$\begin{array}{c}\text { Verbal } \\
\text { self-concept }\end{array}$} & \multicolumn{3}{|c|}{ Age } \\
\hline Australia & 2,836 & 533.81 & 89.92 & 528.53 & 102.95 & 2.60 & 0.78 & 6 & 2.93 & 0.60 & 6 & 15.69 & 0.28 & 1 \\
\hline Czech Republic & 3,056 & 497.78 & 96.29 & 494.86 & 97.43 & 2.32 & 0.87 & 11 & 2.70 & 0.75 & 11 & 15.72 & 0.28 & 6 \\
\hline Finland & 2,703 & 536.16 & 80.32 & 548.66 & 91.08 & 2.40 & 1.00 & 4 & 2.88 & 0.70 & 4 & 15.63 & 0.29 & 0 \\
\hline Germany & 2,793 & 490.23 & 102.5 & 483.13 & 113.48 & 2.46 & 0.95 & 9 & 2.83 & 0.76 & 9 & 15.71 & 0.28 & 1 \\
\hline Hong Kong & 2,438 & 560.45 & 93.67 & 532.05 & 85.13 & 2.40 & 0.95 & 2 & 2.71 & 0.66 & 1 & 15.72 & 0.30 & 0 \\
\hline Ireland & 2,111 & 503.56 & 83.42 & 528.17 & 93.94 & 2.38 & 0.96 & 3 & 3.09 & 0.77 & 3 & 15.70 & 0.28 & 1 \\
\hline Italy & 2,747 & 457.89 & 89.94 & 487.34 & 91.26 & 2.49 & 0.99 & 2 & 3.10 & 0.77 & 2 & 15.73 & 0.28 & 3 \\
\hline Norway & 2,269 & 500.61 & 90.88 & 503.73 & 104.26 & 2.34 & 1.02 & 9 & 2.87 & 0.76 & 8 & 15.72 & 0.28 & 1 \\
\hline Portugal & 2,524 & 454.58 & 90.86 & 467.46 & 97.85 & 2.24 & 0.95 & 4 & 2.88 & 0.70 & 3 & 15.63 & 0.28 & 1 \\
\hline Russian Federation & 3,713 & 478.52 & 103.99 & 457.32 & 92.37 & 2.47 & 0.96 & 7 & 2.97 & 0.74 & 6 & 15.70 & 0.28 & 0 \\
\hline Sweden & 2,447 & 510.41 & 93.06 & 515.60 & 92.90 & 2.39 & 0.85 & 5 & 2.97 & 0.62 & 5 & 15.73 & 0.28 & 0 \\
\hline (Weighted) mean & 2,694 & 502.24 & 92.50 & 503.05 & 96.39 & 2.39 & 0.93 & 6 & 2.90 & 0.72 & 5 & 15.71 & 0.28 & 1 \\
\hline
\end{tabular}


Table S9

(Pooled) Descriptive Statistics for PISA 2003 Based on the Imputed Data Sets

\begin{tabular}{|c|c|c|c|c|c|c|c|c|}
\hline \multirow[b]{2}{*}{ Country } & \multirow[b]{2}{*}{$N$} & \multicolumn{2}{|c|}{$\begin{array}{l}\text { Mathematics } \\
\text { achievement }\end{array}$} & \multicolumn{3}{|c|}{$\begin{array}{l}\text { Mathematics } \\
\text { self-concept }\end{array}$} & \multicolumn{2}{|c|}{ Age } \\
\hline & & $M$ & $S D$ & $M$ & $S D$ & \%missing & $M$ & $S D$ \\
\hline Australia & 12,551 & 524.27 & 95.42 & 2.51 & 0.69 & 4 & 15.77 & 0.29 \\
\hline Austria & 4,597 & 505.61 & 93.09 & 2.45 & 0.80 & 5 & 15.84 & 0.29 \\
\hline Czech Republic & 6,320 & 516.46 & 95.94 & 2.32 & 0.70 & 5 & 15.89 & 0.28 \\
\hline Finland & 5,796 & 544.29 & 83.68 & 2.42 & 0.78 & 2 & 15.71 & 0.29 \\
\hline Germany & 4,614 & 503.42 & 102.33 & 2.50 & 0.84 & 9 & 15.77 & 0.28 \\
\hline Hong Kong & 4,478 & 550.38 & 100.19 & 2.21 & 0.68 & 1 & 15.80 & 0.29 \\
\hline Hungary & 4,765 & 490.01 & 93.51 & 2.29 & 0.64 & 2 & 15.74 & 0.29 \\
\hline Ireland & 3,880 & 502.84 & 85.26 & 2.38 & 0.70 & 5 & 15.71 & 0.28 \\
\hline Italy & 11,639 & 465.66 & 95.69 & 2.41 & 0.75 & 3 & 15.71 & 0.28 \\
\hline Norway & 4,064 & 495.19 & 92.04 & 2.27 & 0.82 & 7 & 15.79 & 0.28 \\
\hline Portugal & 4,608 & 466.02 & 87.63 & 2.27 & 0.70 & 4 & 15.87 & 0.28 \\
\hline Russian Federation & 5,974 & 468.41 & 92.25 & 2.51 & 0.58 & 4 & 15.82 & 0.28 \\
\hline Sweden & 4,624 & 509.05 & 94.75 & 2.50 & 0.75 & 6 & 15.74 & 0.28 \\
\hline (Weighted) mean & 5,993 & 503.21 & 93.02 & 2.39 & 0.73 & 4 & 15.78 & 0.28 \\
\hline
\end{tabular}


Table S10

(Pooled) Descriptive Statistics for PISA 2012 Based on the Imputed Data Sets

\begin{tabular}{|c|c|c|c|c|c|c|c|c|}
\hline \multirow[b]{2}{*}{ Country } & \multirow[b]{2}{*}{$N$} & \multicolumn{2}{|c|}{$\begin{array}{l}\text { Mathematics } \\
\text { achievement }\end{array}$} & \multicolumn{3}{|c|}{$\begin{array}{l}\text { Mathematics } \\
\text { self-concept }\end{array}$} & \multicolumn{2}{|c|}{ Age } \\
\hline & & $M$ & $S D$ & $M$ & $S D$ & $\%_{\text {missing }}$ & $M$ & $S D$ \\
\hline Australia & 14,481 & 504.15 & 96.29 & 2.52 & 0.74 & 37 & 15.79 & 0.29 \\
\hline Austria & 4,755 & 505.54 & 92.48 & 2.46 & 0.83 & 37 & 15.80 & 0.29 \\
\hline Czech Republic & 5,327 & 498.96 & 94.94 & 2.29 & 0.78 & 36 & 15.75 & 0.28 \\
\hline Finland & 8,829 & 518.75 & 85.29 & 2.48 & 0.8 & 46 & 15.71 & 0.28 \\
\hline Germany & 5,001 & 513.53 & 96.30 & 2.51 & 0.86 & 37 & 15.83 & 0.29 \\
\hline Hong Kong & 4,670 & 561.24 & 96.31 & 2.32 & 0.73 & 35 & 15.74 & 0.29 \\
\hline Hungary & 4,810 & 477.04 & 93.62 & 2.35 & 0.70 & 35 & 15.72 & 0.29 \\
\hline Ireland & 5,016 & 501.50 & 84.58 & 2.41 & 0.74 & 35 & 15.70 & 0.28 \\
\hline Italy & 31,073 & 485.32 & 92.78 & 2.46 & 0.76 & 35 & 15.76 & 0.29 \\
\hline Norway & 4,686 & 489.37 & 90.48 & 2.37 & 0.85 & 40 & 15.79 & 0.29 \\
\hline Portugal & 5,722 & 487.06 & 93.95 & 2.37 & 0.72 & 36 & 15.75 & 0.29 \\
\hline Russian Federation & 5,231 & 482.17 & 86.37 & 2.53 & 0.65 & 35 & 15.81 & 0.29 \\
\hline Sweden & 4,736 & 478.26 & 91.75 & 2.54 & 0.77 & 39 & 15.73 & 0.28 \\
\hline (Weighted) mean & 8,026 & 500.22 & 91.85 & 2.43 & 0.76 & 37 & 15.76 & 0.29 \\
\hline
\end{tabular}




\section{Table S11}

Reliabilities for the Achievement and Self-Concept Scales as Observed in TIMSS 2011 in Grades 4 and 8

\begin{tabular}{lccccc}
\hline & \multicolumn{2}{c}{ Grade 4} & & \multicolumn{2}{c}{ Grade 8} \\
\cline { 2 - 3 } \cline { 5 - 6 } \multicolumn{1}{c}{ Country } & $\begin{array}{c}\text { Mathematics } \\
\text { achievement }\end{array}$ & $\begin{array}{c}\text { Mathematics } \\
\text { self-concept } \mathrm{t}^{\mathrm{b}}\end{array}$ & & $\begin{array}{c}\text { Mathematics } \\
\text { achievement }^{\mathrm{a}}\end{array}$ & $\begin{array}{c}\text { Mathematics } \\
\text { self-concept }^{\mathrm{b}}\end{array}$ \\
\hline Australia & .86 & .86 & & .90 & .90 \\
Austria & .79 & .87 & & - & - \\
Czech Republic & .82 & .87 & & - & - \\
Finland & .82 & .89 & & .86 & .93 \\
Germany & .81 & .89 & & - & - \\
Hong Kong & .80 & .87 & & .91 & .90 \\
Hungary & .87 & .88 & & .90 & .92 \\
Ireland & .84 & .86 & & - & - \\
Italy & .82 & .81 & & .87 & .91 \\
Norway & .80 & .83 & & .83 & .91 \\
Portugal & .83 & .86 & & - & - \\
Russian Federation & .83 & .88 & & .90 & .90 \\
Sweden & .80 & .85 & & .85 & .91 \\
\hline
\end{tabular}

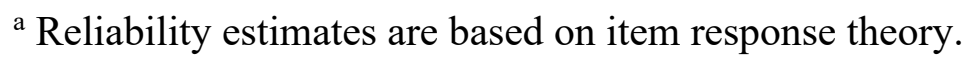

${ }^{b}$ Reliability was estimated in terms of Cronbach's Alpha. 
Table S12

Reliabilities for the Achievement and Self-Concept Scales as Observed in TIMSS 2015 in Grades 4 and 8

\begin{tabular}{|c|c|c|c|c|}
\hline \multirow[b]{2}{*}{ Country } & \multicolumn{2}{|c|}{ Grade 4} & \multicolumn{2}{|c|}{ Grade 8} \\
\hline & $\begin{array}{l}\text { Mathematics } \\
\text { achievement }^{\text {a }}\end{array}$ & $\begin{array}{l}\text { Mathematics } \\
\text { self-concept }{ }^{\mathrm{b}}\end{array}$ & $\begin{array}{l}\text { Mathematics } \\
\text { achievement }^{\mathrm{a}}\end{array}$ & $\begin{array}{l}\text { Mathematics } \\
\text { self-concept }^{\text {b }}\end{array}$ \\
\hline Australia & .86 & .87 & .89 & .90 \\
\hline Czech Republic & .83 & .88 & - & - \\
\hline Finland & .81 & .86 & - & - \\
\hline Germany & .82 & .89 & - & - \\
\hline Hong Kong & .81 & .86 & .89 & .91 \\
\hline Hungary & .88 & .88 & .91 & .91 \\
\hline Ireland & .84 & .85 & .88 & .89 \\
\hline Italy & .82 & .85 & .86 & .92 \\
\hline Norway & .81 & .84 & .83 & .91 \\
\hline Portugal & .84 & .86 & - & - \\
\hline Russian Federation & .84 & .89 & .89 & .91 \\
\hline Sweden & .81 & .87 & .86 & .92 \\
\hline
\end{tabular}

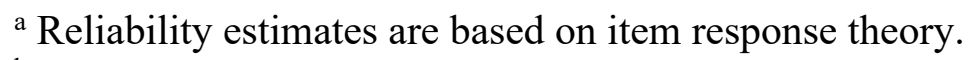

${ }^{\mathrm{b}}$ Reliability was estimated in terms of Cronbach's Alpha. 
Table S13

Reliabilities for the Mathematics Achievement and Self-Concept Scales as Observed in PISA 2000, 2003, and 2012

\begin{tabular}{|c|c|c|c|c|c|c|}
\hline \multirow[b]{2}{*}{ Country } & \multicolumn{2}{|c|}{2000} & \multicolumn{2}{|c|}{2003} & \multicolumn{2}{|c|}{2012} \\
\hline & $\begin{array}{l}\text { Mathematics } \\
\text { self-concept }^{\mathrm{b}}\end{array}$ & $\begin{array}{l}\text { Verbal self- } \\
\text { concept }^{\mathrm{b}}\end{array}$ & $\begin{array}{l}\text { Mathematics } \\
\text { achievement }^{\mathrm{a}}\end{array}$ & $\begin{array}{l}\text { Mathematics } \\
\text { self-concept }^{b}\end{array}$ & $\begin{array}{l}\text { Mathematics } \\
\text { achievemen }^{\text {a }}\end{array}$ & $\begin{array}{l}\text { Mathematics } \\
\text { self-concept }\end{array}$ \\
\hline Australia & .85 & .76 & .91 & .89 & .94 & .89 \\
\hline Austria & .88 & .81 & .92 & .89 & .93 & .90 \\
\hline Czech Republic & .84 & .74 & .91 & .89 & .94 & .91 \\
\hline Finland & .93 & .80 & .89 & .92 & .92 & .92 \\
\hline Germany & .90 & .82 & .93 & .91 & .94 & .91 \\
\hline Hong Kong & - & - & .92 & .89 & .92 & .89 \\
\hline Hungary & .87 & .66 & .90 & .81 & .94 & .82 \\
\hline Ireland & .87 & .79 & .91 & .89 & .92 & .89 \\
\hline Italy & .87 & .82 & .91 & .91 & .93 & .88 \\
\hline Norway & .90 & .74 & .90 & .90 & .92 & .91 \\
\hline Portugal & .87 & .74 & .90 & .89 & .93 & .89 \\
\hline Russian Federation & .87 & .67 & .88 & .89 & .91 & .83 \\
\hline Sweden & .88 & .75 & .90 & .89 & .92 & .89 \\
\hline
\end{tabular}

Note. In PISA 2000, only averaged reliabilities were reported for the international PISA scales; mathematics achievement: $\alpha=.81^{\text {a }}$, reading achievement: $\alpha=.89^{\mathrm{a}}$.

${ }^{a}$ Reliability estimates are based on item response theory.

${ }^{\mathrm{b}}$ Reliability was estimated in terms of Cronbach's Alpha. 
Table S14

Reliabilities for the Achievement and Self-Concept Scales as Observed in PIRLS 2011 and 2016

\begin{tabular}{lccccc}
\hline & \multicolumn{2}{c}{2011} & & \multicolumn{2}{c}{2016} \\
\cline { 2 - 3 } \cline { 5 - 6 } \multicolumn{1}{c}{ Country } & $\begin{array}{c}\text { Reading } \\
\text { achievement }^{\mathrm{a}}\end{array}$ & $\begin{array}{c}\text { Reading } \\
\text { self-concept }^{\mathrm{b}}\end{array}$ & & $\begin{array}{c}\text { Reading } \\
\text { achievement }^{\mathrm{a}}\end{array}$ & $\begin{array}{c}\text { Reading }^{\text {self-concept }} \\
\text { self }^{\mathrm{b}}\end{array}$ \\
\hline Australia & .90 & .72 & & .91 & .81 \\
Austria & .87 & .75 & & .86 & .81 \\
Czech Republic & .86 & .77 & & .88 & .79 \\
Finland & .85 & .69 & & .88 & .80 \\
Germany & .89 & .76 & & .90 & .82 \\
Hong Kong & .86 & .69 & & .85 & .80 \\
Hungary & .90 & .77 & & .89 & .82 \\
Ireland & .89 & .71 & & .89 & .82 \\
Italy & .87 & .66 & & .87 & .75 \\
Norway & .86 & .67 & & .87 & .79 \\
Portugal & .86 & .73 & & .87 & .72 \\
Russian Federation & .88 & .64 & & .87 & .79 \\
Sweden & .87 & .74 & & .88 & .82 \\
\hline
\end{tabular}

${ }^{a}$ Reliability estimates are based on item response theory.

${ }^{b}$ Reliability was estimated in terms of Cronbach's Alpha. 
Table S15

Mathematics Self-Concept Items as Used in TIMSS

\begin{tabular}{ll}
\hline \multicolumn{1}{c}{ Item wording } & \multicolumn{1}{c}{ Cycles (grades) } \\
\hline How much do you agree with these statements about mathematics? & \\
\hline I usually do well in mathematics. & $2011(4,8), 2015(4,8)$ \\
Mathematics is harder for me than for many of my classmates. & $2011(4,8), 2015(4,8)$ \\
& \\
(R) & $2011(4), 2015(4)$ \\
I am are just not good at mathematics. (R) & $2011(4,8), 2015(4,8)$ \\
I learn things quickly in mathematics. & $2011(4,8), 2015(4,8)$ \\
I am good at working out difficult mathematics problems. & $2011(4,8), 2015(4,8)$ \\
My teacher tells me I am good at mathematics. & $2011(4,8), 2015(4,8)$ \\
Mathematics is harder for me than any other subject. (R) & $2015(4,8)$ \\
Mathematics makes me nervous. (R) & $2015(4,8)$ \\
Mathematics makes me confused. (R) & $2011(8)$ \\
Mathematics makes me confused and nervous. (R) & $2011(8), 2015(8)$ \\
Mathematics is not one of my strengths. (R) & $2011(8)$ \\
My teacher thinks I can do well in mathematics & \\
<programs/classes/lessons $>^{\text {a }}$ with difficult materials. &
\end{tabular}

Note. Responses given on a 4-point rating scale: $4=$ agree $a$ lot, 3 =agree a little, $2=$ disagree $a$ little, 1 = disagree a lot. $(\mathrm{R})=$ reversed.

${ }^{\text {a }}$ The terms in brackets $<>$ were replaced in the national versions of the TIMSS questionnaires by the corresponding national equivalent. 
Table S16

Mathematics Self-Concept Items as Used in PISA

\begin{tabular}{|c|c|}
\hline Item wording & Cycles \\
\hline I get good $<$ marks $>^{c}$ in mathematics. ${ }^{\text {a, b }}$ & $2000,2003,2012$ \\
\hline Mathematics is one of my best subjects. ${ }^{a}$ & 2000 \\
\hline I have always done well in mathematics. ${ }^{\text {a }}$ & 2000 \\
\hline I am just not good at mathematics. $(\mathrm{R})^{\mathrm{b}}$ & 2003,2012 \\
\hline I learn mathematics quickly. ${ }^{\mathrm{b}}$ & 2003,2012 \\
\hline I have always believed that mathematics is one of my best subjects. ${ }^{\text {b }}$ & 2003,2012 \\
\hline In my mathematics class, I understand even the most difficult work. ${ }^{\mathrm{b}}$ & 2003,2012 \\
\hline
\end{tabular}

Note. $(\mathrm{R})=$ reversed.

a 4 -point rating scale $(1=$ disagree to $4=$ agree $)$.

${ }^{\mathrm{b}} 4$-point rating scale $(1=$ strongly disagree to $4=$ strongly agree $)$.

${ }^{\mathrm{c}}$ The terms in brackets $<>$ were replaced in the national versions of the PISA questionnaires by the corresponding national equivalent. 
Table S17

Reading Self-Concept Items as Used in PIRLS 2011 and 2016

\begin{tabular}{ll}
\hline \multicolumn{1}{c}{ Item wording } & \multicolumn{1}{c}{ Cycles } \\
\hline I usually do well in reading. & 2011,2016 \\
Reading is easy for me. & 2011,2016 \\
Reading is harder for me than for many of my classmates. (R) & 2011,2016 \\
If a book is interesting, I don't care how hard it is to read. & 2011 \\
I have trouble reading stories with difficult words. (R) & 2011,2016 \\
My teacher tells me that I am a good reader. & 2011 \\
Reading is harder for me than any other subject. (R) & 2016 \\
I am just not good at reading. (R) & 2016 \\
\hline
\end{tabular}

Note. Responses given on a 4-point rating scale: $4=$ agree a lot, 3 = agree a little, 2 = disagree a little, $1=$ disagree a lot. $(\mathrm{R})=$ reversed. 


\section{Table S18}

Verbal Self-Concept Items as Used in PISA 2000

\begin{tabular}{l} 
Item wording \\
\hline I'm hopeless in $<$ test language $>^{\mathrm{a}}$. $(\mathrm{R})$ \\
I learn things quickly in the $<$ test language $>^{\mathrm{a}}$ classes. \\
I get good marks in the $<$ test language $>^{\mathrm{a}}$. \\
\hline Note. Responses given on a 4-point rating scale $(1=$ disagree to $4=$ agree $)$. \\
$(\mathrm{R})=$ reversed. \\
${ }^{\mathrm{a}}$ The terms in brackets $<>$ were replaced in the national versions of the PISA \\
questionnaires by the corresponding national equivalent.
\end{tabular}


Table S19

Standardized Regression Coefficients from Linear and Quadratic Regression Models (Mathematics Self-Concept on Mathematics Achievement) with Confidence Intervals (95\% CI) and Explained Variance $\left(R^{2}\right)$ in TIMSS (Grade 4)

\begin{tabular}{|c|c|c|c|c|c|c|c|c|c|}
\hline \multirow[b]{3}{*}{ Country } & \multirow[b]{3}{*}{ Cycle } & \multicolumn{3}{|c|}{ Linear model } & \multicolumn{5}{|c|}{ Quadratic model } \\
\hline & & \multicolumn{2}{|c|}{ Linear effect } & \multirow[b]{2}{*}{$R^{2}$} & \multicolumn{2}{|c|}{ Linear effect } & \multicolumn{2}{|c|}{ Quadratic effect } & \multirow[b]{2}{*}{$R^{2}$} \\
\hline & & $\beta$ & $95 \% \mathrm{CI}$ & & $\beta$ & $95 \% \mathrm{CI}$ & $\beta$ & $95 \% \mathrm{CI}$ & \\
\hline \multirow[t]{2}{*}{ Australia } & 2011 & 0.28 & {$[0.25,0.32]$} & .080 & 0.29 & {$[0.26,0.33]$} & 0.08 & {$[0.05,0.11]$} & .087 \\
\hline & 2015 & 0.45 & {$[0.42,0.48]$} & .202 & 0.45 & {$[0.42,0.49]$} & 0.09 & {$[0.05,0.12]$} & .209 \\
\hline Austria & 2011 & 0.34 & {$[0.31,0.38]$} & .118 & 0.34 & {$[0.31,0.38]$} & -0.01 & {$[-0.04,0.03]$} & .118 \\
\hline \multirow[t]{2}{*}{ Czech Republic } & 2011 & 0.30 & {$[0.25,0.35]$} & .091 & 0.32 & {$[0.28,0.36]$} & 0.06 & {$[-0.02,0.14]$} & .095 \\
\hline & 2015 & 0.45 & {$[0.42,0.48]$} & .202 & 0.45 & {$[0.42,0.48]$} & 0.02 & {$[0.00,0.05]$} & .202 \\
\hline \multirow[t]{2}{*}{ Finland } & 2011 & 0.36 & {$[0.32,0.40]$} & .133 & 0.38 & {$[0.35,0.41]$} & 0.10 & {$[0.06,0.15]$} & .144 \\
\hline & 2015 & 0.45 & {$[0.41,0.48]$} & .198 & 0.46 & {$[0.43,0.49]$} & 0.07 & {$[0.04,0.11]$} & .204 \\
\hline \multirow[t]{2}{*}{ Germany } & 2011 & 0.36 & {$[0.32,0.39]$} & .126 & 0.37 & {$[0.34,0.40]$} & 0.07 & {$[0.02,0.11]$} & .131 \\
\hline & 2015 & 0.46 & {$[0.42,0.49]$} & .211 & 0.46 & {$[0.42,0.49]$} & -0.02 & {$[-0.06,0.03]$} & .211 \\
\hline \multirow[t]{2}{*}{ Hong Kong } & 2011 & 0.30 & {$[0.27,0.34]$} & .092 & 0.31 & {$[0.28,0.35]$} & 0.06 & {$[0.02,0.10]$} & .095 \\
\hline & 2015 & 0.45 & {$[0.39,0.50]$} & .199 & 0.46 & {$[0.41,0.51]$} & 0.09 & {$[0.04,0.13]$} & .206 \\
\hline \multirow[t]{2}{*}{ Hungary } & 2011 & 0.45 & {$[0.43,0.48]$} & .206 & 0.48 & {$[0.45,0.51]$} & 0.07 & {$[0.03,0.10]$} & .210 \\
\hline & 2015 & 0.54 & {$[0.50,0.57]$} & .287 & 0.56 & {$[0.53,0.59]$} & 0.05 & {$[0.00,0.11]$} & .289 \\
\hline \multirow[t]{2}{*}{ Ireland } & 2011 & 0.27 & {$[0.23,0.31]$} & .075 & 0.29 & {$[0.25,0.33]$} & 0.07 & {$[0.03,0.11]$} & .079 \\
\hline & 2015 & 0.45 & {$[0.42,0.48]$} & .202 & 0.45 & {$[0.42,0.48]$} & 0.01 & {$[-0.02,0.05]$} & .202 \\
\hline \multirow[t]{2}{*}{ Italy } & 2011 & 0.27 & {$[0.23,0.31]$} & .073 & 0.25 & {$[0.21,0.29]$} & 0.04 & {$[-0.02,0.10]$} & .061 \\
\hline & 2015 & 0.35 & {$[0.31,0.39]$} & .122 & 0.35 & {$[0.31,0.39]$} & 0.00 & {$[-0.03,0.03]$} & .122 \\
\hline \multirow[t]{2}{*}{ Norway } & 2011 & 0.24 & {$[0.20,0.28]$} & .060 & 0.43 & {$[0.38,0.48]$} & 0.08 & {$[0.03,0.14]$} & .185 \\
\hline & 2015 & 0.45 & {$[0.41,0.48]$} & .199 & 0.45 & {$[0.41,0.48]$} & 0.00 & {$[-0.05,0.05]$} & .199 \\
\hline \multirow[t]{2}{*}{ Portugal } & 2011 & 0.42 & {$[0.38,0.47]$} & .178 & 0.31 & {$[0.28,0.35]$} & 0.00 & {$[-0.04,0.04]$} & .099 \\
\hline & 2015 & 0.52 & {$[0.50,0.55]$} & .274 & 0.52 & {$[0.50,0.55]$} & 0.05 & {$[0.02,0.09]$} & .276 \\
\hline Russian & 2011 & 0.31 & {$[0.28,0.35]$} & .099 & 0.26 & {$[0.23,0.29]$} & 0.05 & {$[0.01,0.09]$} & .070 \\
\hline Federation & 2015 & 0.42 & {$[0.39,0.45]$} & .177 & 0.42 & {$[0.39,0.45]$} & -0.01 & {$[-0.05,0.02]$} & .177 \\
\hline
\end{tabular}


Table S19 (Continued)

\begin{tabular}{|c|c|c|c|c|c|c|c|c|c|}
\hline \multirow[b]{3}{*}{ Country } & \multirow[b]{3}{*}{ Cycle } & \multicolumn{3}{|c|}{ Linear model } & \multicolumn{5}{|c|}{ Quadratic model } \\
\hline & & \multicolumn{2}{|c|}{ Linear effect } & \multirow[b]{2}{*}{$R^{2}$} & \multicolumn{2}{|c|}{ Linear effect } & \multicolumn{2}{|c|}{ Quadratic effect } & \multirow[b]{2}{*}{$R^{2}$} \\
\hline & & $\beta$ & $95 \% \mathrm{CI}$ & & $\beta$ & $95 \% \mathrm{CI}$ & $\beta$ & $95 \% \mathrm{CI}$ & \\
\hline \multirow[t]{2}{*}{ Sweden } & 2011 & 0.26 & {$[0.23,0.29]$} & .067 & 0.27 & {$[0.24,0.31]$} & 0.03 & {$[0.00,0.06]$} & .073 \\
\hline & 2015 & 0.39 & {$[0.36,0.43]$} & .155 & 0.40 & {$[0.37,0.44]$} & 0.05 & {$[0.00,0.10]$} & .157 \\
\hline Weighted mean & & 0.38 & {$[0.35,0.42]$} & .152 & 0.39 & {$[0.36,0.42]$} & 0.04 & {$[0.03,0.06]$} & .155 \\
\hline
\end{tabular}


Table S20

Standardized Regression Coefficients from Linear and Quadratic Regression Models (Mathematics Self-Concept on Mathematics Achievement) with Confidence Intervals (95\% CI) and Explained Variance $\left(R^{2}\right)$ in TIMSS (Grade 8)

\begin{tabular}{|c|c|c|c|c|c|c|c|c|c|}
\hline \multirow[b]{3}{*}{ Country } & \multirow[b]{3}{*}{ Cycle } & \multicolumn{3}{|c|}{ Linear model } & \multicolumn{5}{|c|}{ Quadratic model } \\
\hline & & \multicolumn{2}{|c|}{ Linear effect } & \multirow[b]{2}{*}{$R^{2}$} & \multicolumn{2}{|c|}{ Linear effect } & \multicolumn{2}{|c|}{ Quadratic effect } & \multirow[b]{2}{*}{$R^{2}$} \\
\hline & & $\beta$ & $95 \% \mathrm{CI}$ & & $\beta$ & $95 \% \mathrm{CI}$ & $\beta$ & $95 \%$ CI & \\
\hline \multirow{2}{*}{ Australia } & 2011 & 0.55 & {$[0.52,0.58]$} & .302 & 0.54 & {$[0.51,0.58]$} & 0.03 & {$[-0.02,0.09]$} & .303 \\
\hline & 2015 & 0.53 & {$[0.50,0.56]$} & .278 & 0.54 & {$[0.51,0.56]$} & 0.10 & {$[0.07,0.14]$} & .289 \\
\hline Finland & 2011 & 0.63 & {$[0.60,0.65]$} & .391 & 0.64 & {$[0.61,0.67]$} & 0.13 & {$[0.10,0.17]$} & .409 \\
\hline \multirow[t]{2}{*}{ Hong Kong } & 2011 & 0.39 & {$[0.35,0.44]$} & .156 & 0.47 & {$[0.43,0.51]$} & 0.18 & {$[0.10,0.27]$} & .184 \\
\hline & 2015 & 0.39 & {$[0.35,0.42]$} & .149 & 0.45 & {$[0.40,0.50]$} & 0.18 & {$[0.11,0.25]$} & .178 \\
\hline \multirow[t]{2}{*}{ Hungary } & 2011 & 0.53 & {$[0.50,0.57]$} & .283 & 0.62 & {$[0.59,0.66]$} & 0.25 & {$[0.19,0.30]$} & .335 \\
\hline & 2015 & 0.55 & {$[0.52,0.58]$} & .302 & 0.60 & {$[0.57,0.64]$} & 0.17 & {$[0.11,0.22]$} & .327 \\
\hline Ireland & 2015 & 0.45 & {$[0.41,0.50]$} & .207 & 0.51 & {$[0.48,0.55]$} & 0.18 & {$[0.12,0.25]$} & .236 \\
\hline \multirow[t]{2}{*}{ Italy } & 2011 & 0.53 & {$[0.50,0.56]$} & .281 & 0.54 & {$[0.51,0.58]$} & 0.08 & {$[0.04,0.12]$} & .287 \\
\hline & 2015 & 0.50 & {$[0.47,0.54]$} & .255 & 0.53 & {$[0.50,0.57]$} & 0.13 & {$[0.09,0.16]$} & .270 \\
\hline \multirow[t]{2}{*}{ Norway } & 2011 & 0.64 & {$[0.61,0.66]$} & .406 & 0.65 & {$[0.62,0.68]$} & 0.07 & {$[0.03,0.10]$} & .410 \\
\hline & 2015 & 0.63 & {$[0.61,0.65]$} & .394 & 0.64 & {$[0.62,0.66]$} & 0.09 & {$[0.05,0.13]$} & .402 \\
\hline Russian & 2011 & 0.49 & {$[0.47,0.52]$} & .245 & 0.50 & {$[0.47,0.53]$} & 0.04 & {$[0.01,0.08]$} & .246 \\
\hline Federation & 2015 & 0.46 & {$[0.43,0.49]$} & .213 & 0.46 & {$[0.43,0.50]$} & 0.03 & {$[-0.01,0.06]$} & .214 \\
\hline \multirow[t]{2}{*}{ Sweden } & 2011 & 0.61 & {$[0.59,0.63]$} & .375 & 0.62 & {$[0.60,0.64]$} & 0.09 & {$[0.06,0.12]$} & .383 \\
\hline & 2015 & 0.61 & {$[0.58,0.64]$} & .372 & 0.64 & {$[0.61,0.67]$} & 0.15 & {$[0.11,0.19]$} & .394 \\
\hline Weighted mean & & 0.53 & {$[0.48,0.58]$} & .289 & 0.56 & {$[0.52,0.61]$} & 0.12 & {$[0.08,0.15]$} & .306 \\
\hline
\end{tabular}




\section{Table S21}

Standardized Regression Coefficients from Linear and Quadratic Regression Models (Mathematics Self-Concept on Mathematics Achievement) with Confidence Intervals (95\% CI) and Explained Variance $\left(R^{2}\right)$ in PISA

\begin{tabular}{|c|c|c|c|c|c|c|c|c|c|}
\hline \multirow[b]{3}{*}{ Country } & \multirow[b]{3}{*}{ Cycle } & \multicolumn{3}{|c|}{ Linear model } & \multicolumn{5}{|c|}{ Quadratic model } \\
\hline & & \multicolumn{2}{|c|}{ Linear effect } & \multirow[b]{2}{*}{$R^{2}$} & \multicolumn{2}{|c|}{ Linear effect } & \multicolumn{2}{|c|}{ Quadratic effect } & \multirow[b]{2}{*}{$R^{2}$} \\
\hline & & $\beta$ & $95 \% \mathrm{CI}$ & & $\beta$ & $95 \% \mathrm{CI}$ & $\beta$ & $95 \% \mathrm{CI}$ & \\
\hline \multirow[t]{3}{*}{ Australia } & 2000 & 0.29 & {$[0.24,0.33]$} & .082 & 0.29 & {$[0.25,0.34]$} & 0.10 & {$[0.05,0.15]$} & .092 \\
\hline & 2003 & 0.41 & {$[0.39,0.43]$} & .169 & 0.42 & {$[0.39,0.44]$} & 0.08 & {$[0.05,0.10]$} & .175 \\
\hline & 2012 & 0.45 & {$[0.43,0.47]$} & .199 & 0.43 & {$[0.41,0.45]$} & 0.08 & {$[0.06,0.11]$} & .206 \\
\hline \multirow[t]{3}{*}{ Austria } & 2000 & 0.23 & {$[0.18,0.27]$} & .051 & 0.23 & {$[0.18,0.28]$} & 0.12 & {$[0.08,0.17]$} & .066 \\
\hline & 2003 & 0.30 & {$[0.27,0.34]$} & .091 & 0.32 & {$[0.28,0.35]$} & 0.11 & {$[0.08,0.14]$} & .103 \\
\hline & 2012 & 0.36 & {$[0.33,0.40]$} & .131 & 0.37 & {$[0.33,0.40]$} & 0.10 & {$[0.06,0.13]$} & .141 \\
\hline \multirow[t]{3}{*}{ Czech Republic } & 2000 & 0.27 & {$[0.23,0.32]$} & .074 & 0.28 & {$[0.23,0.32]$} & 0.08 & {$[0.02,0.13]$} & .080 \\
\hline & 2003 & 0.40 & {$[0.37,0.43]$} & .163 & 0.42 & {$[0.40,0.45]$} & 0.07 & {$[0.03,0.10]$} & .167 \\
\hline & 2012 & 0.46 & {$[0.42,0.50]$} & .214 & 0.49 & {$[0.45,0.52]$} & 0.07 & {$[0.00,0.13]$} & .218 \\
\hline \multirow[t]{3}{*}{ Finland } & 2000 & 0.48 & {$[0.43,0.52]$} & .226 & 0.50 & {$[0.47,0.54]$} & 0.14 & {$[0.09,0.20]$} & .246 \\
\hline & 2003 & 0.58 & {$[0.56,0.60]$} & .336 & 0.58 & {$[0.56,0.61]$} & 0.12 & {$[0.09,0.14]$} & .349 \\
\hline & 2012 & 0.55 & {$[0.52,0.57]$} & .301 & 0.53 & {$[0.50,0.56]$} & 0.17 & {$[0.14,0.20]$} & .330 \\
\hline \multirow[t]{3}{*}{ Germany } & 2000 & 0.16 & {$[0.11,0.22]$} & .027 & 0.20 & {$[0.15,0.25]$} & 0.10 & {$[0.05,0.16]$} & .036 \\
\hline & 2003 & 0.25 & {$[0.22,0.29]$} & .064 & 0.28 & {$[0.24,0.31]$} & 0.10 & {$[0.06,0.15]$} & .074 \\
\hline & 2012 & 0.34 & {$[0.30,0.38]$} & .114 & 0.35 & {$[0.31,0.39]$} & 0.10 & {$[0.06,0.15]$} & .126 \\
\hline \multirow[t]{3}{*}{ Hong Kong } & 2000 & 0.22 & {$[0.17,0.26]$} & .048 & 0.27 & {$[0.22,0.31]$} & 0.15 & {$[0.11,0.19]$} & .067 \\
\hline & 2003 & 0.35 & {$[0.32,0.39]$} & .123 & 0.40 & {$[0.36,0.44]$} & 0.13 & {$[0.09,0.17]$} & .138 \\
\hline & 2012 & 0.35 & {$[0.32,0.38]$} & .124 & 0.38 & {$[0.34,0.41]$} & 0.10 & {$[0.07,0.14]$} & 134 \\
\hline \multirow[t]{3}{*}{ Hungary } & 2000 & 0.26 & {$[0.21,0.32]$} & .070 & 0.26 & {$[0.21,0.31]$} & 0.14 & {$[0.10,0.18]$} & .088 \\
\hline & 2003 & 0.26 & {$[0.22,0.30]$} & .068 & 0.26 & {$[0.23,0.29]$} & 0.14 & {$[0.11,0.17]$} & .087 \\
\hline & 2012 & 0.37 & {$[0.32,0.41]$} & .134 & 0.38 & {$[0.34,0.42]$} & 0.23 & {$[0.18,0.27]$} & .186 \\
\hline \multirow[t]{2}{*}{ Ireland } & 2000 & 0.24 & {$[0.19,0.29]$} & .056 & 0.28 & {$[0.24,0.32]$} & 0.17 & {$[0.10,0.23]$} & .083 \\
\hline & 2003 & 0.39 & {$[0.35,0.43]$} & .152 & 0.40 & {$[0.36,0.44]$} & 0.10 & {$[0.07,0.14]$} & .163 \\
\hline
\end{tabular}


Table S21 (Continued)

\begin{tabular}{|c|c|c|c|c|c|c|c|c|c|}
\hline \multirow[b]{3}{*}{ Country } & \multirow[b]{3}{*}{ Cycle } & \multicolumn{3}{|c|}{ Linear model } & \multicolumn{5}{|c|}{ Quadratic model } \\
\hline & & \multicolumn{2}{|c|}{ Linear effect } & \multirow[b]{2}{*}{$R^{2}$} & \multicolumn{2}{|c|}{ Linear effect } & \multicolumn{2}{|c|}{ Quadratic effect } & \multirow[b]{2}{*}{$R^{2}$} \\
\hline & & $\beta$ & $95 \% \mathrm{CI}$ & & $\beta$ & $95 \%$ CI & $\beta$ & $95 \%$ CI & \\
\hline Ireland & 2012 & 0.40 & {$[0.37,0.43]$} & .162 & 0.41 & {$[0.38,0.44]$} & 0.14 & {$[0.11,0.17]$} & .181 \\
\hline \multirow[t]{3}{*}{ Italy } & 2000 & 0.25 & {$[0.22,0.29]$} & .065 & 0.27 & {$[0.23,0.31]$} & 0.08 & {$[0.03,0.13]$} & .071 \\
\hline & 2003 & 0.27 & {$[0.24,0.30]$} & .074 & 0.31 & {$[0.28,0.33]$} & 0.08 & {$[0.05,0.11]$} & .079 \\
\hline & 2012 & 0.34 & {$[0.32,0.36]$} & .118 & 0.36 & {$[0.34,0.37]$} & 0.10 & {$[0.08,0.12]$} & .128 \\
\hline \multirow[t]{3}{*}{ Norway } & 2000 & 0.45 & {$[0.41,0.49]$} & .201 & 0.47 & {$[0.43,0.51]$} & 0.16 & {$[0.10,0.22]$} & .226 \\
\hline & 2003 & 0.57 & {$[0.54,0.60]$} & .323 & 0.58 & {$[0.55,0.60]$} & 0.17 & {$[0.14,0.21]$} & .353 \\
\hline & 2012 & 0.61 & {$[0.58,0.64]$} & .374 & 0.62 & {$[0.59,0.65]$} & 0.13 & {$[0.10,0.16]$} & .392 \\
\hline \multirow[t]{3}{*}{ Portugal } & 2000 & 0.23 & {$[0.18,0.28]$} & .053 & 0.26 & {$[0.22,0.31]$} & 0.15 & {$[0.10,0.19]$} & .074 \\
\hline & 2003 & 0.39 & {$[0.36,0.43]$} & .152 & 0.39 & {$[0.36,0.42]$} & 0.16 & {$[0.12,0.19]$} & .177 \\
\hline & 2012 & 0.45 & {$[0.42,0.48]$} & .202 & 0.45 & {$[0.42,0.48]$} & 0.15 & {$[0.11,0.19]$} & .224 \\
\hline Russian & 2000 & 0.27 & {$[0.23,0.31]$} & .073 & 0.27 & {$[0.23,0.31]$} & 0.03 & {$[0.00,0.07]$} & .074 \\
\hline \multirow[t]{2}{*}{ Federation } & 2003 & 0.33 & {$[0.30,0.36]$} & .109 & 0.33 & {$[0.30,0.36]$} & 0.08 & {$[0.05,0.12]$} & .116 \\
\hline & 2012 & 0.37 & {$[0.34,0.40]$} & .137 & 0.37 & {$[0.34,0.40]$} & 0.09 & {$[0.05,0.13]$} & .145 \\
\hline \multirow[t]{3}{*}{ Sweden } & 2000 & 0.39 & {$[0.35,0.42]$} & .151 & 0.42 & {$[0.39,0.46]$} & 0.19 & {$[0.15,0.24]$} & .188 \\
\hline & 2003 & 0.50 & {$[0.47,0.53]$} & .250 & 0.51 & {$[0.48,0.54]$} & 0.14 & {$[0.11,0.17]$} & .270 \\
\hline & 2012 & 0.49 & {$[0.46,0.52]$} & .237 & 0.49 & {$[0.46,0.52]$} & 0.12 & {$[0.09,0.15]$} & .252 \\
\hline Weighted mean & & 0.37 & {$[0.32,0.42]$} & .146 & 0.38 & {$[0.33,0.43]$} & 0.12 & {$[0.10,0.14]$} & .161 \\
\hline
\end{tabular}




\section{Table S22}

Standardized Regression Coefficients from Linear and Quadratic Regression Models (Reading SelfConcept on Reading Achievement) with Confidence Intervals (95\% CI) and Explained Variance $\left(R^{2}\right)$ in PIRLS

\begin{tabular}{|c|c|c|c|c|c|c|c|c|c|}
\hline \multirow[b]{3}{*}{ Country } & \multirow[b]{3}{*}{ Cycle } & \multicolumn{3}{|c|}{ Linear model } & \multicolumn{5}{|c|}{ Quadratic model } \\
\hline & & \multicolumn{2}{|c|}{ Linear effect } & \multirow[b]{2}{*}{$R^{2}$} & \multicolumn{2}{|c|}{ Linear effect } & \multicolumn{2}{|c|}{ Quadratic effect } & \multirow[b]{2}{*}{$R^{2}$} \\
\hline & & $\beta$ & $95 \%$ CI & & $\beta$ & $95 \% \mathrm{CI}$ & $\beta$ & $95 \% \mathrm{CI}$ & \\
\hline \multirow[t]{2}{*}{ Australia } & 2011 & 0.50 & {$[0.47,0.54]$} & .253 & 0.50 & {$[0.46,0.53]$} & -0.02 & {$[-0.05,0.01]$} & .253 \\
\hline & 2016 & 0.56 & {$[0.54,0.59]$} & .315 & 0.55 & {$[0.53,0.58]$} & -0.04 & {$[-0.07,-0.01]$} & .317 \\
\hline \multirow[t]{2}{*}{ Austria } & 2011 & 0.39 & {$[0.36,0.43]$} & .154 & 0.39 & {$[0.35,0.42]$} & -0.03 & {$[-0.06,0.00]$} & .155 \\
\hline & 2016 & 0.42 & {$[0.40,0.45]$} & .179 & 0.42 & {$[0.40,0.45]$} & 0.01 & {$[-0.03,0.05]$} & .179 \\
\hline \multirow[t]{2}{*}{ Czech Republic } & 2011 & 0.42 & {$[0.38,0.46]$} & .179 & 0.43 & {$[0.39,0.47]$} & 0.01 & {$[-0.05,0.07]$} & .179 \\
\hline & 2016 & 0.43 & {$[0.40,0.46]$} & .187 & 0.43 & {$[0.40,0.46]$} & -0.01 & {$[-0.06,0.04]$} & 187 \\
\hline \multirow[t]{2}{*}{ Finland } & 2011 & 0.41 & {$[0.37,0.45]$} & .167 & 0.41 & {$[0.37,0.44]$} & -0.02 & {$[-0.06,0.03]$} & 167 \\
\hline & 2016 & 0.44 & {$[0.41,0.47]$} & .194 & 0.44 & {$[0.41,0.47]$} & 0.00 & {$[-0.04,0.03]$} & .194 \\
\hline \multirow[t]{2}{*}{ Germany } & 2011 & 0.42 & {$[0.39,0.46]$} & .180 & 0.42 & {$[0.39,0.45]$} & -0.01 & {$[-0.05,0.03]$} & .180 \\
\hline & 2016 & 0.46 & {$[0.41,0.51]$} & .214 & 0.45 & {$[0.41,0.49]$} & -0.04 & {$[-0.09,0.02]$} & .216 \\
\hline \multirow[t]{2}{*}{ Hong Kong } & 2011 & 0.38 & {$[0.35,0.41]$} & .145 & 0.39 & {$[0.36,0.43]$} & 0.03 & {$[0.00,0.07]$} & .146 \\
\hline & 2016 & 0.41 & {$[0.37,0.44]$} & .165 & 0.42 & {$[0.39,0.46]$} & 0.04 & {$[0.00,0.09]$} & .167 \\
\hline \multirow[t]{2}{*}{ Hungary } & 2011 & 0.53 & {$[0.49,0.56]$} & .278 & 0.53 & {$[0.50,0.57]$} & 0.02 & {$[-0.03,0.06]$} & .278 \\
\hline & 2016 & 0.51 & {$[0.47,0.54]$} & .257 & 0.50 & {$[0.46,0.53]$} & -0.03 & {$[-0.06,0.00]$} & .258 \\
\hline \multirow[t]{2}{*}{ Ireland } & 2011 & 0.42 & {$[0.39,0.46]$} & .180 & 0.42 & {$[0.39,0.45]$} & -0.01 & {$[-0.05,0.03]$} & .180 \\
\hline & 2016 & 0.46 & {$[0.43,0.49]$} & 210 & 0.45 & {$[0.41,0.48]$} & -0.04 & {$[-0.08,0.00]$} & .212 \\
\hline \multirow[t]{2}{*}{ Italy } & 2011 & 0.34 & {$[0.31,0.37]$} & .115 & 0.34 & {$[0.31,0.37]$} & 0.01 & {$[-0.02,0.05]$} & .115 \\
\hline & 2016 & 0.34 & {$[0.31,0.38]$} & .119 & 0.33 & {$[0.30,0.36]$} & -0.05 & {$[-0.09,-0.01]$} & .121 \\
\hline \multirow[t]{2}{*}{ Norway } & 2011 & 0.41 & {$[0.37,0.45]$} & .170 & 0.41 & {$[0.37,0.45]$} & -0.02 & {$[-0.08,0.04]$} & .170 \\
\hline & 2016 & 0.48 & {$[0.44,0.51]$} & .229 & 0.47 & {$[0.44,0.49]$} & -0.06 & {$[-0.11,-0.01]$} & .232 \\
\hline \multirow[t]{2}{*}{ Portugal } & 2011 & 0.46 & {$[0.43,0.49]$} & .212 & 0.46 & {$[0.42,0.49]$} & -0.02 & {$[-0.06,0.02]$} & .212 \\
\hline & 2016 & 0.44 & {$[0.40,0.47]$} & .193 & 0.44 & {$[0.40,0.47]$} & -0.05 & {$[-0.09,-0.01]$} & .195 \\
\hline
\end{tabular}

(table continues) 
Table S22 (Continued)

\begin{tabular}{|c|c|c|c|c|c|c|c|c|c|}
\hline \multirow[b]{3}{*}{ Country } & \multirow[b]{3}{*}{ Cycle } & \multicolumn{3}{|c|}{ Linear model } & \multicolumn{5}{|c|}{ Quadratic model } \\
\hline & & \multicolumn{2}{|c|}{ Linear effect } & \multirow[b]{2}{*}{$R^{2}$} & \multicolumn{2}{|c|}{ Linear effect } & \multicolumn{2}{|c|}{ Quadratic effect } & \multirow[b]{2}{*}{$R^{2}$} \\
\hline & & $\beta$ & $95 \% \mathrm{CI}$ & & $\beta$ & $95 \% \mathrm{CI}$ & $\beta$ & $95 \% \mathrm{CI}$ & \\
\hline Russian & 2011 & 0.40 & {$[0.36,0.44]$} & .162 & 0.40 & {$[0.36,0.44]$} & 0.00 & {$[-0.03,0.03]$} & .162 \\
\hline Federation & 2016 & 0.46 & {$[0.42$,} & .208 & 0.44 & {$[0.41,0.47]$} & -0.04 & {$[-0.09,0.00]$} & .210 \\
\hline \multirow[t]{2}{*}{ Sweden } & 2011 & 0.42 & {$[0.39,0.45]$} & .177 & 0.42 & {$[0.38,0.45]$} & -0.01 & {$[-0.06,0.03]$} & .177 \\
\hline & 2016 & 0.44 & {$[0.41,0.47]$} & .194 & 0.42 & {$[0.39,0.45]$} & -0.08 & {$[-0.11,-0.05]$} & .200 \\
\hline Weighted mean & & 0.44 & {$[0.41,0.46]$} & .193 & 0.43 & {$[0.41,0.46]$} & -0.02 & {$[-0.03,-0.01]$} & .194 \\
\hline
\end{tabular}


Table S23

Standardized Regression Coefficients from Linear and Quadratic Regression Models (Verbal SelfConcept on Reading Achievement) with Confidence Intervals $\left(95 \%\right.$ CI) and Explained Variance ( $\left.R^{2}\right)$ in PISA

\begin{tabular}{|c|c|c|c|c|c|c|c|c|c|}
\hline \multirow[b]{3}{*}{ Country } & \multirow[b]{3}{*}{ Cycle } & \multicolumn{3}{|c|}{ Linear model } & \multicolumn{5}{|c|}{ Quadratic model } \\
\hline & & \multicolumn{2}{|c|}{ Linear effect } & \multirow[b]{2}{*}{$R^{2}$} & \multicolumn{2}{|c|}{ Linear effect } & \multicolumn{2}{|c|}{ Quadratic effect } & \multirow[b]{2}{*}{$R^{2}$} \\
\hline & & $\beta$ & $95 \% \mathrm{CI}$ & & $\beta$ & $95 \% \mathrm{CI}$ & $\beta$ & $95 \% \mathrm{CI}$ & \\
\hline Australia & 2000 & 0.28 & {$[0.23,0.33]$} & .081 & 0.29 & {$[0.24,0.34]$} & 0.05 & {$[0.01,0.10]$} & .084 \\
\hline Austria & 2000 & 0.27 & {$[0.23,0.30]$} & .071 & 0.28 & {$[0.24,0.31]$} & 0.08 & {$[0.04,0.12]$} & .077 \\
\hline Czech Republic & 2000 & 0.26 & {$[0.21,0.32]$} & .069 & 0.29 & {$[0.23,0.34]$} & 0.07 & {$[0.01,0.13]$} & .074 \\
\hline Finland & 2000 & 0.38 & {$[0.34,0.42]$} & .147 & 0.41 & {$[0.37,0.45]$} & 0.10 & {$[0.01,0.18]$} & .156 \\
\hline Germany & 2000 & 0.20 & {$[0.15,0.25]$} & .042 & 0.23 & {$[0.19,0.28]$} & 0.06 & {$[-0.01,0.14]$} & .046 \\
\hline Hong Kong & 2000 & 0.14 & {$[0.10,0.19]$} & .021 & 0.15 & {$[0.10,0.20]$} & 0.01 & {$[-0.04,0.06]$} & .021 \\
\hline Hungary & 2000 & 0.28 & {$[0.24,0.32]$} & .078 & 0.29 & {$[0.25,0.33]$} & 0.07 & {$[0.02,0.12]$} & .084 \\
\hline Ireland & 2000 & 0.10 & {$[0.06,0.15]$} & .011 & 0.11 & {$[0.07,0.16]$} & 0.03 & {$[-0.03,0.08]$} & .012 \\
\hline Italy & 2000 & 0.27 & {$[0.23,0.31]$} & .072 & 0.26 & {$[0.22,0.30]$} & -0.03 & {$[-0.07,0.02]$} & .073 \\
\hline Norway & 2000 & 0.37 & {$[0.33,0.40]$} & .134 & 0.38 & {$[0.34,0.42]$} & 0.05 & {$[0.00,0.10]$} & .136 \\
\hline Portugal & 2000 & 0.30 & {$[0.27,0.34]$} & .092 & 0.31 & {$[0.27,0.35]$} & 0.02 & {$[-0.02,0.07]$} & .093 \\
\hline Russian Federation & 2000 & 0.27 & {$[0.24,0.31]$} & .073 & 0.27 & {$[0.24,0.31]$} & 0.03 & {$[-0.01,0.07]$} & .074 \\
\hline Sweden & 2000 & 0.33 & {$[0.28,0.37]$} & .107 & 0.35 & {$[0.31,0.39]$} & 0.10 & {$[0.06,0.15]$} & .117 \\
\hline Weighted mean & & 0.27 & {$[0.23,0.31]$} & .075 & 0.28 & {$[0.24,0.32]$} & 0.05 & {$[0.03,0.07]$} & .079 \\
\hline
\end{tabular}




\section{Table S24}

Standardized Regression Coefficients from Linear and Quadratic Regression Models (Mathematics Self-Concept on Mathematics Achievement), Confidence Intervals (95\% CI) and Explained Variance ( $\left.R^{2}\right)$ in TIMSS (Grade 4) Controlling for Students' Gender

\begin{tabular}{|c|c|c|c|c|c|c|c|c|c|c|c|c|c|}
\hline \multirow[b]{3}{*}{ Country } & \multirow[b]{3}{*}{ Cycle } & \multicolumn{5}{|c|}{ Linear model } & \multicolumn{7}{|c|}{ Quadratic model } \\
\hline & & \multicolumn{2}{|c|}{ Linear effect } & \multicolumn{2}{|c|}{ Gender effect } & \multirow[b]{2}{*}{$R^{2}$} & \multicolumn{2}{|c|}{ Linear effect } & \multicolumn{2}{|c|}{ Quadratic effect } & \multicolumn{2}{|c|}{ Gender effect } & \multirow[b]{2}{*}{$R^{2}$} \\
\hline & & $\beta$ & $95 \% \mathrm{CI}$ & $\beta$ & $95 \% \mathrm{CI}$ & & $\beta$ & $95 \% \mathrm{CI}$ & $\beta$ & $95 \% \mathrm{CI}$ & $\beta$ & $95 \% \mathrm{CI}$ & \\
\hline \multirow[t]{2}{*}{ Australia } & 2011 & 0.28 & {$[0.25,0.31]$} & 0.10 & {$[0.06,0.13]$} & .089 & 0.29 & {$[0.26,0.32]$} & 0.08 & {$[0.05,0.11]$} & 0.09 & {$[0.06,0.12]$} & .096 \\
\hline & 2015 & 0.44 & {$[0.41,0.47]$} & 0.14 & {$[0.10,0.17]$} & .221 & 0.45 & {$[0.41,0.48]$} & 0.08 & {$[0.05,0.11]$} & 0.13 & {$[0.10,0.17]$} & .227 \\
\hline Austria & 2011 & 0.33 & {$[0.30,0.37]$} & 0.15 & {$[0.12,0.19]$} & .141 & 0.33 & {$[0.30,0.37]$} & -0.01 & {$[-0.05,0.02]$} & 0.15 & {$[0.12,0.19]$} & .141 \\
\hline \multirow[t]{2}{*}{ Czech Republic } & 2011 & 0.29 & {$[0.24,0.34]$} & 0.13 & {$[0.08,0.17]$} & .107 & 0.31 & {$[0.26,0.35]$} & 0.05 & {$[-0.03,0.14]$} & 0.12 & {$[0.08,0.16]$} & .109 \\
\hline & 2015 & 0.44 & {$[0.42,0.47]$} & 0.11 & {$[0.08,0.15]$} & .215 & 0.45 & {$[0.42,0.48]$} & 0.02 & {$[0.00,0.05]$} & 0.11 & {$[0.08,0.15]$} & .215 \\
\hline \multirow[t]{2}{*}{ Finland } & 2011 & 0.35 & {$[0.31,0.39]$} & 0.19 & {$[0.16,0.22]$} & .168 & 0.37 & {$[0.33,0.40]$} & 0.10 & {$[0.05,0.15]$} & 0.18 & {$[0.16,0.21]$} & .178 \\
\hline & 2015 & 0.46 & {$[0.42,0.49]$} & 0.16 & {$[0.12,0.19]$} & .223 & 0.47 & {$[0.44,0.50]$} & 0.07 & {$[0.03,0.10]$} & 0.16 & {$[0.12,0.19]$} & .228 \\
\hline \multirow[t]{2}{*}{ Germany } & 2011 & 0.34 & {$[0.31,0.37]$} & 0.18 & {$[0.15,0.22]$} & .160 & 0.35 & {$[0.32,0.38]$} & 0.06 & {$[0.01,0.11]$} & 0.18 & $0.21]$ & .164 \\
\hline & 2015 & 0.45 & {$[0.42,0.49]$} & 0.16 & {$[0.14,0.19]$} & .238 & 0.45 & {$[0.42,0.49]$} & -0.02 & {$[-0.06,0.02]$} & 0.16 & {$[0.14,0.19]$} & .238 \\
\hline \multirow[t]{2}{*}{ Hong Kong } & 2011 & 0.29 & {$[0.26,0.33]$} & 0.21 & {$[0.18,0.25]$} & .137 & 0.30 & {$[0.26,0.34]$} & 0.04 & {$[0.00,0.08]$} & 0.21 & {$[0.18,0.24]$} & .139 \\
\hline & 2015 & 0.43 & {$[0.38,0.48]$} & 0.17 & {$[0.14,0.20]$} & .227 & 0.44 & {$[0.39,0.49]$} & 0.08 & {$[0.04,0.12]$} & 0.17 & {$[0.13,0.20]$} & .233 \\
\hline \multirow[t]{2}{*}{ Hungary } & 2011 & 0.45 & {$[0.43,0.48]$} & 0.08 & {$[0.06,0.11]$} & .213 & 0.48 & {$[0.45,0.51]$} & 0.06 & {$[0.03,0.10]$} & 0.08 & {$[0.05,0.11]$} & .216 \\
\hline & 2015 & 0.53 & {$[0.50,0.57]$} & 0.11 & {$[0.08,0.14]$} & .298 & 0.55 & {$[0.52,0.58]$} & 0.05 & {$[-0.01,0.10]$} & 0.11 & {$[0.08,0.13]$} & .300 \\
\hline \multirow[t]{2}{*}{ Ireland } & 2011 & 0.27 & {$[0.23,0.31]$} & 0.07 & {$[0.03,0.11]$} & .080 & 0.29 & {$[0.25,0.33]$} & 0.06 & {$[0.02,0.11]$} & 0.07 & {$[0.03,0.11]$} & .084 \\
\hline & 2015 & 0.45 & {$[0.42,0.48]$} & 0.06 & {$[0.03,0.10]$} & .206 & 0.45 & {$[0.42,0.48]$} & 0.01 & {$[-0.02,0.05]$} & 0.06 & {$[0.03,0.10]$} & .206 \\
\hline \multirow[t]{2}{*}{ Italy } & 2011 & 0.24 & {$[0.20,0.28]$} & 0.08 & {$[0.03,0.12]$} & .066 & 0.25 & {$[0.21,0.29]$} & 0.03 & {$[-0.03,0.10]$} & 0.07 & {$[0.03,0.12]$} & .067 \\
\hline & 2015 & 0.34 & {$[0.30,0.37]$} & 0.09 & {$[0.05,0.12]$} & .129 & 0.34 & {$[0.30,0.37]$} & 0.00 & {$[-0.04,0.03]$} & 0.09 & {$[0.05,0.12]$} & .129 \\
\hline \multirow[t]{2}{*}{ Norway } & 2011 & 0.42 & {$[0.37,0.46]$} & 0.13 & {$[0.09,0.18]$} & .195 & 0.43 & {$[0.38,0.48]$} & 0.08 & {$[0.02,0.13]$} & 0.13 & {$[0.08,0.17]$} & .201 \\
\hline & 2015 & 0.45 & {$[0.41,0.48]$} & 0.06 & {$[0.03,0.10]$} & .203 & 0.45 & {$[0.41,0.48]$} & -0.01 & {$[-0.05,0.04]$} & 0.06 & {$[0.03,0.10]$} & .203 \\
\hline \multirow[t]{2}{*}{ Portugal } & 2011 & 0.32 & {$[0.28,0.35]$} & 0.09 & {$[0.05,0.13]$} & .107 & 0.31 & {$[0.28,0.35]$} & -0.01 & {$[-0.04,0.03]$} & 0.09 & {$[0.06,0.13]$} & .107 \\
\hline & 2015 & 0.51 & {$[0.49,0.54]$} & 0.13 & {$[0.10,0.16]$} & .290 & 0.51 & {$[0.49,0.54]$} & 0.05 & {$[0.01,0.08]$} & 0.13 & {$[0.09,0.16]$} & .293 \\
\hline \multirow[t]{2}{*}{ Russian Federation } & 2011 & 0.26 & {$[0.22,0.29]$} & 0.04 & {$[0.01,0.08]$} & .069 & 0.26 & {$[0.23,0.29]$} & 0.05 & {$[0.01,0.09]$} & 0.04 & {$[0.00,0.08]$} & .071 \\
\hline & 2015 & 0.42 & {$[0.39,0.45]$} & 0.10 & {$[0.07,0.13]$} & .186 & 0.42 & {$[0.39,0.45]$} & -0.02 & {$[-0.05,0.02]$} & 0.10 & {$[0.07,0.13]$} & .187 \\
\hline
\end{tabular}




\begin{tabular}{|c|c|c|c|c|c|c|c|c|c|c|c|c|}
\hline \multicolumn{13}{|c|}{ Table S24 (Continued) } \\
\hline \multirow[b]{3}{*}{ Country } & \multirow[b]{3}{*}{ Cycle } & \multicolumn{5}{|c|}{ Linear model } & \multicolumn{6}{|c|}{ Quadratic model } \\
\hline & & \multicolumn{2}{|c|}{ Linear effect } & \multicolumn{2}{|c|}{ Gender effect } & \multirow[b]{2}{*}{$R^{2}$} & \multicolumn{2}{|c|}{ Linear effect } & \multicolumn{2}{|c|}{ Quadratic effect } & Gender effect & \multirow[b]{2}{*}{$R^{2}$} \\
\hline & & $\beta$ & $95 \% \mathrm{CI}$ & $\beta$ & $95 \% \mathrm{CI}$ & & $\beta$ & $95 \% \mathrm{CI}$ & $\beta$ & $95 \% \mathrm{CI}$ & $\beta \quad 95 \%$ CI & \\
\hline \multirow[t]{2}{*}{ Sweden } & 2011 & 0.26 & {$[0.23,0.30]$} & 0.11 & {$[0.08,0.15]$} & .085 & 0.27 & {$[0.23,0.30]$} & 0.03 & {$[0.00,0.06]$} & $0.11[0.08,0.14]$ & .086 \\
\hline & 2015 & 0.39 & {$[0.36,0.43]$} & 0.06 & {$[0.02,0.10]$} & .159 & 0.40 & {$[0.37,0.44]$} & 0.05 & {$[0.00,0.10]$} & $0.06[0.02,0.10]$ & .161 \\
\hline Weighted mean & & 0.38 & {$[0.34,0.41]$} & 0.12 & {$[0.10,0.14]$} & .168 & 0.38 & {$[0.35,0.42]$} & 0.04 & {$[0.02,0.05]$} & $0.12[0.09,0.14]$ & .170 \\
\hline
\end{tabular}




\section{Table S25}

Standardized Regression Coefficients from Linear and Quadratic Regression Models (Mathematics Self-Concept on Mathematics Achievement), Confidence Intervals (95\% CI) and Explained Variance ( $\left.R^{2}\right)$ in TIMSS (Grade 8) Controlling for Students' Gender

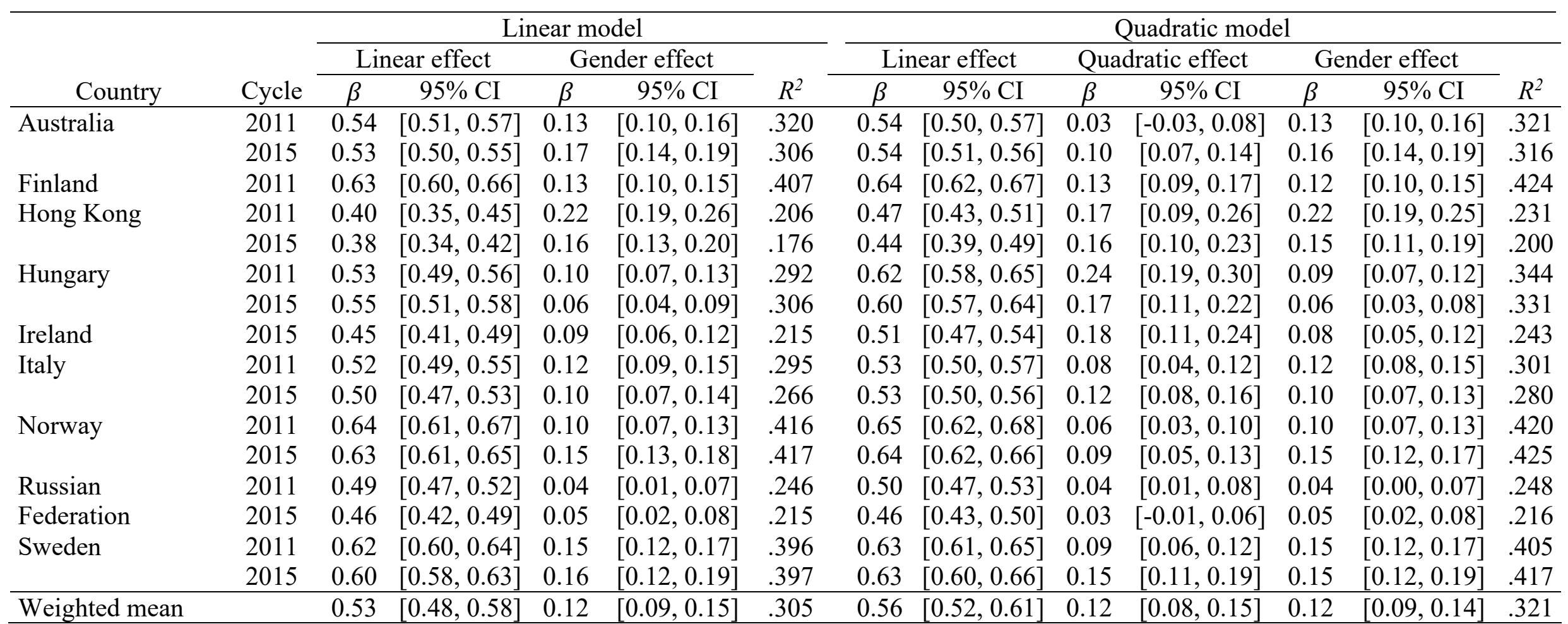




\section{Table S26}

Standardized Regression Coefficients from Linear and Quadratic Regression Models (Mathematics Self-Concept on Mathematics Achievement), Confidence Intervals (95\% CI) and Explained Variance (R2) in PISA Controlling for Students' Gender

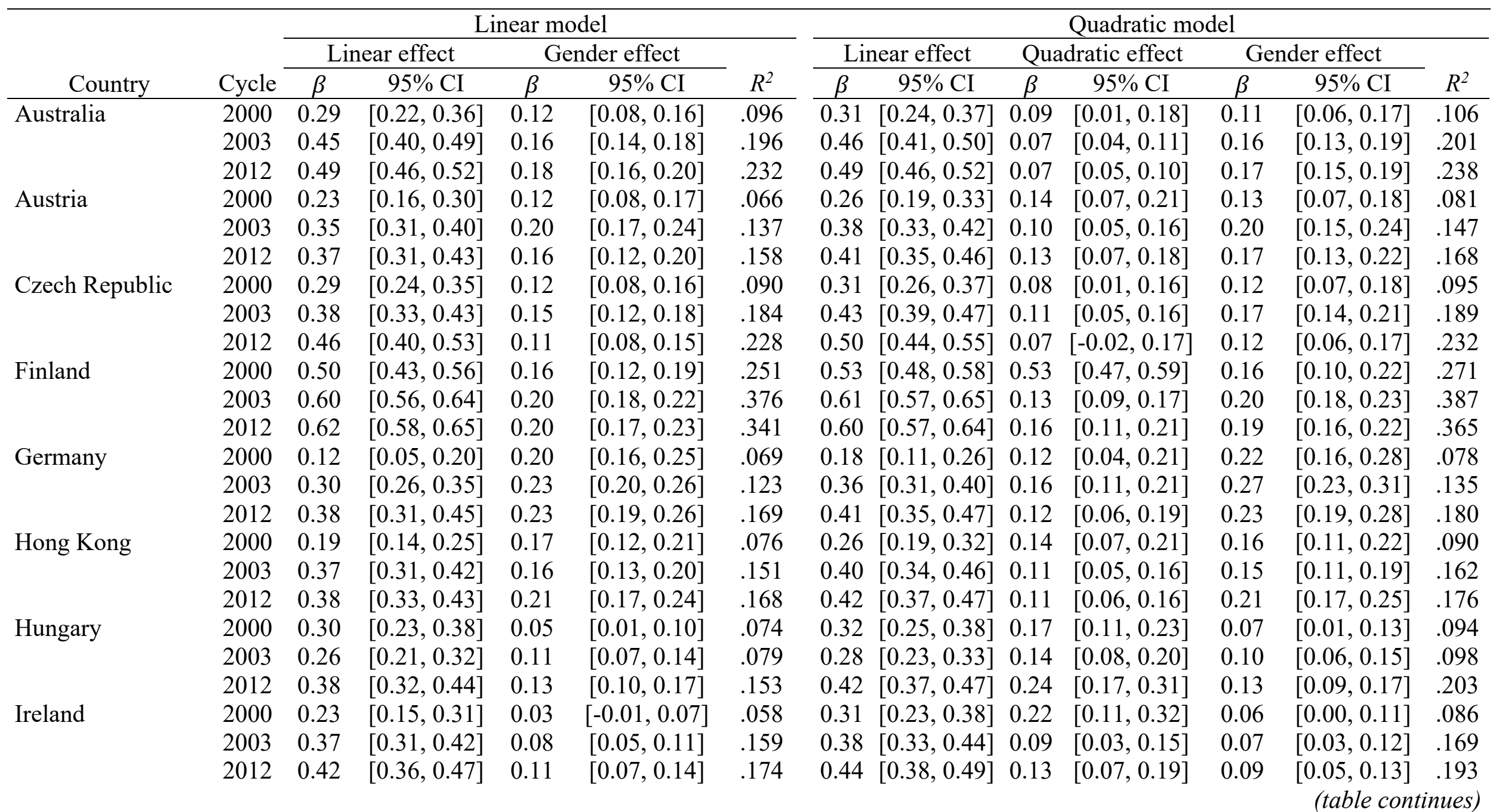


Table S26 (Continued)

\begin{tabular}{|c|c|c|c|c|c|c|c|c|c|c|c|c|c|}
\hline \multirow{2}{*}{ Country } & \multirow{2}{*}{ Cycle } & \multicolumn{5}{|c|}{ Linear model } & \multicolumn{7}{|c|}{ Quadratic model } \\
\hline & & \multicolumn{2}{|c|}{ Linear effect } & \multicolumn{2}{|c|}{ Gender effect } & $R^{2}$ & \multicolumn{2}{|c|}{ Linear effect } & \multicolumn{2}{|c|}{ Quadratic effect } & \multicolumn{2}{|c|}{ Gender effect } & $R^{2}$ \\
\hline \multirow[t]{2}{*}{ Italy } & 2000 & 0.26 & {$[0.21,0.32]$} & 0.06 & {$[0.02,0.11]$} & .069 & 0.28 & {$[0.22,0.34]$} & 0.07 & {$[0.00,0.13]$} & 0.06 & {$[0.00,0.11]$} & .075 \\
\hline & 2012 & 0.38 & {$[0.35,0$} & 0.09 & {$[0.07,0.11]$} & .128 & 0.41 & {$[0.38,0.44]$} & 0.10 & {$[0.07,0.14]$} & 0.08 & {$[0.06,0.11]$} & .138 \\
\hline \multirow[t]{2}{*}{ Norway } & 2000 & 0.46 & {$[0.41,0.52]$} & 0.20 & {$[0.15,0.24]$} & 240 & 0.51 & {$[0.45,0.56]$} & 0.19 & {$[0.09,0.28]$} & 0.21 & {$[0.15,0.26]$} & .262 \\
\hline & 2003 & 0.61 & {$[0.57,0.65]$} & 0.19 & {$[0.16,0.22]$} & .361 & 0.63 & {$[0.58,0.67]$} & 0.17 & {$[0.13,0.22]$} & 0.18 & {$[0.15,0.22]$} & .388 \\
\hline \multirow{2}{*}{ Portugal } & 2003 & 0.45 & {$[0.40,0.49]$} & 0.08 & {$[0.04,0.12]$} & .161 & 0.46 & {$[0.41,0.51]$} & 0.14 & {$[0.09,0.19]$} & 0.05 & {$[0.01,0.09]$} & .186 \\
\hline & 2012 & 0.49 & {$[0.44,0.54]$} & 0.10 & {$[0.07,0.14]$} & .214 & 0.51 & {$[0.46,0.55]$} & 0.15 & {$[0.09,0.22]$} & 0.10 & {$[0.05,0.14]$} & .236 \\
\hline Russian & 2000 & 0.30 & {$[0.23,0.37]$} & -0.04 & {$[-0.11,0.02]$} & .074 & 0.30 & {$[0.23,0.37]$} & 0.01 & {$[-0.05,0.07]$} & -0.01 & {$[-0.06,0.03]$} & .076 \\
\hline \multirow[t]{2}{*}{ Federation } & 2003 & 0.33 & {$[0.29,0.38]$} & -0.08 & {$[-0.14,-0.02]$} & .109 & 0.35 & {$[0.30,0.39]$} & 0.09 & {$[0.03$,} & 0.01 & $, 0.05]$ & .116 \\
\hline & 2012 & 0.38 & {$[0.33,0.42]$} & -0.07 & {$[-0.12,-0.02]$} & .142 & 0.37 & {$[0.33,0.42]$} & 0.08 & {$[0.04,0.13]$} & 0.06 & {$[0.02,0.10]$} & .150 \\
\hline Sweden & 2000 & 0.44 & {$[0.39,0.49]$} & 0.19 & {$[0.16,0.23]$} & 192 & 0.48 & {$[0.43,0.53]$} & 0.18 & {$[0.13,0.23]$} & 0.19 & {$[0.14,0.23]$} & .228 \\
\hline
\end{tabular}




\section{Table S27}

Standardized Regression Coefficients from Linear and Quadratic Regression Models (Reading Self-Concept on Reading Achievement), Confidence Intervals (95\% CI) and Explained Variance $\left(R^{2}\right)$ in PIRLS Controlling for Students' Gender

\begin{tabular}{|c|c|c|c|c|c|c|c|c|c|c|c|c|c|}
\hline \multirow[b]{3}{*}{ Country } & \multirow[b]{3}{*}{ Cycle } & \multicolumn{5}{|c|}{ Linear model } & \multicolumn{7}{|c|}{ Quadratic model } \\
\hline & & \multicolumn{2}{|c|}{ Linear effect } & \multicolumn{2}{|c|}{ Gender effect } & \multirow[b]{2}{*}{$R^{2}$} & \multicolumn{2}{|c|}{ Linear effect } & \multicolumn{2}{|c|}{ Quadratic effect } & \multicolumn{2}{|c|}{ Gender effect } & \multirow[b]{2}{*}{$R^{2}$} \\
\hline & & $\beta$ & $95 \%$ CI & $\beta$ & $95 \% \mathrm{CI}$ & & $\beta$ & $95 \% \mathrm{CI}$ & $\beta$ & $95 \% \mathrm{CI}$ & $\beta$ & $95 \% \mathrm{CI}$ & \\
\hline \multirow[t]{2}{*}{ Australia } & 2011 & 0.50 & {$[0.47,0.53]$} & -0.03 & {$[-0.06,0.00]$} & .254 & 0.49 & {$[0.46,0.53]$} & -0.02 & {$[-0.05,0.01]$} & -0.03 & {$[-0.06,0.00]$} & .254 \\
\hline & 2016 & 0.56 & {$[0.54,0.59]$} & 0.00 & {$[-0.02,0.03]$} & .315 & 0.55 & {$[0.53,0.58]$} & -0.04 & {$[-0.07,-0.01]$} & 0.00 & {$[-0.02,0.03]$} & .317 \\
\hline \multirow[t]{2}{*}{ Austria } & 2011 & 0.39 & {$[0.35,0.42]$} & -0.11 & {$[-0.14,-0.08]$} & 166 & 0.38 & {$[0.35,0.41]$} & -0.03 & {$[-0.06,0.01]$} & -0.11 & {$[-0.14,-0.08]$} & 167 \\
\hline & 2016 & 0.42 & {$[0.39,0.45]$} & -0.06 & {$[-0.09,-0.03]$} & .182 & 0.42 & {$[0.40,0.45]$} & 0.01 & {$[-0.03,0.05]$} & -0.06 & {$[-0.09,-0.03]$} & .183 \\
\hline \multirow[t]{2}{*}{ Czech Republic } & 2011 & 0.42 & {$[0.38,0.46]$} & -0.03 & {$[-0.06,0.00]$} & .180 & 0.43 & {$[0.38,0.47]$} & 0.01 & {$[-0.05,0.07]$} & -0.03 & {$[-0.06,0.00]$} & .180 \\
\hline & 2016 & 0.43 & {$[0.40,0.46]$} & -0.01 & {$[-0.05,0.02]$} & .187 & 0.43 & {$[0.40,0.46]$} & -0.01 & {$[-0.06,0.04]$} & -0.01 & {$[-0.05,0.02]$} & .188 \\
\hline \multirow[t]{2}{*}{ Finland } & 2011 & 0.40 & {$[0.36,0.44]$} & -0.04 & {$[-0.07,-0.01]$} & .169 & 0.40 & {$[0.36,0.44]$} & -0.02 & {$[-0.06,0.03]$} & -0.04 & {$[-0.07,-0.01]$} & .169 \\
\hline & 2016 & 0.44 & {$[0.41,0.47]$} & -0.03 & {$[-0.06,0.00]$} & .195 & 0.43 & {$[0.41,0.46]$} & 0.00 & {$[-0.04,0.03]$} & -0.03 & {$[-0.06,0.00]$} & .195 \\
\hline \multirow[t]{2}{*}{ Germany } & 2011 & 0.42 & {$[0.39,0.45]$} & -0.07 & {$[-0.11,-0.03]$} & .185 & 0.42 & {$[0.39,0.45]$} & -0.01 & {$[-0.05,0.03]$} & -0.07 & {$[-0.11,-0.03]$} & .185 \\
\hline & 2016 & 0.46 & {$[0.41,0.51]$} & -0.04 & {$[-0.08,0.00]$} & .216 & 0.44 & {$[0.40,0.48]$} & -0.04 & {$[-0.09,0.02]$} & -0.04 & {$[-0.08,0.00]$} & .217 \\
\hline \multirow[t]{2}{*}{ Hong Kong } & 2011 & 0.37 & {$[0.33,0.40]$} & -0.11 & {$[-0.14,-0.07]$} & .156 & 0.38 & {$[0.34,0.41]$} & 0.04 & {$[0.01,0.07]$} & -0.11 & {$[-0.14,-0.07]$} & .157 \\
\hline & 2016 & 0.40 & {$[0.37,0.44]$} & -0.06 & {$[-0.09,-0.03]$} & .168 & 0.42 & {$[0.38,0.45]$} & 0.05 & {$[0.00,0.09]$} & -0.06 & {$[-0.09,-0.03]$} & .170 \\
\hline \multirow[t]{2}{*}{ Hungary } & 2011 & 0.52 & {$[0.48,0.55]$} & -0.08 & {$[-0.11,-0.05]$} & .284 & 0.53 & {$[0.49,0.56]$} & 0.02 & {$[-0.03,0.06]$} & -0.08 & {$[-0.11,-0.05]$} & .285 \\
\hline & 2016 & 0.51 & {$[0.47,0.54]$} & 0.01 & {$[-0.02,0.04]$} & .257 & 0.50 & {$[0.46,0.53]$} & -0.03 & {$[-0.06,0.00]$} & 0.01 & {$[-0.02,0.04]$} & .258 \\
\hline \multirow[t]{2}{*}{ Ireland } & 2011 & 0.43 & {$[0.40,0.46]$} & 0.02 & {$[-0.02,0.06]$} & .181 & 0.43 & {$[0.39,0.46]$} & -0.01 & {$[-0.05,0.03]$} & 0.02 & {$[-0.02,0.06]$} & .181 \\
\hline & 2016 & 0.46 & {$[0.43,0.49]$} & 0.01 & {$[-0.03,0.05]$} & .210 & 0.45 & {$[0.41,0.48]$} & -0.04 & {$[-0.07,0.00]$} & 0.01 & {$[-0.03,0.05]$} & .212 \\
\hline \multirow[t]{2}{*}{ Italy } & 2011 & 0.34 & {$[0.30,0.37]$} & -0.07 & {$[-0.10,-0.04]$} & .121 & 0.34 & {$[0.31,0.37]$} & 0.01 & {$[-0.02,0.05]$} & -0.08 & {$[-0.10,-0.05]$} & .121 \\
\hline & 2016 & 0.34 & {$[0.30,0.38]$} & -0.06 & {$[-0.09,-0.03]$} & .122 & 0.33 & {$[0.30,0.36]$} & -0.05 & {$[-0.09,-0.01]$} & -0.06 & {$[-0.09,-0.02]$} & .124 \\
\hline \multirow[t]{2}{*}{ Norway } & 2011 & 0.41 & {$[0.37,0.46]$} & 0.02 & {$[-0.03,0.07]$} & .170 & 0.41 & {$[0.37,0.45]$} & -0.02 & {$[-0.08,0.04]$} & 0.02 & {$[-0.03,0.07]$} & .170 \\
\hline & 2016 & 0.48 & {$[0.45,0.51]$} & 0.01 & {$[-0.04,0.05]$} & .229 & 0.47 & {$[0.44,0.50]$} & -0.06 & {$[-0.11,-0.01]$} & 0.01 & {$[-0.04,0.05]$} & .232 \\
\hline \multirow[t]{2}{*}{ Portugal } & 2011 & 0.45 & {$[0.42,0.49]$} & -0.06 & {$[-0.10,-0.02]$} & .215 & 0.45 & {$[0.41,0.49]$} & -0.01 & {$[-0.05,0.03]$} & -0.06 & {$[-0.10,-0.02]$} & .216 \\
\hline & 2016 & 0.44 & {$[0.40,0.47]$} & -0.06 & {$[-0.09,-0.03]$} & .196 & 0.44 & {$[0.40,0.47]$} & -0.05 & {$[-0.08,-0.01]$} & -0.06 & {$[-0.08,-0.03]$} & .198 \\
\hline Russian & 2011 & 0.39 & {$[0.35,0.43]$} & -0.09 & {$[-0.12,-0.06]$} & .170 & 0.39 & {$[0.35,0.43]$} & 0.00 & {$[-0.03,0.04]$} & -0.09 & {$[-0.12,-0.06]$} & .170 \\
\hline Federation & 2016 & 0.45 & {$[0.41,0.49]$} & -0.06 & {$[-0.09,-0.04]$} & .212 & 0.43 & {$[0.40,0.47]$} & -0.05 & {$[-0.09,-0.01]$} & -0.06 & {$[-0.09,-0.04]$} & .214 \\
\hline
\end{tabular}


Table S27 (Continued)

\begin{tabular}{|c|c|c|c|c|c|c|c|c|c|c|c|c|c|}
\hline \multirow[b]{3}{*}{ Country } & \multirow[b]{3}{*}{ Cycle } & \multicolumn{5}{|c|}{ Linear model } & \multicolumn{7}{|c|}{ Quadratic model } \\
\hline & & \multicolumn{2}{|c|}{ Linear effect } & \multicolumn{2}{|c|}{ Gender effect } & \multirow[b]{2}{*}{$R^{2}$} & \multicolumn{2}{|c|}{ Linear effect } & \multicolumn{2}{|c|}{ Quadratic effect } & \multicolumn{2}{|c|}{ Gender effect } & \multirow[b]{2}{*}{$R^{2}$} \\
\hline & & $\beta$ & $95 \% \mathrm{CI}$ & $\beta$ & $95 \% \mathrm{CI}$ & & $\beta$ & $95 \% \mathrm{CI}$ & $\beta$ & $95 \% \mathrm{CI}$ & $\beta$ & $95 \% \mathrm{CI}$ & \\
\hline Sweden & 2011 & 0.42 & {$[0.38,0.45]$} & -0.04 & {$[-0.07,-0.01]$} & .179 & 0.41 & {$[0.38,0.45]$} & -0.01 & {$[-0.06,0.03]$} & -0.04 & {$[-0.07,-0.01]$} & .179 \\
\hline & 2016 & 0.44 & {$[0.41,0.48]$} & 0.01 & {$[-0.02,0.04]$} & .194 & 0.42 & {$[0.39,0.46]$} & -0.08 & {$[-0.11,-0.05]$} & 0.01 & {$[-0.02,0.04]$} & .200 \\
\hline Weighted mean & & 0.43 & {$[0.41,0.46]$} & -0.04 & {$[-0.06,-0.02]$} & .196 & 0.43 & {$[0.41,0.46]$} & -0.02 & {$[-0.03,0.00]$} & -0.04 & {$[-0.06,-0.02]$} & .197 \\
\hline
\end{tabular}




\section{Table S28}

Standardized Regression Coefficients from Linear and Quadratic Regression Models (Verbal Self-Concept on Reading Achievement), Confidence Intervals $\left(95 \%\right.$ CI) and Explained Variance $\left(R^{2}\right)$ in PISA Controlling for Students' Gender

\begin{tabular}{|c|c|c|c|c|c|c|c|c|c|c|c|c|c|}
\hline \multirow[b]{3}{*}{ Country } & \multirow[b]{3}{*}{ Cycle } & \multicolumn{5}{|c|}{ Linear model } & \multicolumn{7}{|c|}{ Quadratic model } \\
\hline & & \multicolumn{2}{|c|}{ Linear effect } & \multicolumn{2}{|c|}{ Gender effect } & \multirow[b]{2}{*}{$R^{2}$} & \multicolumn{2}{|c|}{ Linear effect } & \multicolumn{2}{|c|}{ Quadratic effect } & \multicolumn{2}{|c|}{ Gender effect } & \multirow[b]{2}{*}{$R^{2}$} \\
\hline & & $\beta$ & $95 \% \mathrm{CI}$ & $\beta$ & $95 \% \mathrm{CI}$ & & $\beta$ & $95 \% \mathrm{CI}$ & $\beta$ & $95 \% \mathrm{CI}$ & $\beta$ & $95 \% \mathrm{CI}$ & \\
\hline Australia & 2000 & 0.28 & {$[0.33,-0.04]$} & -0.04 & {$[0.01,0.08]$} & .082 & 0.28 & {$[0.34,0.05]$} & 0.05 & {$[0.10,-0.04]$} & -0.04 & {$[0.01,0.09]$} & .085 \\
\hline Austria & 00 & 0.24 & {$[0.28,-0.15]$} & 0.15 & {$[-0.11,0.09]$} & .094 & 0.25 & {$[0.29,0.07]$} & 0.07 & 15] & -0.15 & $0.10]$ & .099 \\
\hline Czech Republic & 00 & 0.24 & {$[0.29,-0.13]$} & .13 & {$[-0.08,0.09]$} & .085 & 0.26 & {$[0.31,0.07]$} & 0.07 & $13,-0.13]$ & -0.13 & $8,0.09]$ & .090 \\
\hline Finland & 2000 & 0.35 & {$[0.39,-0.13]$} & -0.13 & {$[-0.08,0.16]$} & .162 & 0.37 & {$[0.41,0.09]$} & 0.09 & {$[0.16,-0.12]$} & -0.12 & {$[-0.08,0.17]$} & 169 \\
\hline Germany & 2000 & 0.18 & {$[0.23,-0.17]$} & -0.17 & {$[-0.12,0.07]$} & .069 & 0.20 & {$[0.25,0.06]$} & 0.06 & {$[0.13,-0.16]$} & -0.16 & {$[-0.12,0.07]$} & .072 \\
\hline Hong Kong & 2000 & 0.14 & {$[0.18,-0.09]$} & -0.09 & {$[-0.04,0.03]$} & .028 & 0.14 & {$[0.19,0.01]$} & 0.01 & {$[0.06,-0.09]$} & -0.09 & {$[-0.04,0.03]$} & .029 \\
\hline Hungary & 2000 & 0.26 & {$[0.30,-0.12]$} & -0.12 & {$[-0.07,0.09]$} & .092 & 0.27 & {$[0.31,0.07]$} & 0.07 & {$[0.12,-0.12]$} & -0.12 & {$[-0.07,0.10]$} & .097 \\
\hline Ireland & 2000 & 0.10 & {$[0.14,-0.05]$} & -0.05 & {$[-0.01,0.01]$} & .014 & 0.10 & {$[0.15,0.03]$} & 0.03 & {$[0.08,-0.05]$} & -0.05 & {$[-0.01,0.02]$} & .015 \\
\hline Italy & 2000 & 0.23 & {$[0.27,-0.15]$} & -0.15 & {$[-0.10,0.10]$} & .095 & 0.23 & {$[0.27,-0.03]$} & -0.03 & {$[0.02$,} & -0.15 & {$[-0.10,0.10]$} & .095 \\
\hline Norw & 2000 & 0.34 & $0.13]$ & -0.13 & {$[-0.0$} & .149 & 0.35 & $0.06]$ & 0.06 & {$[0.11,-0.13]$} & -0.13 & $0.15]$ & .152 \\
\hline Portugal & 2000 & 0.29 & {$[0.33,-0.12]$} & -0.12 & {$[-0.08,0.11]$} & .107 & 0.30 & {$[0.33,0.02]$} & 0.02 & {$[0.07,-0.12]$} & -0.12 & {$[-0.08,0.11]$} & .108 \\
\hline Russian Federation & 2000 & 0.23 & {$[0.27,-0.18]$} & -0.18 & {$[-0.14,0.10]$} & .104 & 0.24 & {$[0.27,0.04]$} & 0.04 & {$[0.08,-0.18]$} & -0.18 & {$[-0.14,0.11]$} & .105 \\
\hline Sweden & 2000 & 0.30 & {$[0.35,-0.13]$} & -0.13 & {$[-0.09,0.12]$} & .123 & 0.33 & {$[0.37,0.10]$} & 0.10 & {$[0.14,-0.13]$} & -0.13 & {$[-0.09,0.13]$} & .133 \\
\hline Weighted mean & & 0.25 & {$[0.32,-0.12]$} & -0.12 & {$[-0.10,0.09]$} & .091 & 0.26 & {$[0.30,0.05]$} & 0.05 & {$[0.07,-0.12]$} & -0.12 & {$[-0.10,0.10]$} & .095 \\
\hline
\end{tabular}


Table S29

Results from Interrupted Regressions (Mathematics Self-Concept on Mathematics Achievement) for TIMSS (Grade 4) with 95\% Confidence Intervals (95\% CI)

\begin{tabular}{lccccccc}
\hline \multicolumn{1}{c}{ Country } & Cycle & $\beta_{1}$ & $95 \%$ CI & $\beta_{2}$ & $95 \%$ CI & Breakpoint & \%NFC \\
\hline Australia & 2011 & 0.01 & {$[-0.16,0.17]$} & 0.36 & {$[0.30,0.41]$} & -1.00 & 16 \\
Austria & 2015 & 0.27 & {$[-0.16,0.69]$} & 0.44 & {$[0.18,0.71]$} & -0.05 & 48 \\
Czech Republic & 2011 & 0.36 & {$[0.30,0.41]$} & 0.22 & {$[0.04,0.41]$} & 1.19 & 12 \\
& 2011 & 0.28 & {$[0.21,0.36]$} & 0.19 & {$[-0.05,0.43]$} & 1.14 & 13 \\
Finland & 2015 & 0.45 & {$[0.40,0.50]$} & 0.38 & {$[0.06,0.70]$} & 1.20 & 11 \\
& 2011 & -0.13 & {$[-0.39,0.13]$} & 0.46 & {$[0.41,0.52]$} & -1.04 & 15 \\
Germany & 2015 & 0.39 & {$[0.18,0.61]$} & 0.29 & {$[-0.04,0.62]$} & 0.90 & 18 \\
& 2011 & 0.24 & {$[-0.20,0.68]$} & 0.34 & {$[0.18,0.49]$} & 0.72 & 24 \\
Hong Kong & 2015 & 0.47 & {$[0.41,0.54]$} & 0.23 & {$[0.01,0.46]$} & 1.19 & 12 \\
& 2011 & 0.16 & {$[-0.19,0.50]$} & 0.28 & {$[-0.02,0.58]$} & 0.16 & 44 \\
Hungary & 2015 & 0.10 & {$[-0.19,0.39]$} & 0.50 & {$[0.37,0.63]$} & -0.97 & 17 \\
Ireland & 2011 & 0.43 & {$[0.39,0.47]$} & 0.27 & {$[0.12,0.42]$} & 1.15 & 13 \\
Italy & 2015 & 0.53 & {$[0.44,0.62]$} & 0.27 & {$[0.06,0.47]$} & 1.15 & 12 \\
& 2011 & 0.11 & {$[-0.09,0.31]$} & 0.35 & {$[0.29,0.41]$} & -0.94 & 17 \\
Norway & 2015 & 0.46 & {$[0.40,0.51]$} & 0.33 & {$[0.04,0.61]$} & 1.16 & 12 \\
& 2011 & 0.25 & {$[0.20,0.30]$} & 0.33 & {$[0.10,0.55]$} & 1.17 & 12 \\
Portugal & 2015 & 0.36 & {$[0.29,0.43]$} & 0.21 & {$[-0.02,0.44]$} & 1.16 & 12 \\
& 2011 & 0.22 & {$[0.04,0.39]$} & 0.23 & {$[-0.13,0.58]$} & 0.96 & 17 \\
Russian Federation & 2015 & 0.46 & {$[0.39,0.53]$} & 0.25 & {$[0.04,0.46]$} & 1.18 & 12 \\
Sweden & 2011 & -0.03 & {$[-0.28,0.23]$} & 0.48 & {$[0.24,0.71]$} & -0.95 & 17 \\
& 2015 & 0.51 & {$[0.45,0.57]$} & 0.25 & {$[-0.02,0.52]$} & 1.24 & 11 \\
Weighted mean & 2011 & 0.34 & {$[0.28,0.39]$} & 0.21 & {$[0.00,0.43]$} & 1.13 & 13 \\
\hline \multirow{2}{*}{ Note. \% } & 0.45 & {$[0.38,0.52]$} & 0.27 & {$[-0.07,0.62]$} & 1.14 & 13 \\
& 2011 & 0.06 & {$[-0.35,0.48]$} & 0.31 & {$[0.26,0.36]$} & -1.15 & 13 \\
& 2015 & 0.38 & {$[0.29,0.47]$} & 0.30 & {$[0.02,0.58]$} & 1.17 & 12 \\
\hline & & 0.32 & {$[0.26,0.39]$} & 0.34 & {$[0.29,0.38]$} & & 17 \\
\hline
\end{tabular}

Note. $\% \mathrm{NFC}=$ Percentage of students for which a single linear regression coefficient did not fully capture the relation between achievement and the corresponding measure of self-concept. 
Table S30

Results from Interrupted Regressions (Mathematics Self-Concept on Mathematics Achievement) for TIMSS (Grade 8) with 95\% Confidence Intervals (95\% CI)

\begin{tabular}{lccccccc}
\hline \multicolumn{1}{c}{ Country } & Cycle & $\beta_{1}$ & $95 \%$ CI & $\beta_{2}$ & $95 \%$ CI & Breakpoint & \%NFC \\
\hline Australia & 2011 & 0.57 & {$[0.51,0.63]$} & 0.19 & {$[-0.07,0.45]$} & 1.25 & 10 \\
& 2015 & 0.10 & {$[-0.17,0.38]$} & 0.66 & {$[0.58,0.73]$} & -1.21 & 11 \\
Finland & 2011 & -0.08 & {$[-0.26,0.10]$} & 0.76 & {$[0.72,0.80]$} & -1.09 & 14 \\
Hong Kong & 2011 & -0.06 & {$[-0.39,0.28]$} & 0.55 & {$[0.50,0.61]$} & -1.17 & 12 \\
& 2015 & -0.13 & {$[-0.32,0.05]$} & 0.57 & {$[0.47,0.66]$} & -1.03 & 15 \\
Hungary & 2011 & -0.02 & {$[-0.15,0.10]$} & 0.76 & {$[0.69,0.82]$} & -0.92 & 18 \\
& 2015 & 0.02 & {$[-0.19,0.23]$} & 0.70 & {$[0.62,0.78]$} & -1.02 & 15 \\
Ireland & 2015 & -0.05 & {$[-0.36,0.25]$} & 0.59 & {$[0.52,0.65]$} & -1.19 & 12 \\
Italy & 2011 & 0.51 & {$[0.45,0.57]$} & 0.30 & {$[0.08,0.53]$} & 1.21 & 11 \\
& 2015 & 0.11 & {$[-0.21,0.43]$} & 0.61 & {$[0.54,0.68]$} & -1.18 & 12 \\
Norway & 2011 & 0.64 & {$[0.60,0.68]$} & 0.39 & {$[0.21,0.57]$} & 1.21 & 11 \\
& 2015 & 0.61 & {$[0.57,0.66]$} & 0.40 & {$[0.22,0.57]$} & 1.22 & 11 \\
Russian Federation & 2011 & 0.48 & {$[0.44,0.53]$} & 0.44 & {$[0.23,0.65]$} & 1.21 & 11 \\
& 2015 & 0.46 & {$[0.39,0.53]$} & 0.44 & {$[0.08,0.79]$} & 1.19 & 12 \\
Sweden & 2011 & 0.59 & {$[0.55,0.62]$} & 0.54 & {$[0.37,0.71]$} & 1.22 & 11 \\
& 2015 & 0.04 & {$[-0.30,0.37]$} & 0.73 & {$[0.67,0.80]$} & -1.22 & 11 \\
\hline Weighted mean & & 0.25 & {$[0.08,0.42]$} & 0.58 & {$[0.50,0.66]$} & & 12 \\
\hline
\end{tabular}

Note. $\% \mathrm{NFC}=$ Percentage of students for which a single linear regression coefficient did not fully capture the relation between achievement and the corresponding measure of self-concept. 
Table S31

Results from Interrupted Regressions (Mathematics Self-Concept on Mathematics Achievement) for PISA with 95\% Confidence Intervals (95\% CI)

\begin{tabular}{|c|c|c|c|c|c|c|c|}
\hline Country & Cycle & $\beta_{1}$ & $95 \% \mathrm{CI}$ & $\beta_{2}$ & $95 \% \mathrm{CI}$ & Breakpoint & $\%{ }_{\mathrm{NFC}}$ \\
\hline \multirow[t]{3}{*}{ Australia } & 2000 & -0.13 & {$[-0.32,0.06]$} & 0.37 & {$[0.33,0.42]$} & -1.04 & 15 \\
\hline & 2003 & 0.22 & {$[0.11,0.34]$} & 0.49 & {$[0.47,0.52]$} & -1.19 & 12 \\
\hline & 2012 & 0.10 & {$[-0.07,0.27]$} & 0.52 & {$[0.49,0.54]$} & -1.18 & 12 \\
\hline \multirow[t]{3}{*}{ Austria } & 2000 & 0.00 & {$[-0.17,0.17]$} & 0.37 & {$[0.30,0.44]$} & -0.65 & 26 \\
\hline & 2003 & 0.02 & {$[-0.12,0.15]$} & 0.37 & {$[0.33,0.40]$} & -1.10 & 14 \\
\hline & 2012 & 0.11 & {$[-0.11,0.32]$} & 0.43 & {$[0.38,0.48]$} & -1.06 & 14 \\
\hline \multirow[t]{3}{*}{ Czech Republic } & 2000 & 0.00 & {$[-0.32,0.32]$} & 0.36 & {$[0.28,0.44]$} & -0.74 & 23 \\
\hline & 2003 & 0.37 & {$[0.17,0.57]$} & 0.53 & {$[0.11,0.96]$} & 1.05 & 15 \\
\hline & 2012 & 0.40 & {$[0.06,0.74]$} & 0.57 & {$[0.26,0.87]$} & 0.94 & 17 \\
\hline \multirow[t]{3}{*}{ Finland } & 2000 & 0.03 & {$[-0.15,0.21]$} & 0.60 & {$[0.57,0.63]$} & -1.09 & 14 \\
\hline & 2003 & 0.08 & {$[-0.30,0.46]$} & 0.66 & {$[0.50,0.83]$} & -0.84 & 20 \\
\hline & 2012 & -0.01 & {$[-0.16,0.14]$} & 0.72 & {$[0.68,0.76]$} & -1.03 & 15 \\
\hline \multirow[t]{3}{*}{ Germany } & 2000 & -0.05 & {$[-0.20,0.10]$} & 0.27 & {$[0.22,0.32]$} & -0.71 & 24 \\
\hline & 2003 & 0.20 & {$[-0.07,0.46]$} & 0.32 & {$[0.28,0.37]$} & -1.08 & 14 \\
\hline & 2012 & 0.03 & {$[-0.21,0.28]$} & 0.41 & {$[0.37,0.46]$} & -1.12 & 13 \\
\hline \multirow[t]{3}{*}{ Hong Kong } & 2000 & -0.15 & {$[-0.24,-0.06]$} & 0.37 & {$[0.33,0.42]$} & -0.75 & 23 \\
\hline & 2003 & 0.02 & {$[-0.11,0.16]$} & 0.45 & {$[0.42,0.48]$} & -1.15 & 13 \\
\hline & 2012 & 0.02 & {$[-0.14,0.17]$} & 0.44 & {$[0.41,0.47]$} & -1.17 & 12 \\
\hline \multirow[t]{3}{*}{ Hungary } & 2000 & 0.04 & {$[-0.10,0.18]$} & 0.39 & {$[0.29,0.50]$} & -0.63 & 26 \\
\hline & 2003 & -0.06 & {$[-0.13,0.02]$} & 0.41 & {$[0.35,0.46]$} & -0.68 & 25 \\
\hline & 2012 & -0.10 & {$[-0.25,0.04]$} & 0.62 & {$[0.53,0.70]$} & -0.61 & 27 \\
\hline \multirow[t]{3}{*}{ Ireland } & 2000 & -0.12 & {$[-0.28,0.04]$} & 0.41 & {$[0.35,0.47]$} & -0.67 & 25 \\
\hline & 2003 & 0.06 & {$[-0.11,0.24]$} & 0.47 & {$[0.44,0.50]$} & -1.12 & 13 \\
\hline & 2012 & 0.13 & {$[0.00,0.25]$} & 0.50 & {$[0.47,0.54]$} & -1.11 & 13 \\
\hline \multirow[t]{3}{*}{ Italy } & 2000 & 0.03 & {$[-0.14,0.19]$} & 0.32 & {$[0.27,0.37]$} & -0.94 & 17 \\
\hline & 2003 & 0.10 & {$[0.01,0.20]$} & 0.32 & {$[0.30,0.35]$} & -1.21 & 11 \\
\hline & 2012 & 0.01 & {$[-0.10,0.12]$} & 0.40 & {$[0.38,0.43]$} & -1.22 & 11 \\
\hline \multirow[t]{3}{*}{ Norway } & 2000 & -0.09 & {$[-0.27,0.09]$} & 0.63 & {$[0.56,0.69]$} & -0.87 & 19 \\
\hline & 2003 & -0.07 & {$[-0.28,0.15]$} & 0.71 & {$[0.67,0.74]$} & -1.10 & 13 \\
\hline & 2012 & 0.18 & {$[0.03,0.32]$} & 0.70 & {$[0.67,0.73]$} & -1.19 & 12 \\
\hline \multirow[t]{3}{*}{ Portugal } & 2000 & -0.07 & {$[-0.19,0.05]$} & 0.41 & {$[0.36,0.47]$} & -0.54 & 30 \\
\hline & 2003 & -0.11 & {$[-0.21,-0.01]$} & 0.52 & {$[0.50,0.55]$} & -0.98 & 16 \\
\hline & 2012 & -0.02 & {$[-0.24,0.20]$} & 0.56 & {$[0.52,0.60]$} & -1.04 & 15 \\
\hline \multirow[t]{3}{*}{ Russian Federation } & 2000 & 0.12 & {$[-0.27,0.51]$} & 0.23 & {$[0.06,0.41]$} & 0.08 & 47 \\
\hline & 2003 & 0.08 & {$[-0.04,0.20]$} & 0.40 & {$[0.37,0.42]$} & -1.13 & 13 \\
\hline & 2012 & 0.13 & {$[-0.08,0.35]$} & 0.44 & {$[0.38,0.51]$} & -0.96 & 17 \\
\hline \multirow[t]{3}{*}{ Sweden } & 2000 & -0.05 & {$[-0.16,0.07]$} & 0.60 & {$[0.55,0.64]$} & -0.83 & 20 \\
\hline & 2003 & 0.07 & {$[-0.11,0.26]$} & 0.60 & {$[0.57,0.63]$} & -1.15 & 12 \\
\hline & 2012 & 0.15 & {$[-0.04,0.33]$} & 0.58 & {$[0.54,0.62]$} & -1.07 & 14 \\
\hline Weighted mean & & 0.03 & {$[-0.01,0.07]$} & 0.47 & {$[0.41,0.53]$} & & 16 \\
\hline
\end{tabular}

Note. $\% \mathrm{NFC}=$ Percentage of students for which a single linear regression coefficient did not fully capture the relation between achievement and the corresponding measure of self-concept. 
Table S32

Results from Interrupted Regressions (Reading Self-Concept on Reading Achievement) for PIRLS with 95\% Confidence Intervals (95\% CI)

\begin{tabular}{|c|c|c|c|c|c|c|c|}
\hline Country & Cycle & $\beta_{1}$ & $95 \%$ CI & $\beta_{2}$ & $95 \% \mathrm{CI}$ & Breakpoint & $\% \mathrm{NFC}$ \\
\hline \multirow[t]{2}{*}{ Australia } & 2011 & 0.53 & {$[0.49,0.58]$} & 0.31 & {$[0.10,0.52]$} & 1.14 & 13 \\
\hline & 2016 & 0.61 & {$[0.57,0.66]$} & 0.18 & {$[-0.05,0.40]$} & 1.12 & 13 \\
\hline \multirow[t]{2}{*}{ Austria } & 2011 & 0.41 & {$[0.37,0.46]$} & 0.30 & {$[0.06,0.53]$} & 1.16 & 12 \\
\hline & 2016 & 0.45 & {$[0.38,0.52]$} & 0.15 & {$[-0.11,0.41]$} & 1.14 & 13 \\
\hline \multirow[t]{2}{*}{ Czech Republic } & 2011 & 0.44 & {$[0.38,0.50]$} & 0.37 & {$[0.11,0.63]$} & 1.13 & 13 \\
\hline & 2016 & 0.44 & {$[0.37,0.52]$} & 0.17 & {$[-0.04,0.38]$} & 1.14 & 13 \\
\hline \multirow[t]{2}{*}{ Finland } & 2011 & 0.42 & {$[0.37,0.48]$} & 0.18 & {$[-0.08,0.43]$} & 1.18 & 12 \\
\hline & 2016 & 0.47 & {$[0.40,0.53]$} & 0.30 & {$[0.06,0.53]$} & 1.13 & 13 \\
\hline \multirow[t]{2}{*}{ Germany } & 2011 & 0.44 & {$[0.38,0.49]$} & 0.25 & {$[0.04,0.46]$} & 1.17 & 12 \\
\hline & 2016 & 0.47 & {$[0.40,0.54]$} & 0.31 & {$[0.09,0.54]$} & 1.14 & 13 \\
\hline \multirow[t]{2}{*}{ Hong Kong } & 2011 & 0.39 & {$[0.34,0.43]$} & 0.31 & {$[0.06,0.57]$} & 1.12 & 13 \\
\hline & 2016 & 0.39 & {$[0.33,0.46]$} & 0.27 & {$[-0.07,0.61]$} & 1.12 & 13 \\
\hline \multirow[t]{2}{*}{ Hungary } & 2011 & 0.53 & {$[0.49,0.58]$} & 0.35 & {$[0.19,0.51]$} & 1.12 & 13 \\
\hline & 2016 & 0.52 & {$[0.46,0.58]$} & 0.31 & {$[0.12,0.50]$} & 1.15 & 12 \\
\hline \multirow[t]{2}{*}{ Ireland } & 2011 & 0.44 & {$[0.39,0.50]$} & 0.28 & {$[0.05,0.51]$} & 1.16 & 12 \\
\hline & 2016 & 0.48 & {$[0.41,0.55]$} & 0.21 & {$[-0.09,0.52]$} & 1.14 & 13 \\
\hline \multirow[t]{2}{*}{ Italy } & 2011 & 0.34 & {$[0.29,0.38]$} & 0.36 & {$[0.06,0.67]$} & 1.18 & 12 \\
\hline & 2016 & 0.37 & {$[0.30,0.43]$} & 0.24 & {$[-0.06,0.54]$} & 1.15 & 13 \\
\hline \multirow[t]{2}{*}{ Norway } & 2011 & 0.43 & {$[0.37,0.49]$} & 0.33 & {$[0.06,0.60]$} & 1.16 & 12 \\
\hline & 2016 & 0.53 & {$[0.46,0.61]$} & 0.24 & {$[0.02,0.46]$} & 1.15 & 13 \\
\hline \multirow[t]{2}{*}{ Portugal } & 2011 & 0.47 & {$[0.42,0.52]$} & 0.20 & {$[-0.09,0.50]$} & 1.17 & 12 \\
\hline & 2016 & 0.46 & {$[0.40,0.53]$} & 0.15 & {$[-0.15,0.46]$} & 1.20 & 11 \\
\hline \multirow[t]{2}{*}{ Russian Federation } & 2011 & 0.41 & {$[0.36,0.47]$} & 0.27 & {$[0.06,0.49]$} & 1.14 & 13 \\
\hline & 2016 & 0.49 & {$[0.42,0.57]$} & 0.26 & {$[0.04,0.49]$} & 1.15 & 13 \\
\hline \multirow[t]{2}{*}{ Sweden } & 2011 & 0.43 & {$[0.38,0.48]$} & 0.28 & {$[0.07,0.49]$} & 1.17 & 12 \\
\hline & 2016 & 0.50 & {$[0.42,0.57]$} & 0.24 & {$[0.01,0.47]$} & 1.11 & 13 \\
\hline Weighted mean & & 0.45 & {$[0.42,0.48]$} & 0.27 & {$[0.22,0.31]$} & & 13 \\
\hline
\end{tabular}

Note. $\% \mathrm{NFC}=$ Percentage of students for which a single linear regression coefficient did not fully capture the relation between achievement and the corresponding measure of self-concept. 
Table S33

Results from Interrupted Regressions (Verbal Self-Concept on Reading Achievement) for PISA with 95\% Confidence Intervals (95\% CI)

\begin{tabular}{lccccccc}
\hline \multicolumn{1}{c}{ Country } & Cycle & $\beta_{1}$ & $95 \%$ CI & $\beta_{2}$ & $95 \%$ CI & Breakpoint & \% \\
\hline Australia & 2000 & 0.24 & {$[-0.01,0.49]$} & 0.16 & {$[-0.28,0.60]$} & 0.88 & 19 \\
Austria & 2000 & 0.05 & {$[-0.20,0.29]$} & 0.34 & {$[0.29,0.39]$} & -0.98 & 16 \\
Czech Republic & 2000 & 0.09 & {$[-0.27,0.44]$} & 0.29 & {$[0.05,0.53]$} & -0.10 & 46 \\
Finland & 2000 & 0.20 & {$[-0.22,0.62]$} & 0.29 & {$[-0.15,0.74]$} & 0.14 & 44 \\
Germany & 2000 & 0.09 & {$[-0.12,0.29]$} & 0.22 & {$[0.05,0.38]$} & -0.76 & 22 \\
Hong Kong & 2000 & 0.13 & {$[0.05,0.21]$} & 0.20 & {$[-0.11,0.50]$} & 0.77 & 22 \\
Hungary & 2000 & 0.10 & {$[-0.11,0.31]$} & 0.33 & {$[0.27,0.38]$} & -1.00 & 16 \\
Ireland & 2000 & 0.08 & {$[-0.06,0.23]$} & 0.21 & {$[-0.17,0.59]$} & -0.43 & 33 \\
Italy & 2000 & 0.29 & {$[0.26,0.33]$} & 0.24 & {$[-0.05,0.54]$} & 1.07 & 14 \\
Norway & 2000 & 0.34 & {$[0.19,0.48]$} & 0.30 & {$[0.05,0.56]$} & 0.96 & 17 \\
Portugal & 2000 & 0.29 & {$[0.26,0.32]$} & 0.16 & {$[-0.09,0.40]$} & 1.14 & 13 \\
Russian Federation & 2000 & 0.25 & {$[0.22,0.28]$} & 0.23 & {$[-0.01,0.48]$} & 1.21 & 11 \\
Sweden & 2000 & 0.03 & {$[-0.18,0.24]$} & 0.43 & {$[0.39,0.46]$} & -1.09 & 14 \\
\hline Weighted mean & & 0.20 & {$[0.14,0.26]$} & 0.32 & {$[0.25,0.39]$} & & 22 \\
\hline
\end{tabular}

Note. $\% \mathrm{NFC}=$ Percentage of students for which a single linear regression coefficient did not fully capture the relation between achievement and the corresponding measure of self-concept. 


\section{References}

Martin, M.O., \& Mullis, I.V.S. (2012). Methods and procedures in TIMSS and PIRLS 2011. Chestnut Hill, MA: TIMSS \& PIRLS International Study Center, Boston College. Mullis, I. V. S., \& Martin, M. O. (2013). TIMSS 2015 assessment framework (2nd ed.). Chestnut Hill, MA: TIMSS \& PIRLS International Study Center, Boston College. Mullis, I. V. S., \& Martin, M. O. (2015). PIRLS 2016 assessment framework (2nd ed.). Chestnut Hill, MA: TIMSS \& PIRLS International Study Center, Boston College. OECD (2002). PISA 2000 technical report. Paris: OECD Publishing. OECD (2013). PISA 2012 assessment and analytical framework: Mathematics, reading, science, problem solving and financial literacy. Paris: OECD Publishing. OECD (2014). PISA 2012 technical report. Paris: OECD Publishing. 